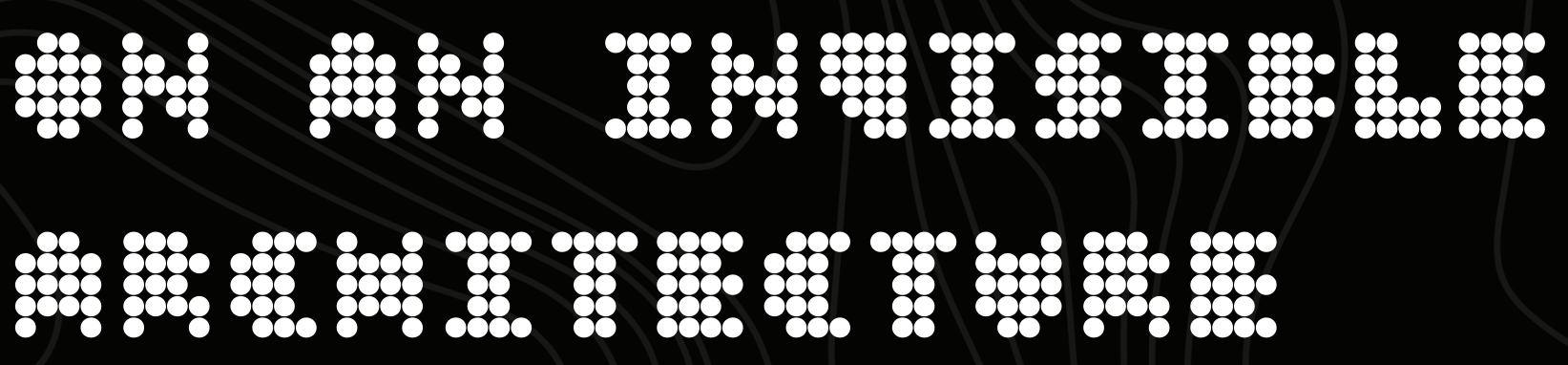

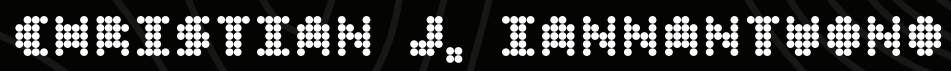





\title{
ON AN INVISIBLE ARCHITECTURE: AN ANTIDOTE TO OCULARCENTRIC SPACE
}

\author{
by \\ Christian J. lannantuono \\ Bachelor of Architectural Science, Ryerson University, \\ 2018
}

\author{
A thesis \\ presented to Ryerson University \\ in partial fulfillment of the \\ requirements for the degree of \\ Master of Architecture \\ in the Program of \\ Architecture
}

Toronto, Ontario, Canada, 2020

(C) Christian J. lannantuono, 2020 



\section{AUTHOR'S DECLARATION FOR ELECTRONIC SUBMISSION OF A THESIS}

I hereby declare that I am the sole author of this thesis. This is a true copy of the thesis, including any required final revisions, as accepted by my examiners.

I authorize Ryerson University to lend this thesis to other institutions or individuals for the purpose of scholarly research.

I further authorize Ryerson University to reproduce this thesis by photocopying or by other means, in total or in part, at the request of other institutions or individuals for the purpose of scholarly research.

I understand that my thesis may be made electronically available to the public. 



\section{ABSTRACT}

On an Invisible Architecture:

An Antidote to Ocularcentric Space

Master of Architecture, 2020

Christian lannantuono

Program of Architecture, Ryerson University

Invisible; something that is unseen, unnoticed, or ignored.

Related to the awareness or recognition of an object as opposed to its actual presence, the problem with the invisible is the unknowingness of its very existence. While our bodies occupy diverse spatial conditions, they absorb a variety of visible and invisible information through the senses. As the geography of our increasingly digitized urban landscape creates conditions of solitude and alienation, the other senses become suppressed, manifested through our obsession with the eye, vision, and image. Identifying the non-place and its effect on inhabitants will serve as a point of departure in exploring the potentials for an architecture to become invisible - that is, for a space to exist beyond our infatuation with its aesthetic or visual character. Designing an atlas for the senses between the urban and natural context of Toronto and its ravines, this thesis aims to reintroduce architectural meaning through the body's sensorial apparatus. In progressing beyond our current ocularcentric state, we can use the senses as perceptual mechanisms to begin a dialogue addressing the non-place-ness of urbanity. In doing so, architecture becomes more relatable, engendering new spatial, perceptual, and emotional relationships within the memory of space. 

I would like to acknowledge the following people for helping to guide me through this intellectual and creative journey:

Cheryl Atkinson; my supervisor, for dedicating countless hours during our frequent meetings and grounding my ideas in architecture.

Colin Ripley; my second reader, for your critical insight into things I had never thought to question and for reminding me that "it's just a thesis."

And finally, to the rest of my committee, for offering your time and valued input in an effort to push my ideas further. 

For my family and friends. 



\section{TABLE OF CONTENTS}

Abstract

Acknowledgments

List of Figures

Chapter 1 An Image Society

1.1 The Eye and Ocularcentrism 3

1.2 Architectural Representation 8

1.3 The Architectural Icon 11

1.4 Conclusion 14

Chapter 2 The Estranged City

2.1 Introduction: The Concept of Emptiness 19

2.2 The New Metropolis 21

2.3 The Non-Place 24

2.4 Case Study: Learning from Las Vegas 28

Chapter $3 \quad$ The Invisible

3.1 Introduction $\quad 35$

3.2 The Senses 38

3.3 Proxemics and the Human Scale 46

3.4 Case Study: Carlo Scarpa 50

3.5 Environmental Psychology 54

3.6 Case Study: Peter Zumthor 58

3.7 On Reintroducing the Invisible 63

Chapter 4 An Atlas to the Senses

4.1 Introduction 67

4.2 Defining the Atlas 70

$\begin{array}{lll}4.3 & \text { The Site } & 72\end{array}$

4.4 Narrative and Experience 78

4.5 Conclusion 103

Chapter $5 \quad$ Appendix

5.1 Bibliography 109

5.2 Glossary 116 



\section{LIST OF FIGURES}

Figure No. 1: Everest expedition

Source: Smithsonian Institution. (2013, May 22). Sixty years ago, Edmund

Hillary reached the top of the world. Retrieved from https://www.

smithsonianmag.com/smithsonian-institution/sixty-years-ago-edmund-

hillary-reached-the-top-of-the-world-hear-him-describe-it-76861267/.

Figure No. 2: Perception and the eye

Source: Ledoux, C. (1847). Eye enclosing the theatre at Besancon.

Retrieved from https://commons.wikimedia.org/wiki/File:Ledoux,_

Theatre_of_Besan\%C3\%A7on.jpg

Figure No. 3: Image as knowledge

Source: Piolle, G. (n.d.). The north rose window of Chartres Cathedral

Retrieved from https://en.wikipedia.org/wiki/Stained_glass\#/media/

File:Chartres__cath\%C3\%A9drale___rosace_nord.jpg.

Figure No. 4: Dematerializing architecture

Source: Staniloff, A. (2019, March 15). Inside the chaos of Hudson Yards'

Opening Day. Retrieved from http://ny.eater.com/2019/3/15/18267777/

hudson-yards-shops-restaurants-nyc-photos.

Figure No. 5: Alvar Aalto landscape sketches

Source: Pallasmaa, J. (2009). The thinking hand: Existential and embodied wisdom in architecture. Chichester: Wiley. 
Figure No. 6: The perspective representation

Source: The Metropolitan Museum of Art. (n.d.). Draughtsman making a perspective drawing of a reclining woman. Retrieved from https://www. metmuseum.org/art/collection/search/366555.

Figure No. 7: Externalized versus internalized

Source: Iannantuono, C. (2020, February). Thesis Milestone 3.

Figure No. 8: Mark's House by Two Islands: rendering vs. reality Source: Sun, J. (2014). The image of architecture. Retrieved from http:// www.jonathan-sun.com/the-image-of-architecture.

Figure No. 9: Distortions of the image

Source: Chaos Group. (n.d.). Camera distortion. Retrieved from https:// docs.chaosgroup.com/display/VRAY2SKETCHUP/Camera.

Figure No. 10: Voyager 1: The Pale Blue Dot, 1990

Source: NASA. (1990, February 14). Voyager 1's Pale Blue Dot. Retrieved from https://solarsystem.nasa.gov/resources/536/voyager-1s-pale-bluedot/.

Figure No. 11: The new urbanism

Source: Khan Academy. (2014). America moves to the city. Retrieved from https://www.khanacademy.org/humanities/us-history/the-gilded-age/ gilded-age/a/america-moves-to-the-city. 
Figure No. 12: Interior of St. Peter's Basilica

Source: Boston Athenaeum. (2014). Giovanni Paolo Panini, "Interior of St.

Peter's, Rome," 1756-1757. Retrieved from https://www. bostonathenaeum.

org/about/publications/selections-acquired-tastes/giovanni-paolo-panini-

interior-st-peters-rome-1756-1757.

Figure No. 13: The non-place

Source: Chung, C. J., Inaba, J., Koolhaas, R., \& Leong, S. T. (Eds.).

(2001). Harvard Design School guide to shopping. Köln: Taschen.

Figure No. 14: The modern city of sensory deprivation

Source: Only in Hobart. (2017, October 11). The ordinary city. Retrieved

from https://onlyinhobart.com.au/the-ordinary-city/.

Figure No. 15: Communication through signs

Source: Venturi, R., Brown, D. S., \& Izenour, S. (1972). Learning from Las

Vegas. Cambridge: The MIT Press.

Figure No. 16: Middle Eastern bazaar

Source: Zohar Productions. (2013, July). The souk: A Middle Eastern

bazaar. Retrieved from https://zoharproductions.wordpress.

com/2013/07/05/the-souk-a-middle-eastern-bazaar/. 
Figure No. 17: Las Vegas signs

Source: ArchDaily. (2018, November 6). Denise Scott Brown's Photography

from the 1950s and 60s Unveiled in New York and London Galleries.

Retrieved from https://www. archdaily.com/905328/denise-scott-browns-

photography-from-the-1950s-and-60s-unveiled-in-new-york-and-london-

galleries.

Figure No. 18: Matter vs. energy

Source: Reiser + Umemoto. (2006). Atlas of Novel Tectonics. Retrieved

from https://parametricmonkey.files.wordpress.com/2015/01/

reiserumerto_2006_p73.jpg

Figure No. 19: The sensorial envelope

Source: Lally, S. (2014). The air from other planets: A brief history of

architecture to come. Zürich: Lars Müller Publishers.

Figure No. 20: Confirmation through touch

Source: Web Gallery of Art. (n.d.). The Incredulity of Saint Thomas.

Retrieved from https://www.wga.hu/frames-e.html?/html/c/

caravagg/06/34thomas.html.

Figure No. 21: Thermoception design research [1:1]

Source: Iannantuono, C. (2019, November). Thesis Milestone 2

Figure No. 22: Sound absorption design research [1:1]

Source: Iannantuono, C. (2019, November). Thesis Milestone 2 
Figure No. 23: Olfactory design research [1:1]

Source: Iannantuono, C. (2020, May). Thesis Milestone 4.

Figure No. 24: Agglomeration of senses

Source: Kauffman, J. (2014). Favourite 2014 canoeing snapshot photo contest. Retrieved from https://www.traversing.ca/blog/2014/11/28/

favourite-2014-canoeing-snapshot-photo-contest.

Figure No. 25: Proxemics and the body

Source: Iannantuono, C. (2019, November). Thesis Milestone 2.

Figure No. 26: Vitruvian Man [extended]

Source: Iannantuono, C. (2020, February). Thesis Milestone 3.

Figure No. 27: Proxemics: rail + guard study [1:1]

Source: Iannantuono, C. (2019, November). AR 8201 Advanced

Construction Case Studies.

Figure No. 28: Proxemics: ending a material [1:1]

Source: Iannantuono, C. (2019, November). AR 8201 Advanced

Construction Case Studies.

Figure No. 29: Stratification of the Alps

Source: Schultz, A.-C. (2007). Carlo Scarpa: Layers. Stuttgart: Edition Axel Menges. 
Figure No. 30: Stratification of material

Source: Chang, H. (2008, August 27). Railing detail. Retrieved from https://

www.flickr.com/photos/hakeechang/2816809421.

Figure No. 31: Door handle exploration - opened [1:1]

Source: Iannantuono, C. (2019, November). Thesis Milestone 2

Figure No. 32: Door handle exploration - closed [1:1]

Source: Iannantuono, C. (2019, November). Thesis Milestone 2.

Figure No. 33: Environmental stimulation diagram

Source: Iannantuono, C. (2019, December). Thesis Milestone 2.

Figure No. 34: Environmental interactions

Source: Iannantuono, C. (2019, December). Thesis Milestone 2.

Figure No. 35: Therme Vals Spa

Source: Dezeen. (2016, September 25). Peter Zumthor's Therme Vals spa

photographed by Fernando Guerra. Retrieved from https://www. dezeen.

com/2016/09/25/peter-zumthor-therme-vals-spa-baths-photography-

fernando-guerra/.

Figure No. 36: Bruder Klaus Field Chapel

Source: Zilliacus, A. (2016, October 29). Peter Zumthor's Bruder Klaus Field

Chapel Through the Lens of Aldo Amoretti. Retrieved from https://www.

archdaily.com/798340/peter-zumthors-bruder-klaus-field-chapel-through-

the-lens-of-aldo-amoretti. 
Figure No. 37: Proxemic handle study - front [1:1]

Source: Iannantuono, C. (2020, February). Thesis Milestone 3.

Figure No. 38: Proxemic handle study - side [1:1]

Source: Iannantuono, C. (2020, February). Thesis Milestone 3.

Figure No. 39: Paul Rudolph's spatial effects

Source: Hidden Architecture. (2016, November). Barcelona Pavilion

Study Drawings and an interview by Paul Rudolph. Retrieved from http://

hiddenarchitecture.net/barcelona-pavilion-study-drawings-and/.

Figure No. 40: The Atlas Minor of Hondius by Gerardus Mercator

Source: Mercator, G. (1500s). The Atlas Minor by Gerardus Mercator.

Retrieved from https://commons.wikimedia.org/wiki/File:Mercator_

Hondius_Atlas_Minor_of_1607_frontispiece.png.

Figure No. 41: The physical atlas

Source: Iannantuono, C. (2019, September). Thesis Milestone 1.

Figure No. 42: Site model [1:200]

Source: Iannantuono, C. (2019, December). Thesis Milestone 2.

Figure No. 43: Site aerial

Source: Iannantuono, C. (2020, February). Thesis Milestone 3.

Figure No. 44: Site context

Source: Iannantuono, C. (2020, February). Thesis Milestone 3. 
Figure No. 45: Entrance model [1:200]

Source: Iannantuono, C. (2020, April). Thesis Milestone 4.

Figure No. 46: Absorption - entrance vignette

Source: Iannantuono, C. (2020, April). Thesis Milestone 4.

Figure No. 47: Dislocation - wells vignette

Source: Iannantuono, C. (2020, April). Thesis Milestone 4.

Figure No. 48: Dislocation - zen garden vignette

Source: Iannantuono, C. (2020, April). Thesis Milestone 4.

Figure No. 49: Zen garden model [1:50]

Source: Iannantuono, C. (2020, February). Thesis Milestone 3.

Figure No. 50: Zen garden model - closeup [1:50]

Source: Iannantuono, C. (2020, February). Thesis Milestone 3.

Figure No. 51: Dislocation - oculus hallway vignette

Source: Iannantuono, C. (2020, April). Thesis Milestone 4.

Figure No. 52: Dislocation - scorched wood room vignette

Source: Iannantuono, C. (2020, April). Thesis Milestone 4.

Figure No. 53: Dislocation - stairs vignette

Source: Iannantuono, C. (2020, April). Thesis Milestone 4. 
Figure No. 54: Dislocation - railing detail Source: Iannantuono, C. (2020, April). Thesis Milestone 4.

Figure No. 55: Dislocation - atmospheric void vignette Source: Iannantuono, C. (2020, April). Thesis Milestone 4.

Figure No. 56: Atmospheric void model [1:50]

Source: Iannantuono, C. (2020, February). Thesis Milestone 3.

Figure No. 57: Navigating the void [1:50]

Source: Iannantuono, C. (2020, February). Thesis Milestone 3.

Figure No. 58: Atmospheric void model - closeup [1:50]

Source: Iannantuono, C. (2020, February). Thesis Milestone 3.

Figure No. 59: Restitution - waterfall courtyard vignette Source: Iannantuono, C. (2020, April). Thesis Milestone 4.

Figure No. 60: Restitution - stairs detail vignette

Source: Iannantuono, C. (2020, April). Thesis Milestone 4.

Figure No. 61: Waterfall courtyard model [1:50]

Source: Iannantuono, C. (2020, April). Thesis Milestone 4.

Figure No. 62: Restitution - wood grid vignette

Source: Iannantuono, C. (2020, April). Thesis Milestone 4. 

Figure No. 63: X-ray floor plan [1:500]

Source: Iannantuono, C. (2020, April). Thesis Milestone 4.

Figure No. 64: Longitudinal section [1:500]

Source: Iannantuono, C. (2020, April). Thesis Milestone 4.

Figure No. 65: X-ray axonometric [1:1000]

Source: Iannantuono, C. (2020, April). Thesis Milestone 4.

Figure No. 66: Site model [1:200]

Source: Iannantuono, C. (2020, April). Thesis Milestone 4. 

Figure No. 1

Everest expedition

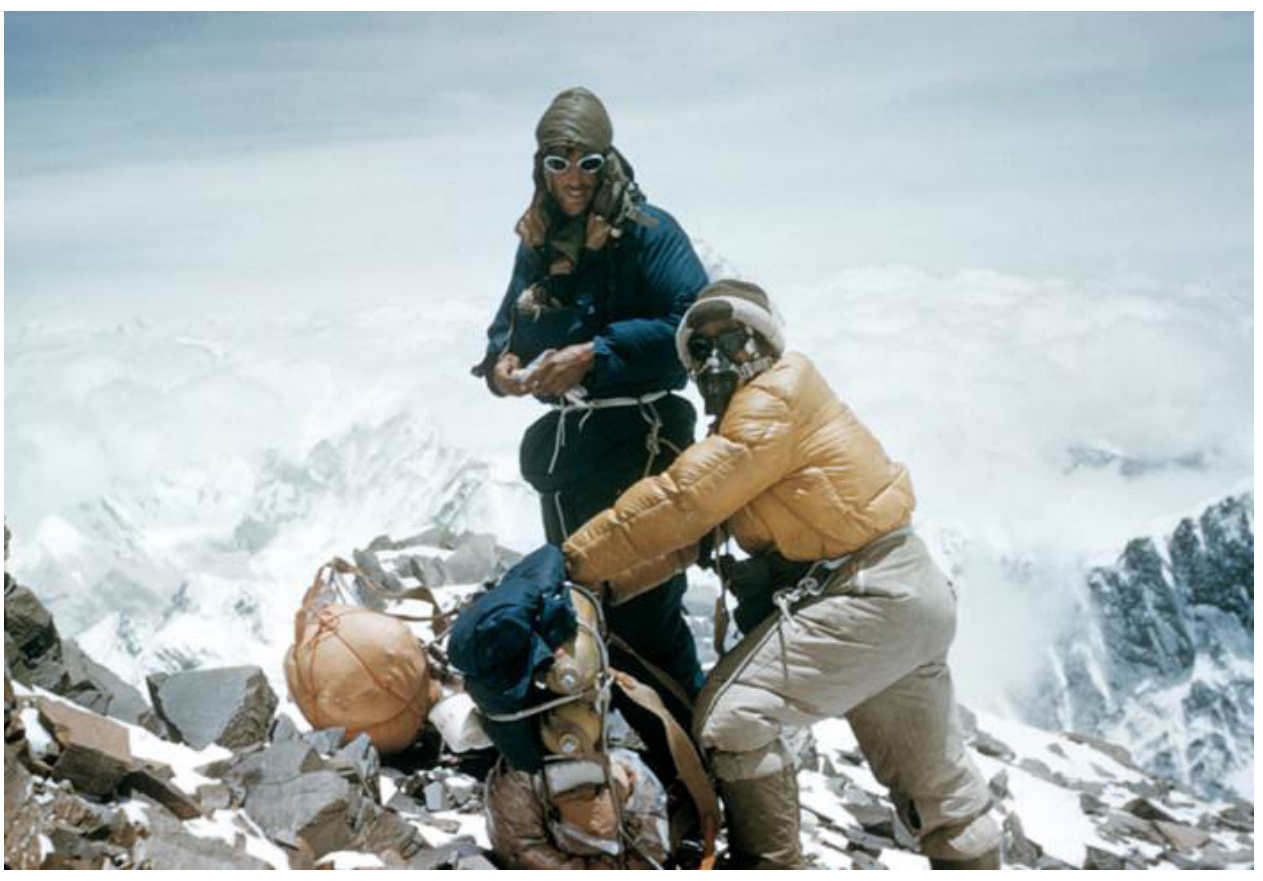

"The architect is not so different from the traditional image of an explorer, someone who sets out to discover new geographic territories never before documented and experienced... In doing so, new human perspective and knowledge is created, changing our relationship to both this new location as well as our initial presumptions about the places we left before"

- Sean Lally, The Air From Other Planets 


"Seeing is believing"
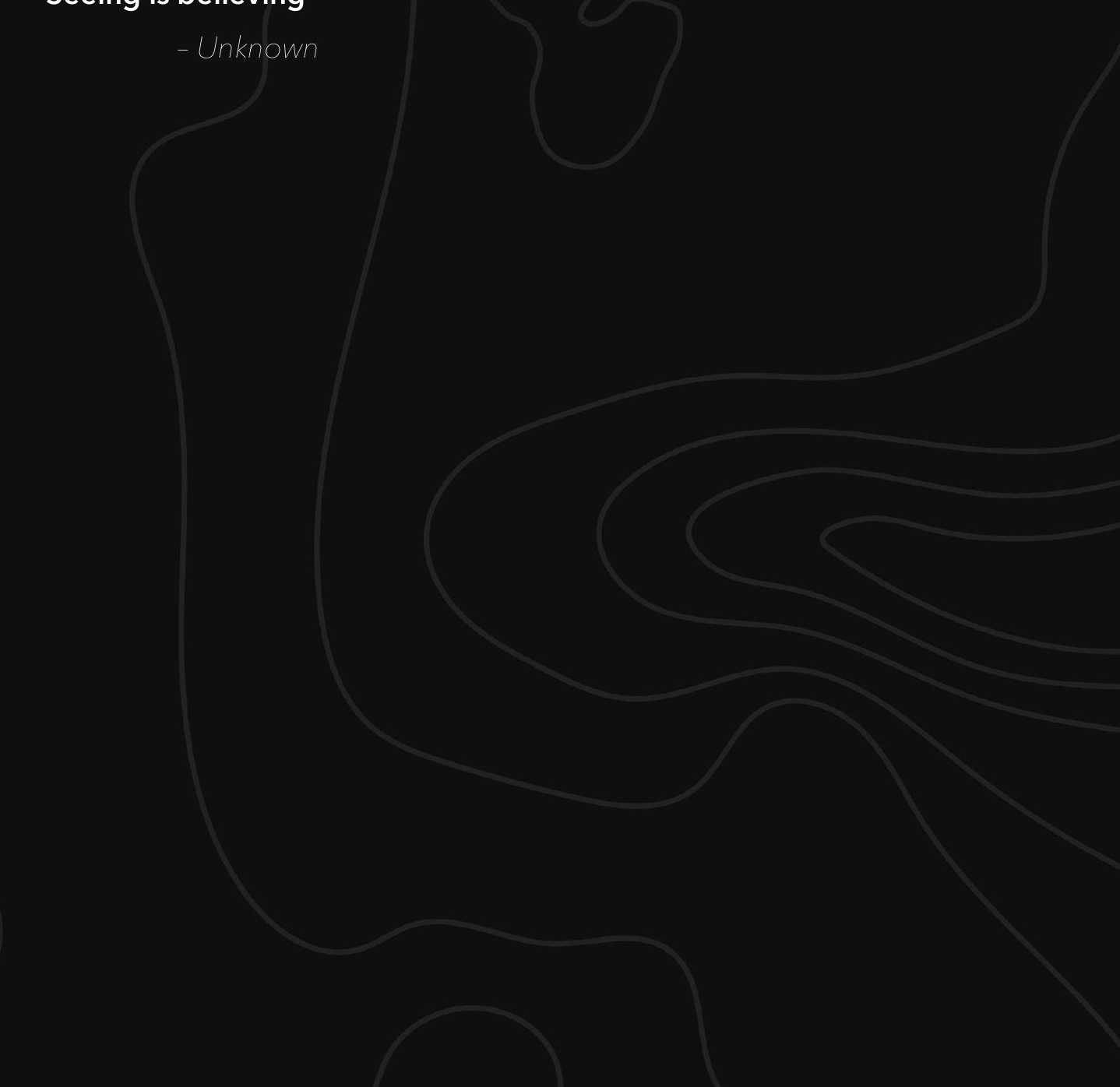


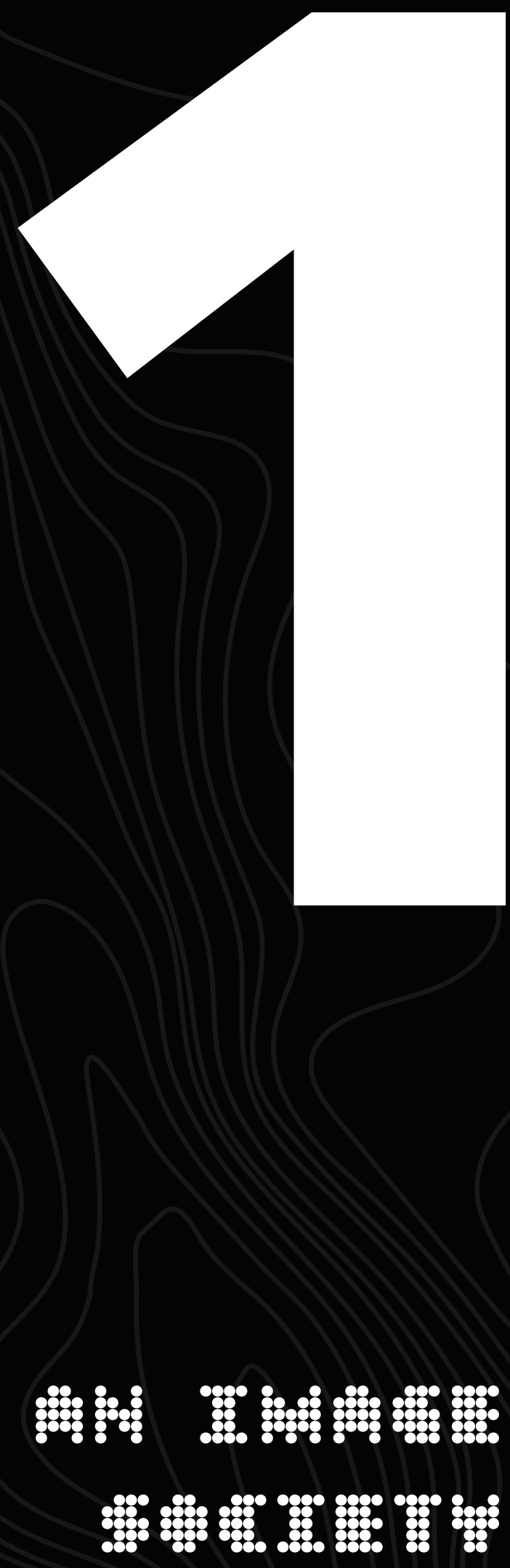





\subsection{THE EYE AND OCULARCENTRISM}

Encountering the world today in our digital centric and globalized culture, individuals have found themselves engrossed by the information gathered through their retinas. The eye in the human sensorial envelope remains one of the most fundamentally utilized yet misunderstood mechanisms in our arsenal of senses. As we traverse the virtual and physical geographies of the built and natural worlds, we predominantly use our eyes as a means of relating to, navigating, and thus deriving meaning from our surrounding environments. The eye serves as the tool through which we as humans are able to confirm our place within the world, offering a verifiable image in the mind with relation to the body, one where a place becomes memorized and thus holds meaning to the individual. The prevalence of the eye today is ironically overlooked. As we go about our daily activities in a variety of environments, the eye holds the power to provide us with countless subconscious confirmations of our surroundings, whether we are walking, driving, doing or resting. This dominance of the eye has

Figure No. 2

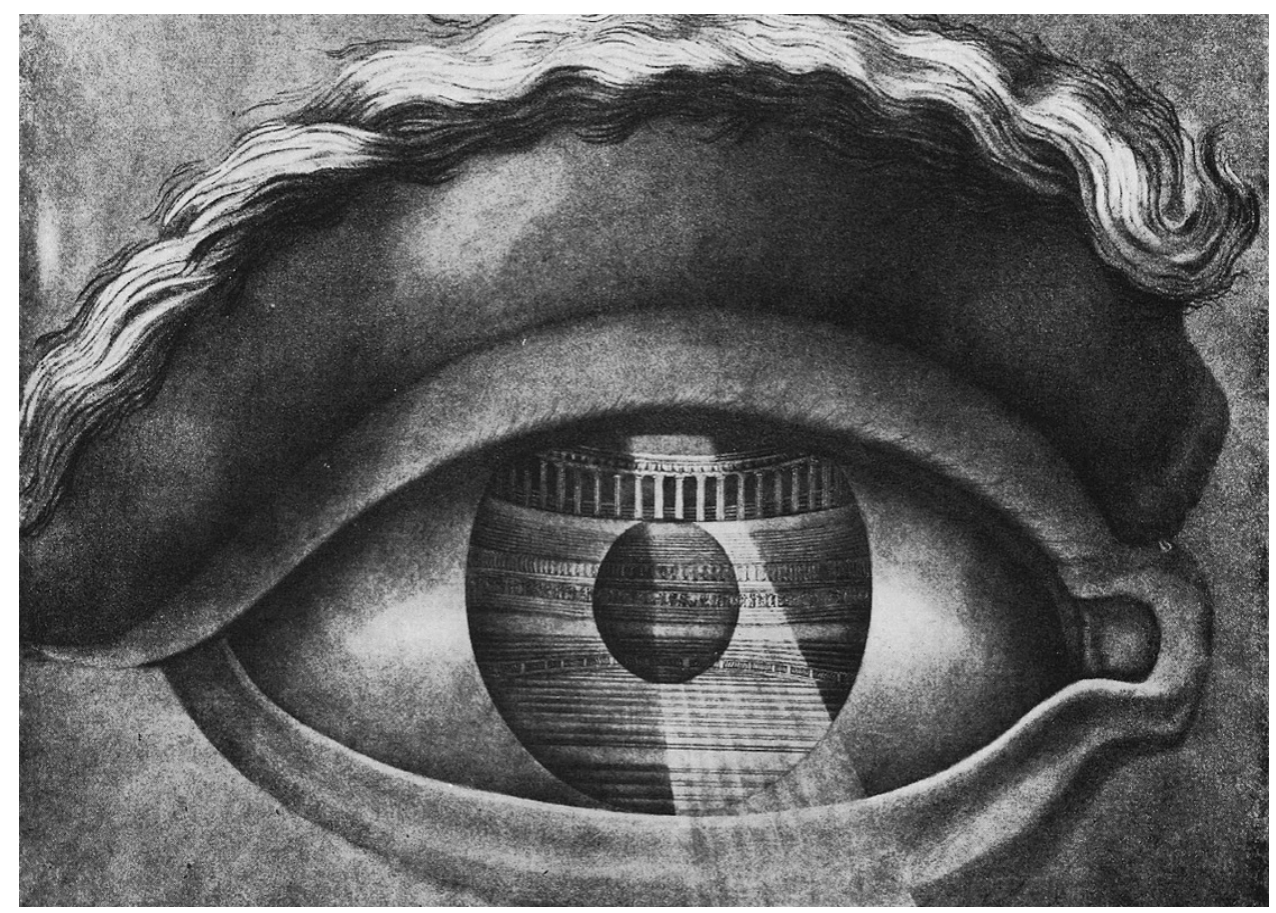


birthed a new societal shift, one where the image takes on incredible meaning and fortitude in creating new knowledge and understanding to the individual and collective alike. As the fundamental event of the digital age progresses towards the world as picture, the supremacy of vision has been reinforced by a hoard of technological innovations and the endless multiplication and production of images (Pallasmaa, 2012, p. 24). As such, it becomes increasingly indisputable that we live in an image society, one where we judge a book by its cover and rely predominantly on the eye as a method of extracting new knowledge from our individualized contexts. As our attention culture craves for the instant gratification offered by the eye's absorption of images, our societal ocularcentrism strengthens. As a result, the individual unknowingly distances themselves from others in an age where we should crave for nothing less than human closeness and connectivity.

Historically in the neo-classical, Renaissance, and early modern periods, the eye was understood as the noblest of the senses, giving sight the ultimate primacy within the human condition (Wolfe \& Kambaskovic, 2013, p. 1). The eye was associated with reason, knowledge, and consciousness, as it was perceived to be the only true way one could derive indisputable fact from their surroundings. In ancient Greek philosophy, Plato derived meaning from the human experience through the eye, understanding it as a source of divine inspiration and truth in a world of darkness, uncertainty, and unknowns (Wolfe \& Kambaskovic, 2013, p. 1). Additionally, the neo-classical Cartesian theory of René Descartes laid foundations for the modern understanding of vision and sight as the primary source of knowledge in the human experience. For him, sight was the only accurate way of discovering and quantifying the external world, as truth could only be consumed through a series of images captured by the eye (Belova, 2006, p. 95). Though the spatial constructions of churches in history had an undeniable understanding of the phenomenological effects 
of space and perception, the church was also able to not only take advantage of the eye in the human sensorial envelope, but also to reinforce its importance in the understanding of humanity. Historically, creating a ritual of progression through a multi-sensorial spatial theatre, the church - striving for growth and following - used the image as a source of information to a largely illiterate population. Before a time of the mass produced and understood written word, illiteracy hampered the general populations ability to acquire knowledge. Employing a more visually-centred source of education to the masses, stained glass and motif images were used as both a show of wealth and power,

Figure No. 3

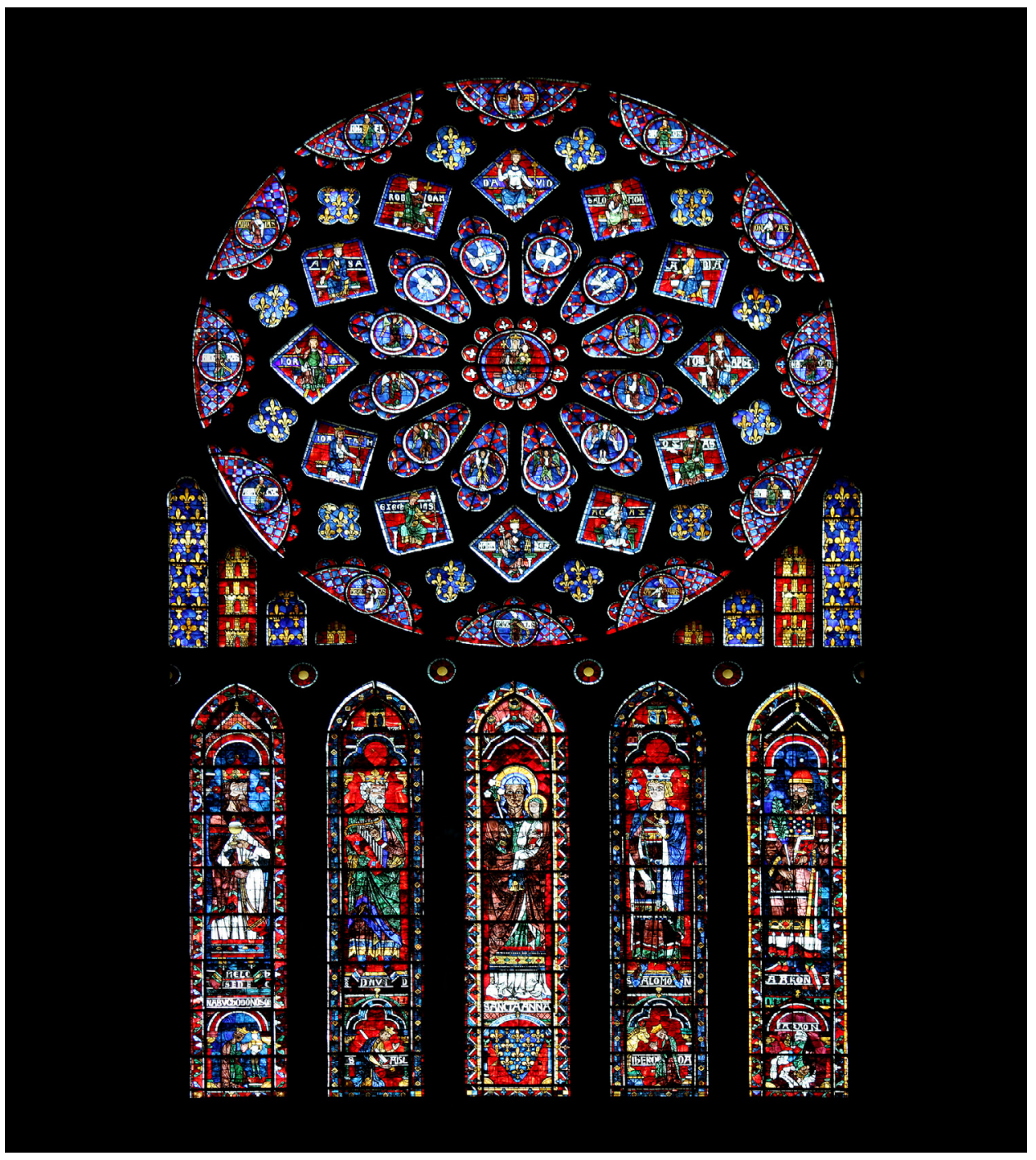


but also as a means to provide the illiterate with easily identifiable and understandable vignettes. These images of the church formed a dialogue of information and knowledge between the individual and the stories and passages of the church. In a clearly visual manner, the church was able to not only communicate with individuals who had no prior knowledge of their teachings, but they were also able to transfer an understanding of their narrative forever engrained in visual imagery. Throughout time, from Greek philosophies to contemporaneity, this emphasis and focus on sight within the human experience not only created a privileging for the eye and the aesthetic, but it also began to create a disconnect between our bodily intuition and the totality of our sensorial apparatuses. In an age of empiricism, enlightenment, and the scientific method, our faith in the image became the primary source of information to the human experience.

As the eye became foregrounded in modern history, it furthered our obsession with the image and vision. Subsequently, our ocularcentric bias created an obsession with light through its very interaction with the eye and its perception in the human

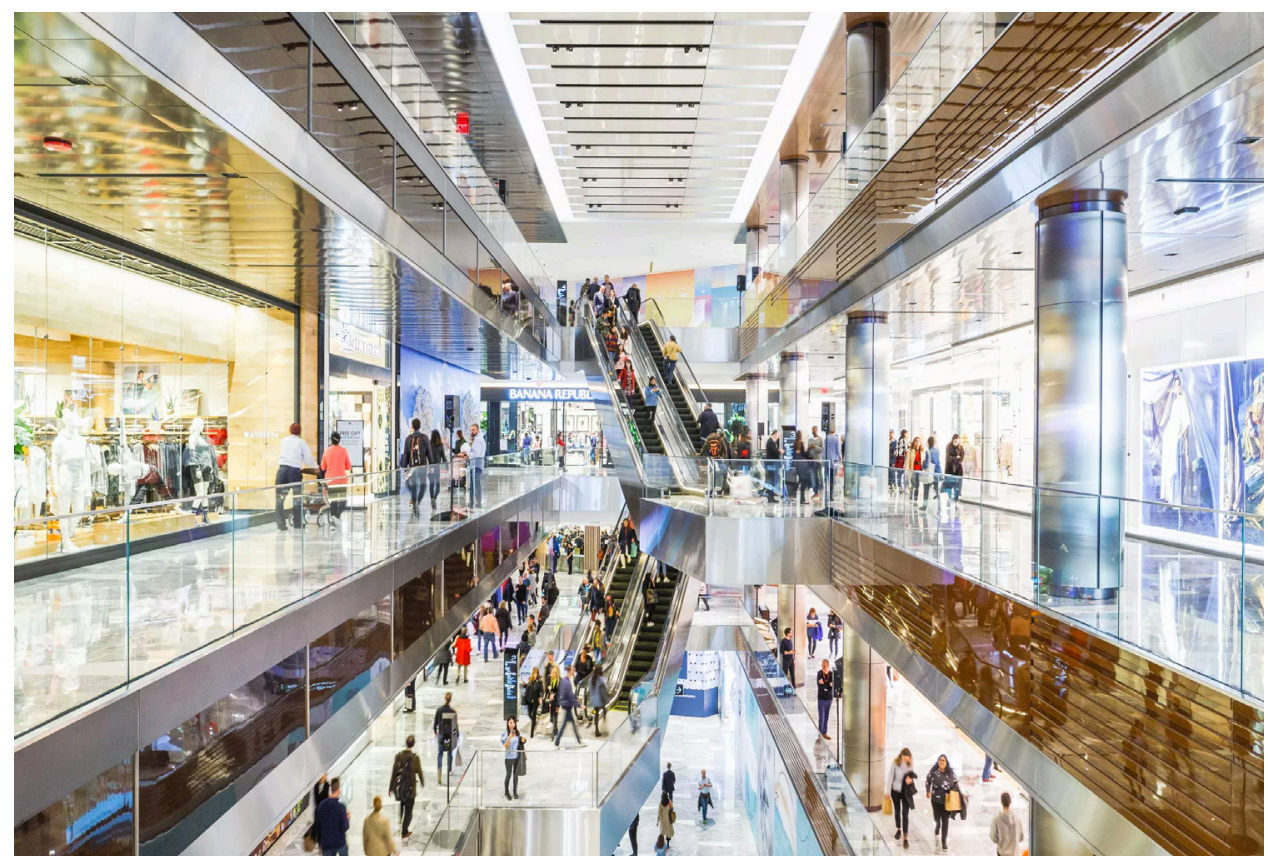

Figure No. 4 
arsenal of senses. A critical element in the perception of space in the contemporary era, light engages with the eye in the form of energy, creating perceivable visual imagery within the mind. As technological advancements allowed for glass to overtake the priorities of modernism, so did the spatial constructions of society and their inevitable privileging of vision. Modernism's obsession with light, combined with an overabundance driven by our occupation in the non-place, results in a disregard for the power light once held in creating memorable and emotional experiences within built form. As society came to prioritize illumination in the architecture of the early twentieth century over the more theatrical potential of a range of shade and shadow, light was no longer used as a provocative tool in the arsenal of senses. Instead, light was reduced and lessened as a function for "dispelling the shadows in the farthest corners" of a space, where it inevitably manufactured "too much light in the halls, on the stairs, in the doorway, the gate, [and] the garden" (Tanizaki,1977, p. 38). Seen in Figure 4, but also in the majority of spaces we occupy in the contemporary environment, our obsession with light has only been compounded by a society hypnotized by digitization, globalization, and capitalism. Here, architecture is meant to disappear, instead forcing consumers to interact with merchandise rather than one another or the space itself. As our societal bias for the ocularcentric grows with digital society, we are simultaneously unaware of its transition in architecture. In going about our everyday lives, we say we will 'believe it when we see it' and that 'seeing is believing'. We engage these questions of the human condition subconscious through the lens of the eye, all while attempting to 'see for ourselves' the source of reason and understanding the image provides to us. The societal shift from the fullness of the senses to the dependance of the eye has not only altered the ways we viewed and approached architecture, but it has also profoundly transformed our methods of creating, designing, and representing them as well. 


\subsection{ARCHITECTURAL REPRESENTATION}

As the eye and vision in society became ever more pervasive and universal over the other senses, so did its prevalence in the field of architecture. One possible hypothesis for the reason we tend to think of architecture as a primarily visual endeavour is due to the fact that we represent architecture through visual means. Since the Renaissance, the architectural drawing and sketch began laying the foundations for understanding architecture visually through the interface between the eye and the paper. The drawing set out to convey necessary information about a physical object that existed in the mind of one individual, to be transferred among others. Historically, the master builder was engaged in the design of space, working and crafting the formal arrangements of elements through the careful and meticulous knowledge that came with their material and tectonic territory. This knowledge was then often transferred to a print or drawing so as to explain through easily identifiable images the process of constructing such a space. Although focused on the imagery of the drawing, the act of the sketch is undoubtably a haptic experience. Though on the surface it may seem to be a purely visual activity, the sketch engages a multitude of senses in its making. The act of sketching brings designers into a haptic dialogue between their mind and the object, employing a multi sensory act that moves beyond the mere coordination between the eye and hand (Monshizade, 2016, p. 359). In Figure 5, architect Alvar Aalto records a landscape through the act of drawing, which offers more

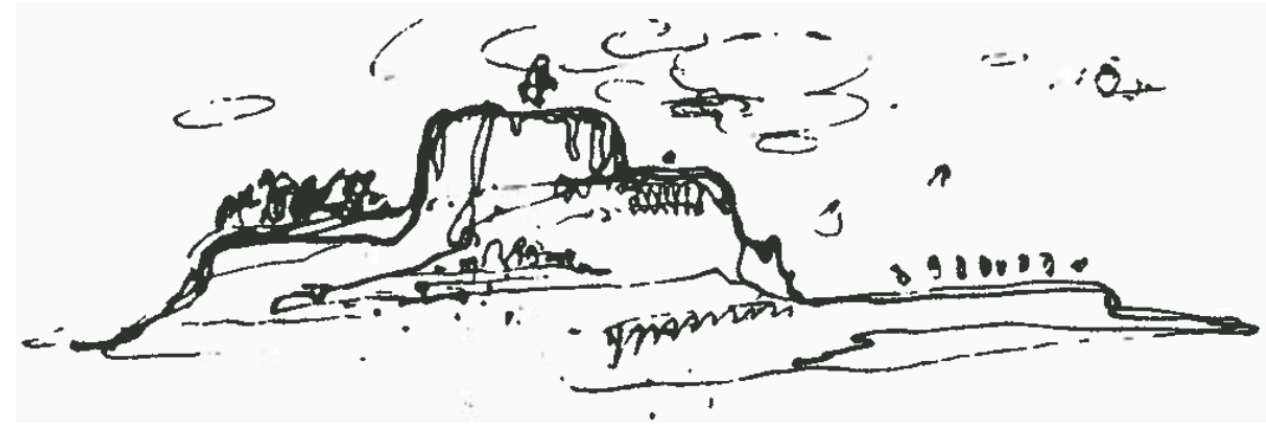

Figure No. 5 
than a photograph might. Through the interaction between his hand, eye, and other sensory receptors, Aalto prioritizes certain elements while diminishing others. The sketch becomes a cumulation of sensory stimuli filtered through the mind of the architect. Unlike the flat twodimensional image, it has the ability to display not only a hierarchy of environmental information beyond what is seen, but also of what is felt. As architects in the contemporary setting have lost much of the craft for the sketch, we have distanced ourselves yet again from the haptic engagement of making architecture, reducing it to a represented end product through the image.

Historically, the development of the perspective furthered the architectural profession towards one of the eye, allowing the totality of a building or construction to be easily visualized as it would appear through the interface between the eye and the mind. The use of sophisticated digital media in our own profession further compounded a clear visual bias in architectural thinking, often resulting in a privileging of the aesthetic over the bodied experience (Monshizade, 2016, p. 360). The rediscovery of the perspective in the Renaissance and beyond offered a new visualization technique for representing architecture as it has since become increasingly powerful in the capacity for understanding a built construction, especially in our current age of digital contemporary design. In today's amplified and digitized society, however, architecture runs the risk of not only being represented

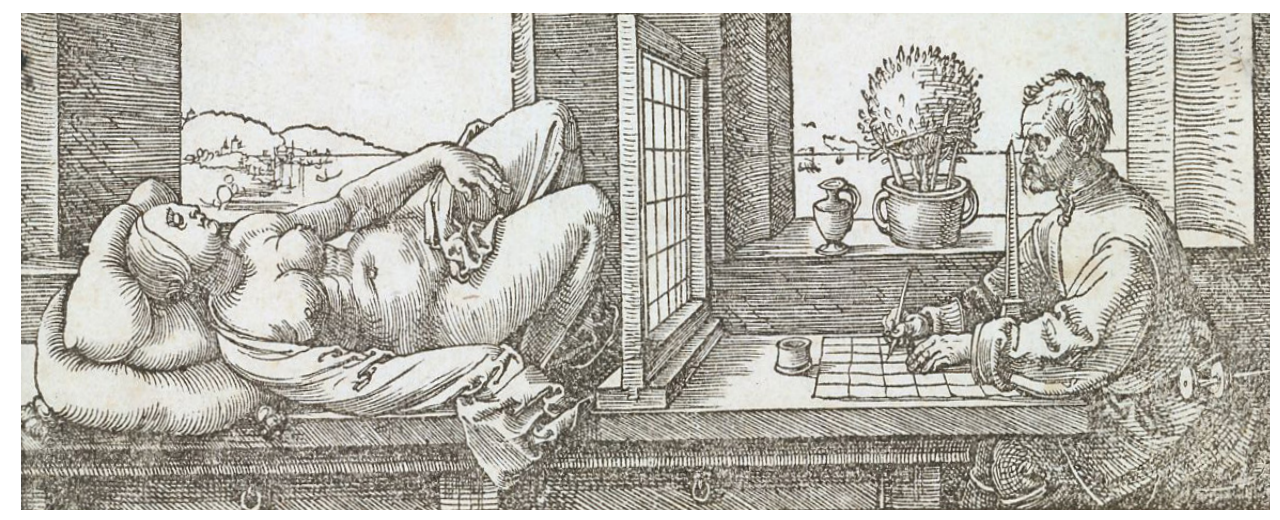


through visual means, but also having an externalized predominating image as its fundamental design philosophy. With today's assortments of CAD, BIM, and visualization technologies, the screen and the pixel hold incredible power in our capacity for designing our lived experience. Though advancements in these computer technologies have their place within the industry, the computer creates an inherent distance between the maker and the object (Monshizade, 2016, p. 359). Designing purely through the computer image forces a reliance on the pixel as a means of producing architectural expression rather than an expression born out of the intricacies of the human senses captured in built form. The problem with fully computer-generated designs is the fact that they take place in a world where "the observer has no skin, hands, or body," one where the designer becomes a bodiless observer and remains an outsider in relation to the design and body (Pallasmaa, 2009, p. 99). As architecture moves its representation further into the digital world earlier in the design process, our spaces fail to engage the senses of the lived experience, reducing the buildings journey to one that is almost entirely retinal and image driven. Understanding that our bodies in space have an extraordinary capacity to absorb a multitude of sensorial information is stifled from our very representation of architecture, as it begins to flatten our multi-sensory capacity to one easily palpable by the computer and the image (Monshizade, 2016, p. 359). Though the representation and creation of architecture by visual means seems innocent enough, its effects fall further out of the control of the architect, ultimately giving rise to the building as a purely visual product rather than an experiential driver. 


\subsection{THE ARCHITECTURAL ICON}

A direct result of the issues caused by architectural representation techniques and the societal preoccupation with visual imagery, architecture has digressed into a mere two dimensional poster of what came before. The image in contemporary architectural understanding has led to the creation of the architectural icon, a representative symbol used solely to misdirect and sensationalize a building rather than prioritizing the bodied experience of the individual in space and their interaction with it. The architectural icon distances one's self from the bodied experience of a space, commodifying it to a stylized and perfected idea of an object as the formal takes importance over the experiential. In the public eye, the architect no longer creates intimate spaces for the experience and memory of the user, but rather creates a novelty of beautified objects simply for the visual consumption of society. Seeing architecture as an icon reinforces the idea of the non-place, creating spaces that are more concerned with the passive viewing of an object rather than the surrounding experience of a spatial condition. This ocularcentric culture the architectural profession currently reinforces has resulted in buildings "designed as landmarks on the skylines of big cities, commissioned both to attract capital

Figure No. 7

Externalized versus internalized
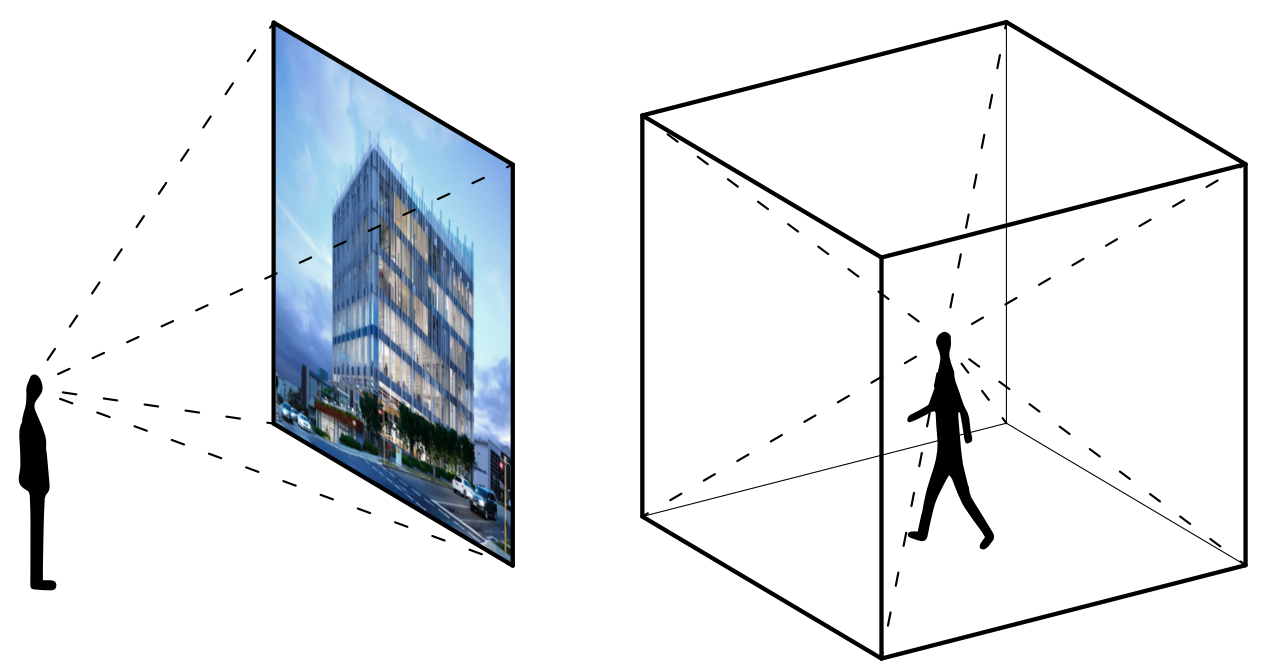
and to express the power of investment," in effect alienating the built environment from its inhabitants (Ursprung \& Goodwin, 2014, p. 47). Ironically however, in recent years their buildings have begun to be seen as emblems of elitism and exclusivity rather than unifying people, a possible result of the financial crisis and property bubbles in Western economies (Ursprung \& Goodwin, 2014, p. 47). When buildings today conform to some idealized image, they reinforce the societal ideal of the architectural icon and simultaneously strengthen the non-place.

As the architectural icon produced an "unending rainfall of images," the understanding of the purpose of building wasn't the only thing to be distorted within people's perceptions (Pallasmaa, 2012, p. 24). The image itself can become distorted as well, providing a falsified reality that directly works against the earlier hypothesis' of figures like Plato or Descartes who believed the image to be a source of truth. The image, being a mere projection of a reality, can become manipulated or misunderstood through the temporal nature of its existence. Focal points, perspectives, and lens distortions all have the potential to mislead the eye from the reality of what it might be seeing.

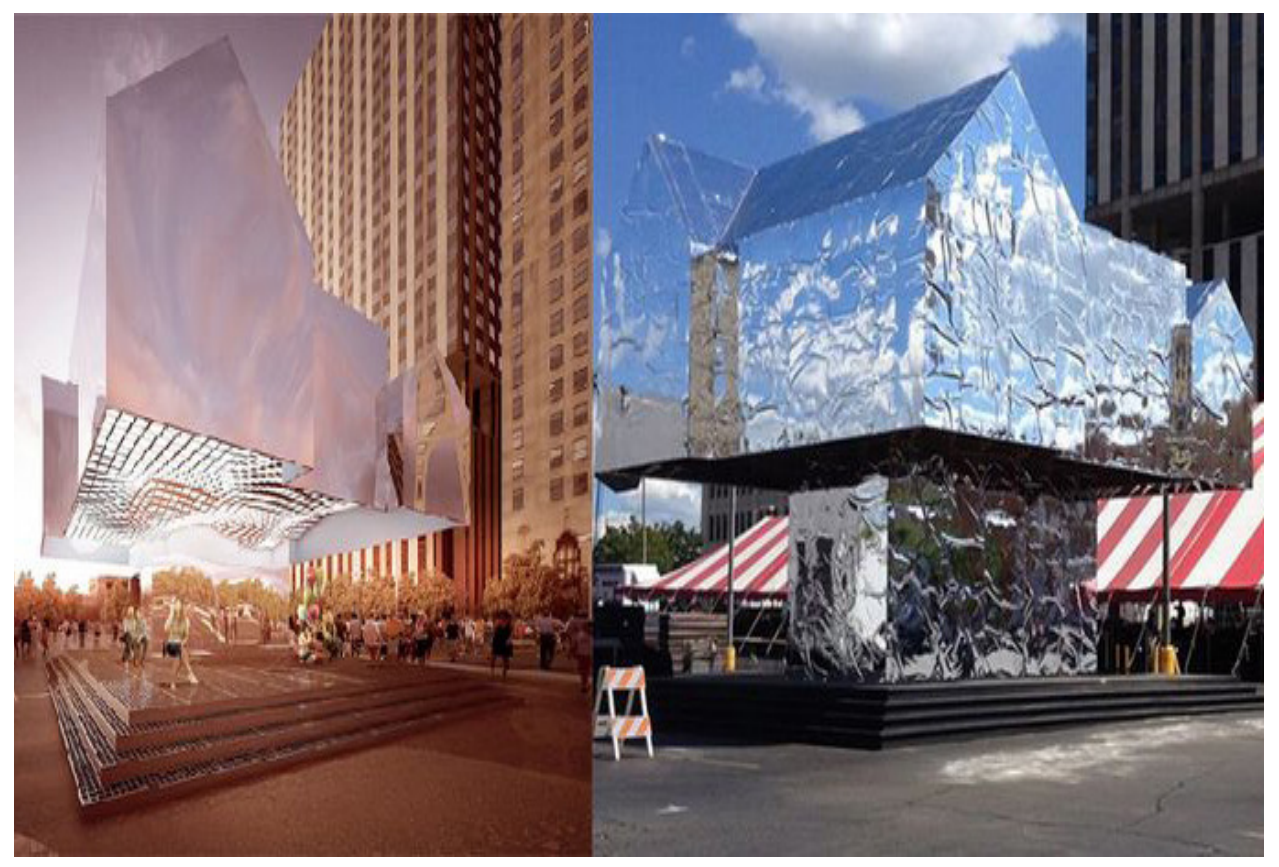

Figure No. 8 
The architectural rendering is no stranger to this phenomenon, often exaggerating an interior space or embellishing a street perspective in the hopes of altering its perception in the eye's of those who encounter it. In this sense, the architectural rendering can be seen as damaging or destructive to architecture itself, supplying an individual with a falsified understanding of a possible reality. The architectural icon in this sense fails in providing any emotional experience at all, falling to the capitalistic and economic properties of the rendering in order to commodify and aestheticize a brand, company, city, or otherwise. As our ocular bias over the last half century has intensified, a type of architecture aimed at striking a memorable visual image has predominated (Pallasmaa, 2012, p. 33). The architectural icon's manifestation in the contemporary era has not only damaged the way society understands the praxis of architecture, but it also limits the very way we engage with architecture beyond the visual. 


\subsection{CONCLUSION}

The gaze in society has taken precedence over the rest of the senses, driving the understanding of architecture to be synonymous with the image rather than inhabitation. Historically, the nobility of the eye has had long lasting effects in the way vision is understood both consciously and subconsciously in our understandings of the human condition. From the early modernists' obsession with communication through proportion and visuals to the contemporary overstimulation of the eye through our predilection for abundant light, glass, and iconic image, much of our architecture today seems to solely serve the
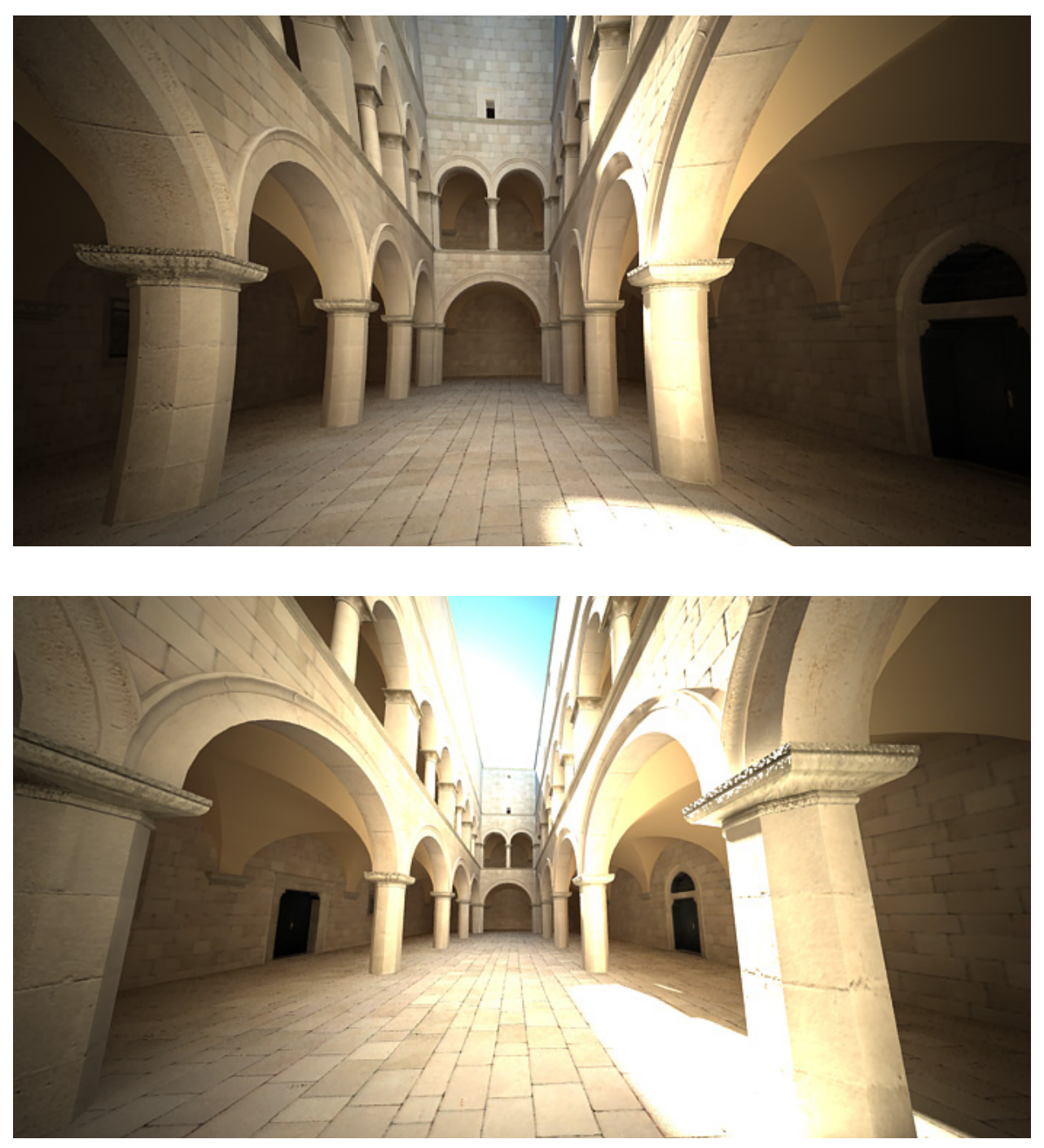

Figure No. 9 
purpose of appeasing the eye rather than the body. As a society, we have inadvertently decided through our privileging of certain senses that it is more important to design for what looks good and attracts attention rather than what feels good. Historic buildings such as the church had obvious visual elements, as their constructions served as icons of power and religion. However, the church also used these visual elements as part of their overall spatial sequences and experiences. They did not privilege one sense over the other, but instead used the senses to create a ritual of passage within their spaces. Using the smell of incense, the echo of music, the reverberation of sound, and luxurious materials, proportions, and light, the church was able to create a full bodied spatial sequence that resonated with the sensory experience of an individual. This experience served not only the individual themselves, but it also reinforced the power of religion to transcend groups into meditative or spiritual states. Today, however, we are trapped in an image society, one that has forgotten the complexities of the human body in space and one that necessitates the design of the aesthetic over the design of feeling through the other senses. This pre-eminence of the ocular has lasting effects on the psychological interaction between citizens of the urban geography, creating a landscape that challenges the very structure of the city and its spaces as well, creating an anxious and alienated society within the fabric of urban life. As the eye becomes ever more dominant in our ocularcentric domain, the problems of the contemporary urban landscape become magnified and can be attributed to our very infatuation with the eye over all else. 


\section{"We shape our buildings;}

thereafter they shape us"

- Winston Churchill 


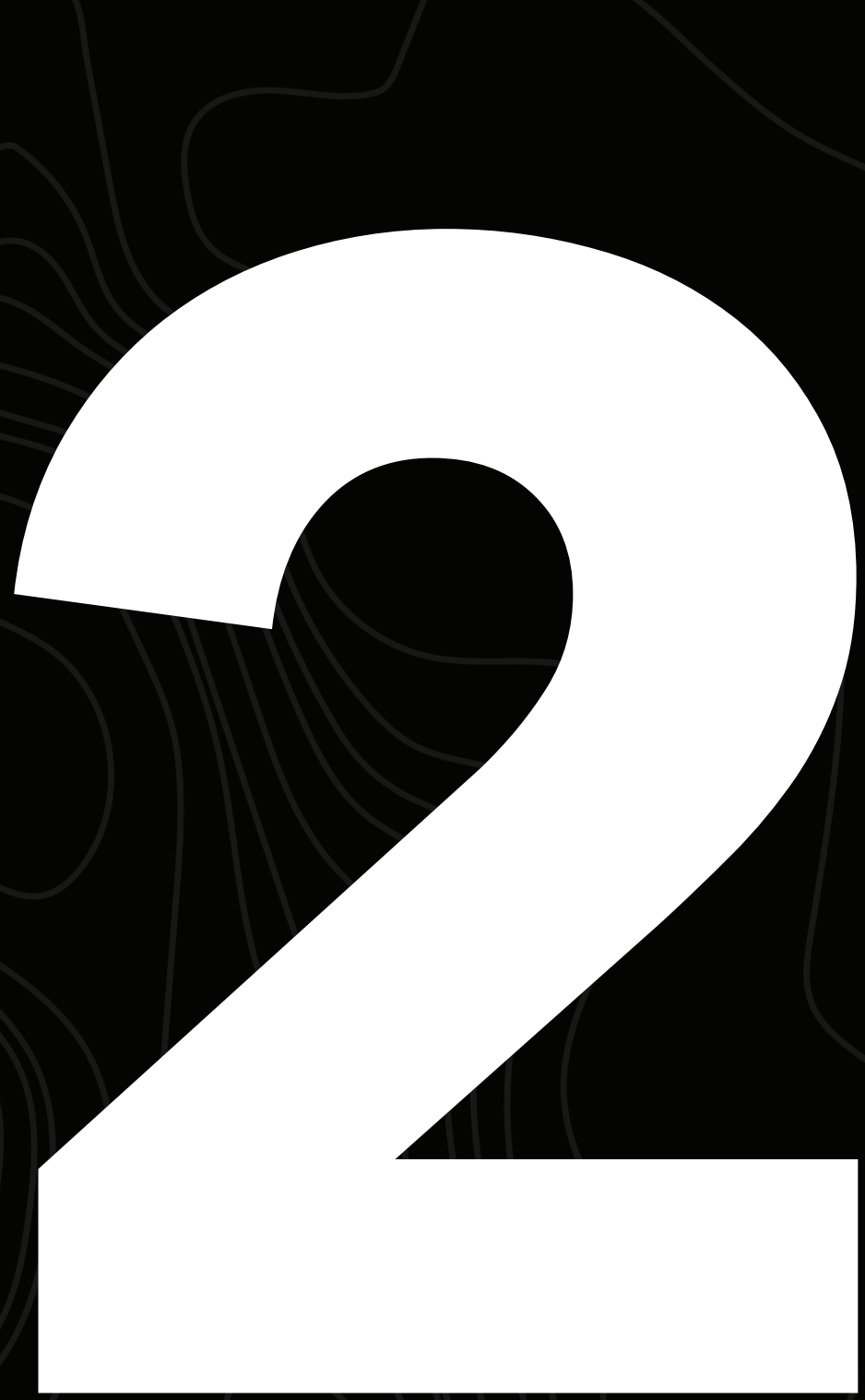

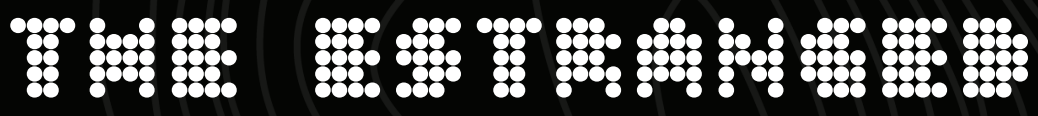

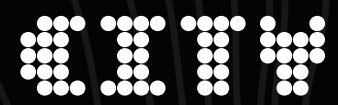





\subsection{INTRODUCTION: THE CONCEPT OF EMPTINESS}

The ocularcentric society we unknowingly occupy has resulted in the estrangement of the body and mind from the physical environment. The built world, though increasingly reducing the engagement of the human senses, cannot be seen as entirely empty of experiential potential. The concept of emptiness itself is a challenging one and likely impossible to define absolutely. In the abstract, emptiness equates to nothingness, the perfect void through which no material, matter, or energy can exist (Campbell, Giovine, \& Keating, 2019, p. 1). However, in reality, nothing is truly empty, for even the perfect vacuum of space contains invisible wavelengths of energy that radiate outwards into what we see as a void. Just as the digitized and contemporary city may seem to be devoid of experiential meaning and connection, it requires the re-evaluation of our understanding of the senses within an architectural discourse that will form relationships between individuals and urbanity. In doing so, we must first acknowledge that spaces are not simply

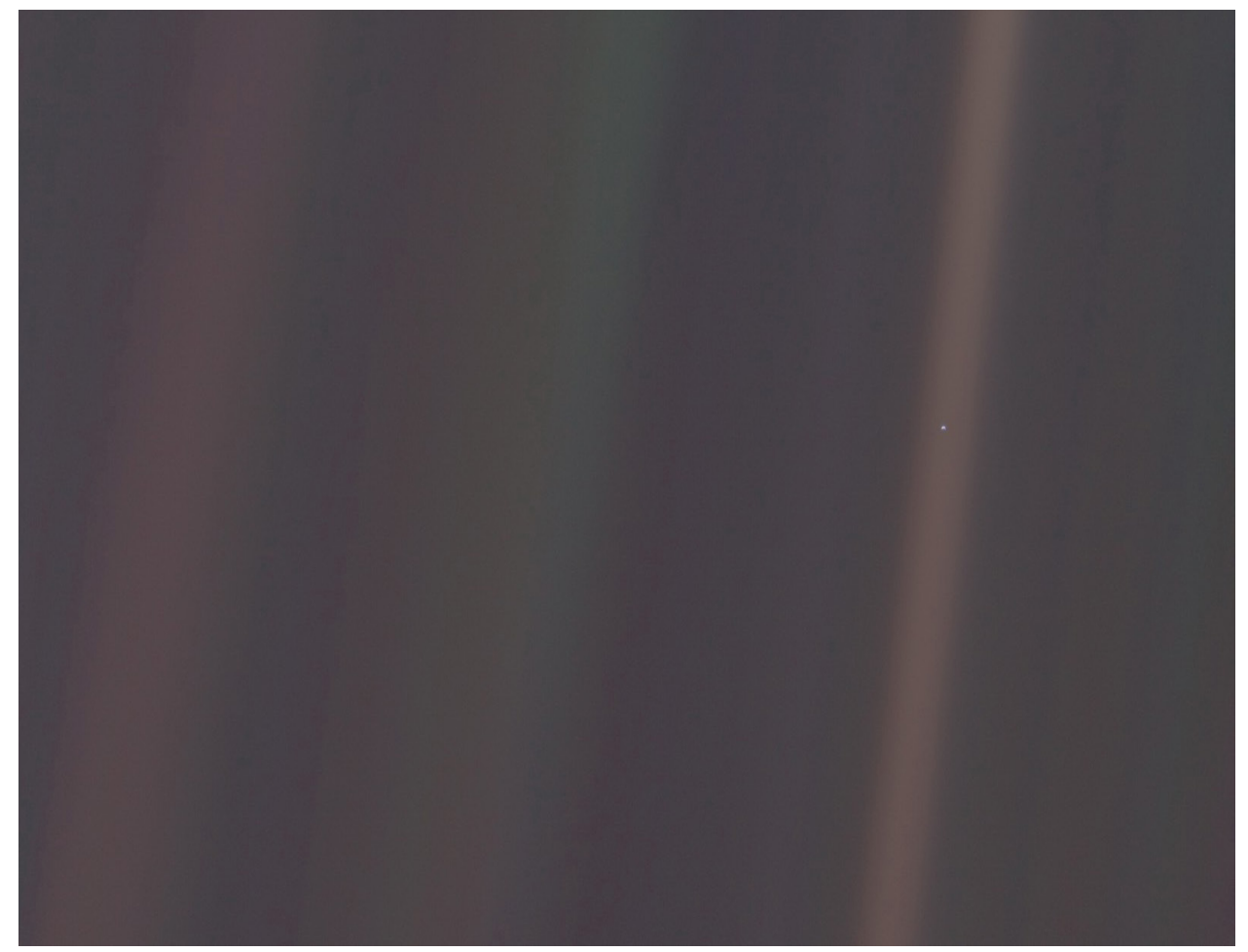


voids. Spaces are filled; they reflect intangible thoughts, memories, perceptions, and emotions off of every wall, corner, reflective surface, texture, and meeting of material. They engage the bodily senses in ways that affect our emotional understanding of a space as well as our understanding of ourselves. A space transcends the concept of emptiness and becomes a place when these individualized moments evoke emotional responses within the memory of the individual, thus affecting its perception and recollection in the mind of the individual. Place-ness in contemporary society is necessary in both producing meaning between a person and space as well as providing structure to the individual condition. As "the inhumanity of contemporary architecture and cities can be understood as the consequence of the neglect of the body and the senses," society needs rescuing from these urban conditions it created (Pallasmaa, 2012, p. 21). The estranged city is not an empty one. Instead, it contains a level of invisible forces within its geography that undoubtably exist but are either misused, misunderstood, or unnoticed. 


\subsection{THE NEW METROPOLIS}

The birth of the early modern metropolis in the nineteenth century brought with it new urban forms and spaces to be lived in and experienced. With it, the new metropolis also left a residue of exaggerated urban phenomena with lasting social effects between and within its own inhabitants. This city, a direct result of industrialization and globalization, continued our endeavour to bring structure out of nature, furthering some form of order out of a perceived chaos or unknown. This new urban life, however, was not without its criticisms as it was seen to "shelter a nervous and feverish population, overexcited and enervated, whose mental life... was relentlessly antisocial, driven by money" (Vidler, 2002, p. 25). Fascinated by this new way of urban life and its psychological effects on humanity, countless descriptions of the anxious geographies and relationships of the city and their spaces began in the early studies of urban psychologists. By the time of the late 1880s, figures of human psychology like that of George Miller Beard began identifying the modern urban anxiety of neurasthenia as

Figure No. 11

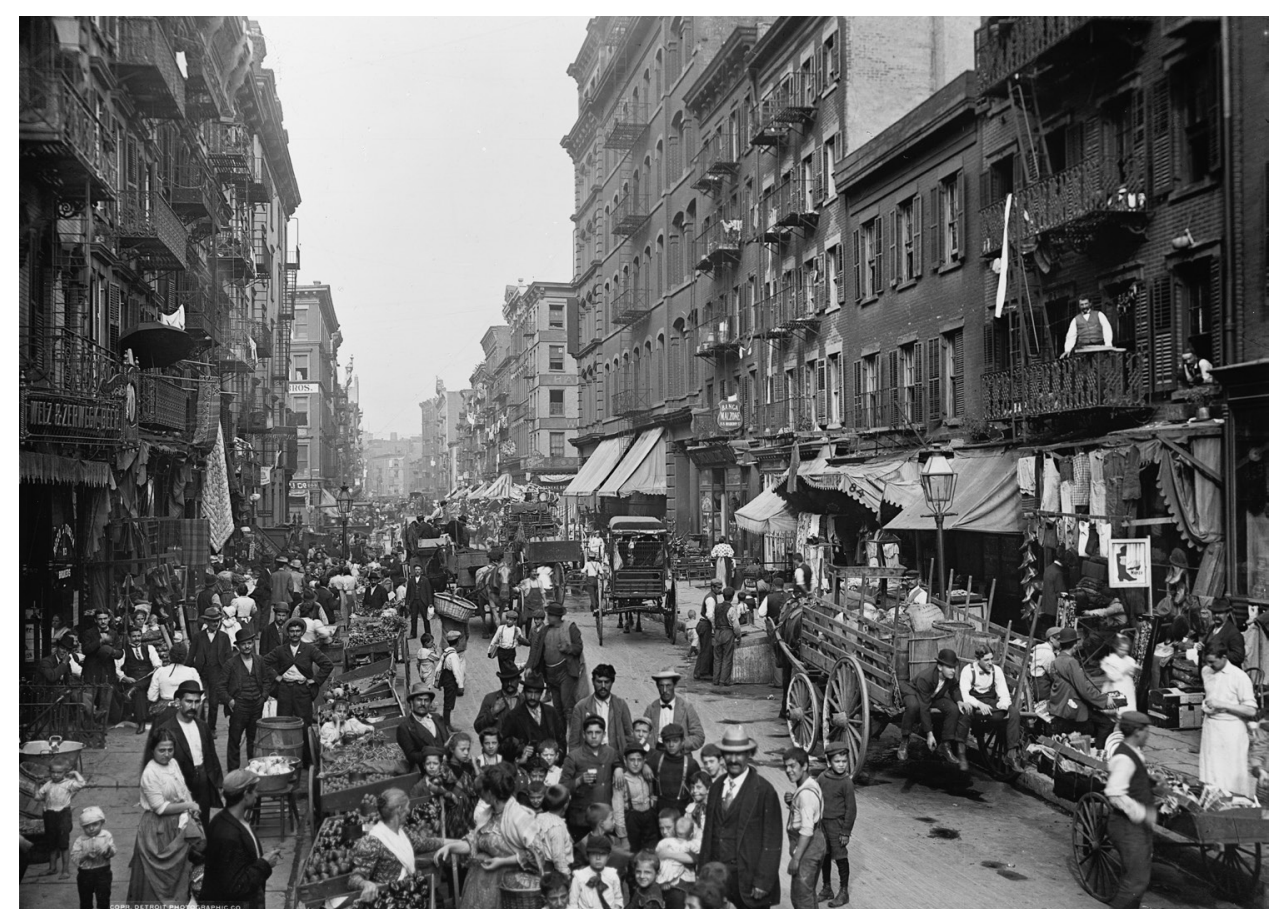


"the principle mental disease of modern life" (Vidler, 2002, p. 25). The new nineteenth century metropolis was home to strange discrete and societal conditions born out of the new physical realities of urbanity, as "the successive closing and sudden opening of the city... [had] the effect of fostering the veritable cause of spatial [discomfort]" within individuals (Vidler, 2002, p. 32). It was at this time of concentrated urban growth that the realities of this anxious city began to amplify, becoming unknowingly synonymous in our architecture and thus in the social relations of the cities inhabitants. These early accounts of the urban environment and the sensorial conditions they produced within people made clear the impact environmental stimuli had over the psychology of the individual. The sensory perception of these emergent hyper-dense urban spaces influenced inhabitants mental state through their emotional and memorial qualities, all channeled through the psychology of the being. Simultaneously, it was these early accounts of the sensorial geographies of the metropolis where stimulation began taking on a different form in people's perception of space. The hyperstimulating environments of the new metropolis became a problem, rather than a mechanism for exploring new relationships between the senses, architectural experience, and the presupposition of a buildings ability to communicate.

Through the form of the new metropolis and the relationships they created brought unforeseen psychological triggers at both the scale of the city and in its spaces. In the past, architects of buildings like the Pantheon, Saint Peter's Basilica, or Santa Maria del Fiore certainly had a deep understanding of space and its phenomenological and psychological effects. Built at different times in architectural history, their use of scale, form, proportion, material, colour, and light all served as provocative tools in the evocation of feeling through architecture. In addition to clearly visual elements highlighted earlier, their constructions used a combination of the senses found through their 
Figure No. 12

Interior of St. Peter's Basilica

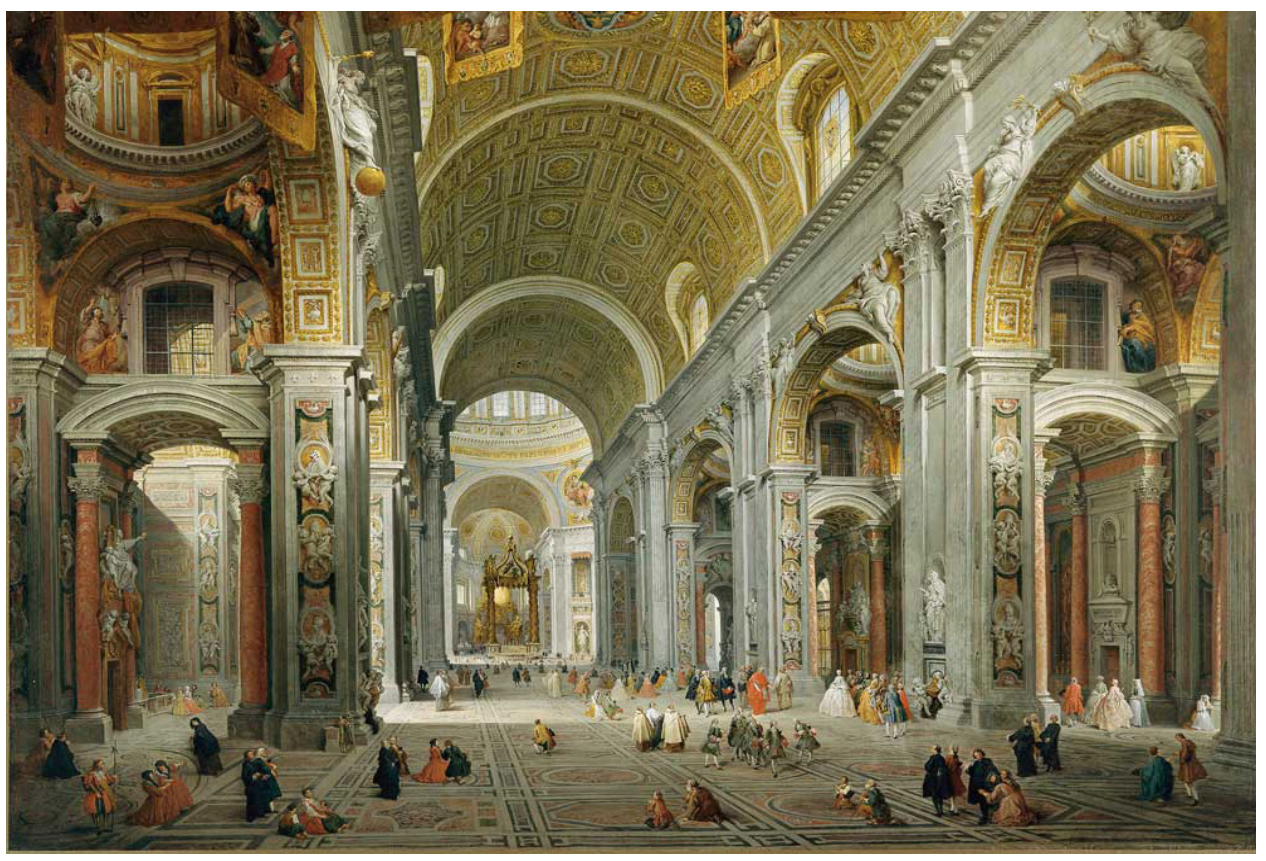

textures, smells of candles and incense, as well as sounds to create a ritual of spatial occupation that mimicked the narrative of the church. Often, their domes acted as pivotal moments in the experience of their spaces, serving as both symbol as well as clear spatial constructions that amplified the sensorial engagement of the body (Venturi, Brown, \& Izenour, 1972, p. 12). The light cast down from the high ceilings, the echoing sound of footsteps and hymn throughout their chambers, even the smells of the spaces, all converge at a point within an individual's experience, shaping their perception and memory of the place. Their built forms generate moments of amplified stimulation, transferring them through the senses and into sublime instances where the individual has no choice but to feel insignificantly small in the shadow of the space. It is only through the tactility and understanding of the senses that allows for this deeper reflection of self, ultimately creating an architecture that reflected the values of the church (Pallasmaa, 2012, p. 12). This transportive experience both creates a geography of self reflection and existentialism while using evocative qualities of spatial perception to engage the mind in place. 


\subsection{THE NON-PLACE}

Contemporary space since the early accounts of new spatial perceptions in the nineteenth century has continued a dialogue that broke away from sensorial engagement. By society further reinforcing the eye and the image, much of contemporary architecture has ignored the physical characteristics and effects spatial constructions have in shaping the perceptions of the individual. As this understanding of the body and the senses was filtered out of architectural discourse, so was an individuals invisible perception of its experience, leaving a residue of meaningless and barren space in todays urban and spatial conditions. This space dominates the contemporary landscape, creating conditions that are neither relational, historical, or concerned with identity (Augé, 1995, p. 63). This 'junkspace' - as Rem Koolhaas coined the term synchronizes its users while consuming people in its meaningless interior space, becoming both extensive and endless as one cannot perceive its limits (Koolhaas, 2002, p. 175). Junkspace is a by-product of modernity, formalizing architecturally into contemporary places like airports, transit stations, shopping malls, and other constructions of the modern city. Today, the architectural quality of these spaces, or lack thereof, results in a dissociation between an individuals experience and memory within them. These spaces - though populated by the journeys, activities, and daily commutes of people's lives - cannot be called places at all. They are what anthropologist and geographer Marc Augé calls non-places (Augé, 1995). The spaces of the non-place are occupied by activity and stimuli, as "thousands of individual itineraries [converge] for a moment, unaware of one another," surrounded by people yet completely alone in a wasteland of space (Augé, 1995, p. 2). As the majority of the spaces we engage with on a daily basis are spaces of passage, transit, and consumption, there becomes a growing disconnect between the language of an architecture and

Figure No. 13

The non-place 


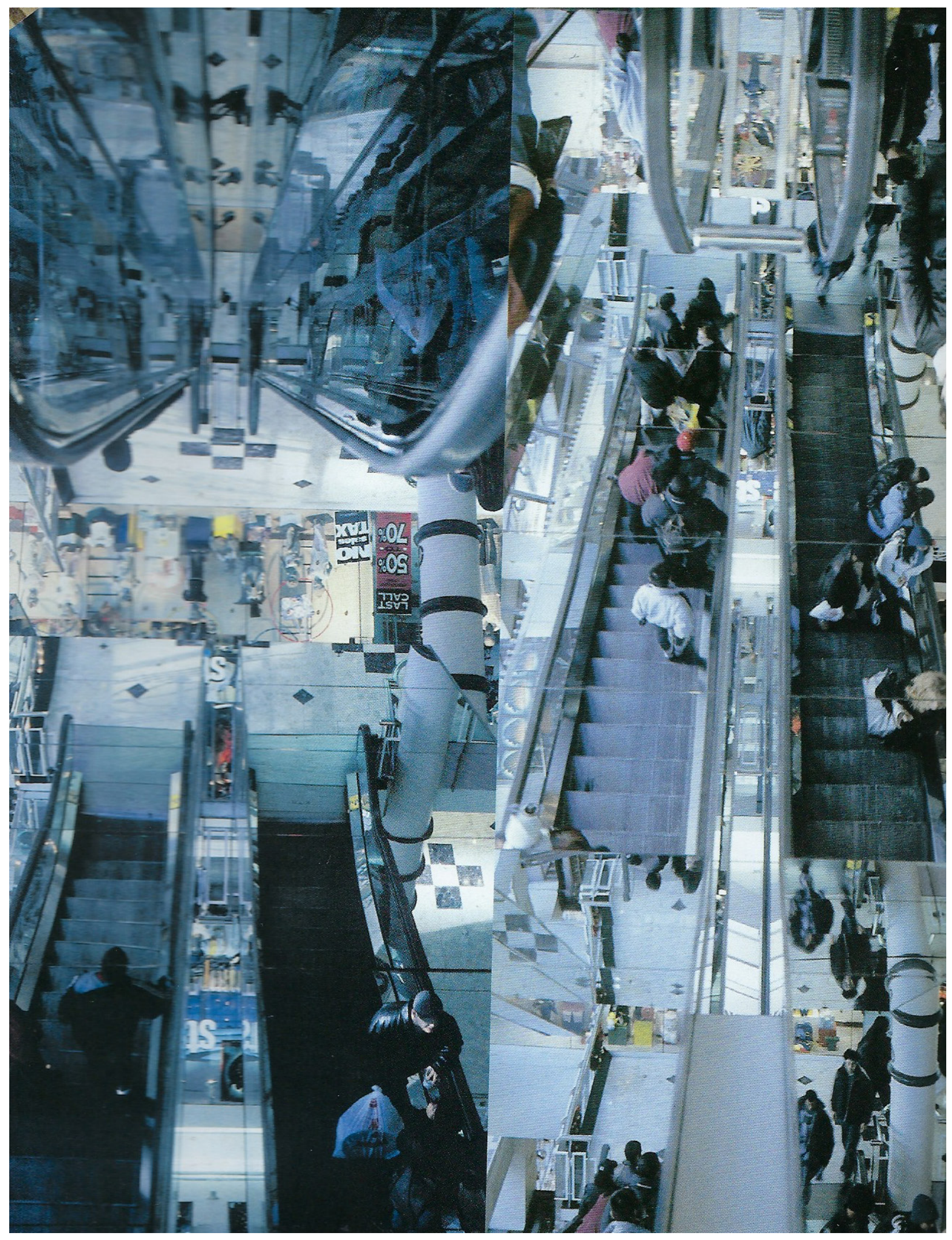


its occupants. The spatial condition of these non-places becomes secondary to life consumed by supermodernity, its essential quality being synonymous with excess and mundanity (Augé, 1995, p. 24). In these banal spaces of passage, the body and mind become lost. With no friction in the physical environment produced by a sense of place and no engagement of the bodily senses, the alienation of the mind is reflected through the spatial experience of its users, ultimately creating the anxious geographies that have since become synonymous with the contemporary city.

Today, as the other senses have become secondary to vision, our lack of comprehension of the psychology of spatial constructions further contributes to our alienation in the landscapes of the nonplace. Currently, the role of the senses has been suppressed by the dominance of vision and the image in contemporary society, consequently resulting in the disappearance of the sensory and sensual qualities of architecture (Pallasmaa, 2012, p. 11). As a result, these nonplace's hold with them an unresolved level of tension between their spatial assembly and an individuals perception. The standardization of the junkspace we complacently occupy is an architecture that simply isn't present, leaving a mere shell of a building to be occupied, but never fully experienced. Drywall, glass, chrome, mechanical equipment, signage, and icons all agglomerate in a meaningless accumulation of excessive junk-in-space. It is this deprivation of the senses in the nonplace that induces an anxious and feverish state amongst individuals, resulting in a disconnect between a person and space, thus alienating the inhabitant from their very environment. These observations suggest that the spatial and architectural settings of our time and their focus on the building envelope as image above all else tend to make us outsiders, in comparison with the forceful emotional engagement of more natural and historic settings (Pallasmaa, 2012, p. 15). As our senses are "aggressively seeking mechanisms rather than mere passive 
receivers," the mind becomes disturbed and anxious through the mundanity of this sterilized built environment (Pallasmaa, 2012, p. 45). With no levels of haptic engagement, emotion, relation or release, the anxious geographies of contemporary space remain unresolved, evident in the non-place-ness of their built form. Instead of giving space an identity through existential grounding and a focus on experience, architecture has since adopted the psychological strategy of advertising and instant persuasion; buildings have turned into image products detached from existential depth and sincerity (Pallasmaa, 2012, p. 33). Our cities and spaces have lost their echo, as in the interiors of today's buildings sounds and haptics are absorbed and censored. The programmed recorded music and the hum of mechanical equipment eliminate the possibility of grasping the acoustic volume of space, furthering the blinding of the senses (Pallasmaa, 2012, p. 55). As the future of the non-place remains uncertain throughout this digital revolution, the spatial perceptions and experiences of individuals will remain crucial in addressing the anxious geographies and sterilization of these communal spaces.

Figure No. 14

The modern city of sensory deprivation

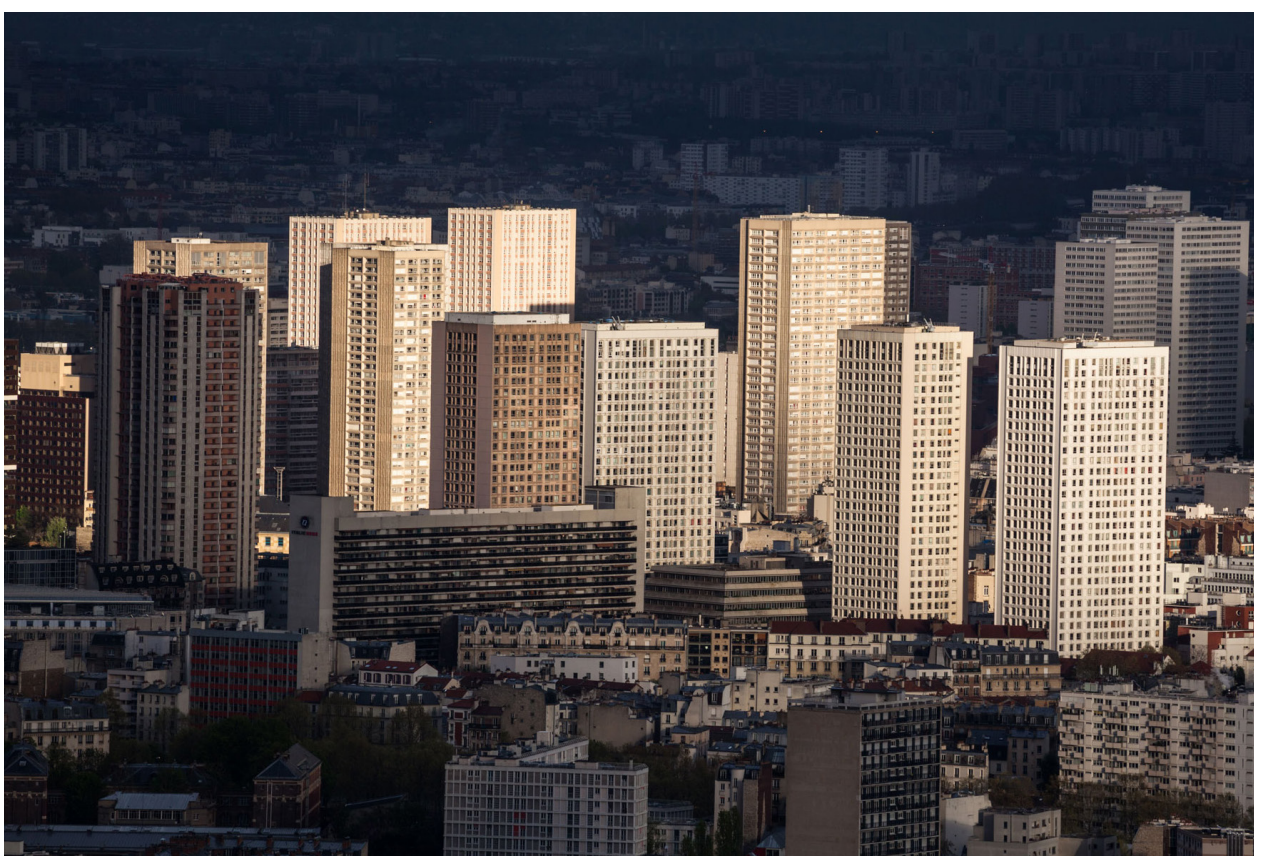

The Estranged City 


\subsection{CASE STUDY: LEARNING FROM LAS VEGAS}

The dominance of vision, the metropolis, and the non-place all come together in numerous contemporary examples across the world. As identified by Denise Scott Brown and Robert Venture in Learning from Las Vegas in 1972, the city presents us with a unique opportunity to see first hand the effects of ocularcentrism on both an individual level as well as examining the spatial constructions of the city itself. Although it would be much too easy to criticize Las Vegas for its overabundant, enervating, and anxiety inducing qualities, it would be much more useful to use Las Vegas as a unique specimen of a city, analyzing the spatial conditions of its making and its psychological effects on individuals. Hosting people from around the world, Las Vegas becomes a unique urban landscape of distinctive social, political, and geographical relationships between people and spaces, an example hardly found anywhere else in the world at this scale and level of intensity. A typical ocularcentric non-place, Las Vegas is almost entirely composed of symbols and signs that work on the level of instant persuasion. Its architecture relies on the image, as buildings along the strip have one job and that is to capture the attention of as many eyeballs as it can in an attempt to transfer the most amount of capital from an individual to the corporation. Las Vegas in a way is a machine, its architecture acts as a highly efficient apparatus for extracting wealth

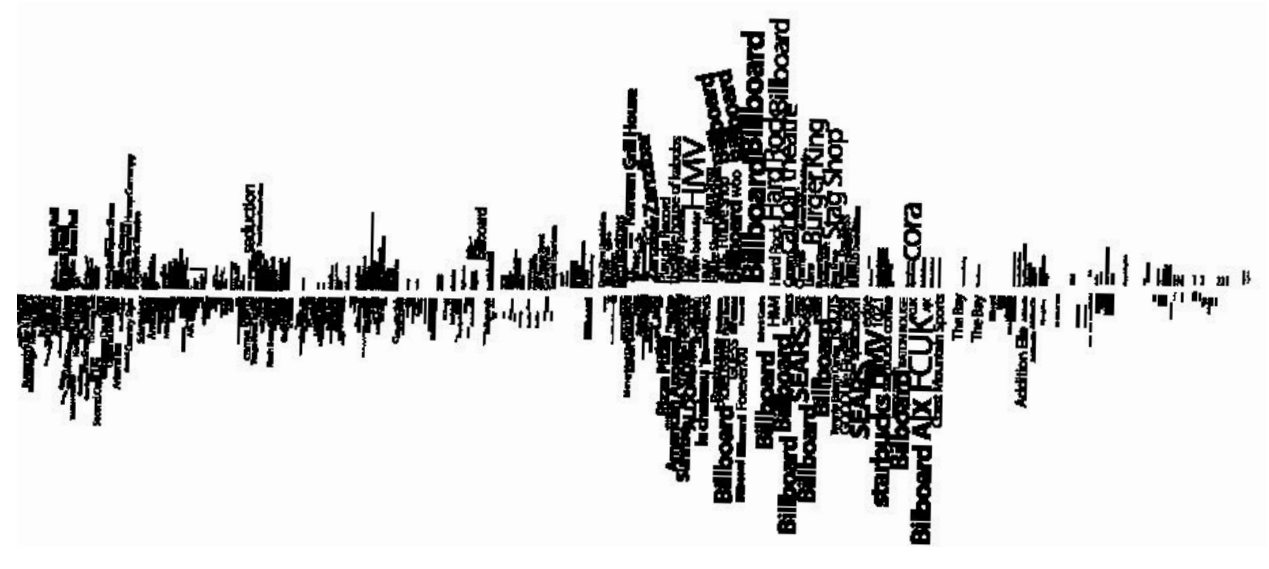


Figure No. 16

Middle Eastern bazaar

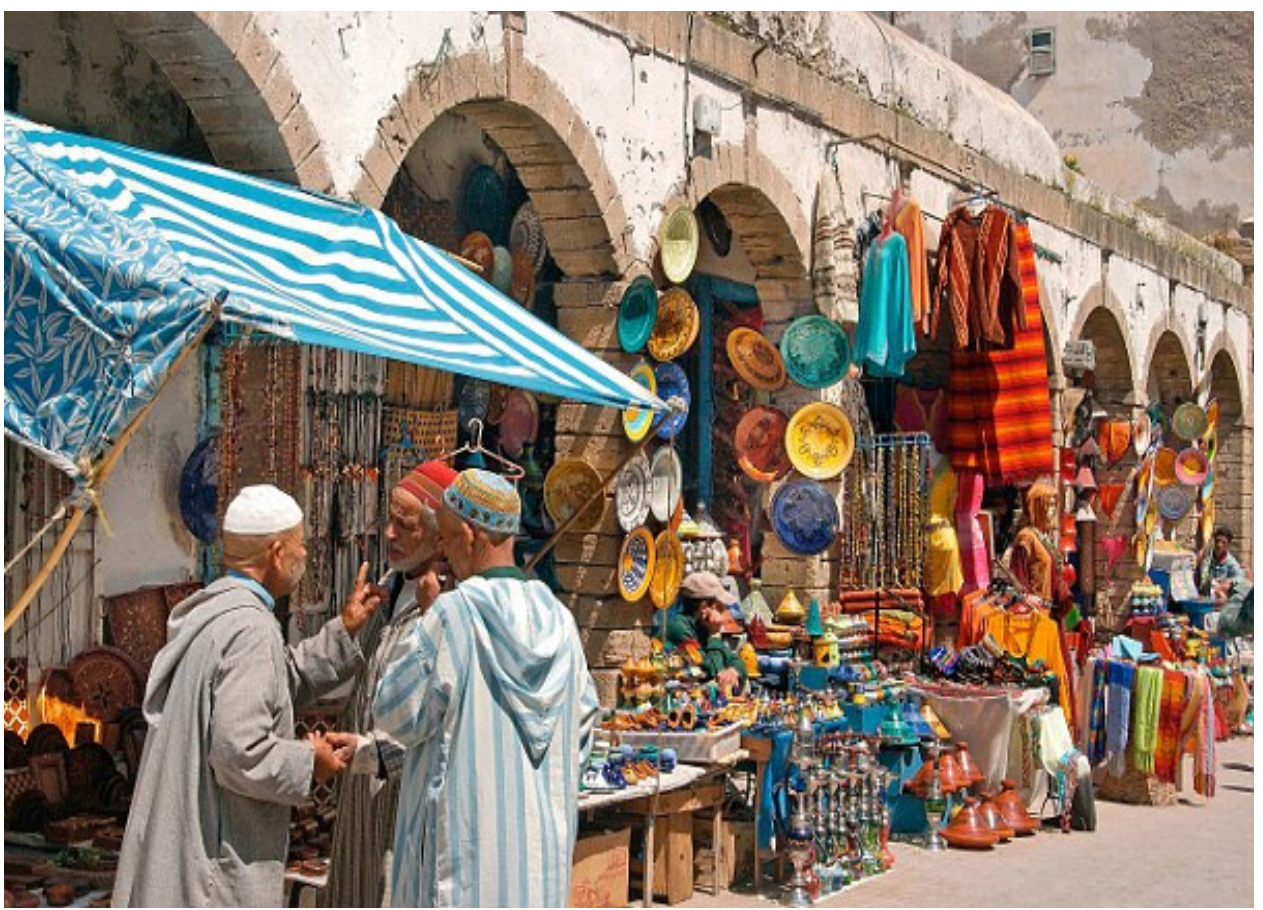

through the use of the image, sign, and symbol. In return, individuals are not provided with much else other than the slim chance of winning big and the shot of dopamine that comes with it, leaving us craving for more. Here, true architectural expression is absent, as in this landscape the graphic sign communicates with the individual rather than form, space, or sensorial effects (Venturi, Brown, \& Izenour, 1972, p. 9-10). As the architecture of the strip continues to dominate the capitalist suburban landscape, the sensorial engagement necessary for creating connection, community, and relationship between inhabitants and the places they occupy are denied to them. From Brown and Venture's analysis in 1972, Las Vegas has intensified in its own nonplace-ness. The evolution of the automobile, digital technology, and a further societal adoration for the aesthetic has resulted in a city and its spaces designed for their iconic, drive-by, and sculptural impact as opposed to any historical, cultural, or social significance. The Las Vegas of the contemporary era is a simulated landscape, one that offers little to no sensory grounding for the individual through meaningful 
architectural expression and one that prioritizes the iconization of building rather than the intimacy of architecture. As overstimulating places like Las Vegas become increasingly common in our digitized society as a result of contemporaneity, we digress further from more historical architectural precedents like that of Middle Eastern bazaars. Traditionally existing in non-western cultures, the bazaar contains almost no signs, as communication works through proximity. The constant play of narrow aisles, smells, and aromas provide haptic engagement to an individual in this somewhat chaotic yet familiar space. Oral persuasion entices human interaction, connection, and transaction, as the experience the bazaar's spatial conditions form carry a strong sense of bodily place within its labyrinth (Venturi, Brown, \& Izenour, 1977, p. 9). As such, the bazaar serves as a critical precedent in understanding the potential for architecture to not only shape our physical spaces, but also its ability to influence our social and communal behaviours for the better. In the junkspace and non-places of the contemporary landscape, our reliance on the eye has led architecture to become lazy in a way. As architectural potential further reduces itself to the digital and the appeasing of aesthetic, it risks taking with it the very character a space can project to the individualized experience. In doing so, it reduces experience to a sterilized landscape, flattening it to a level where the sign, symbol, text, and image guide us through the non-places of the city instead of the haptic bodily engagement of the senses. 


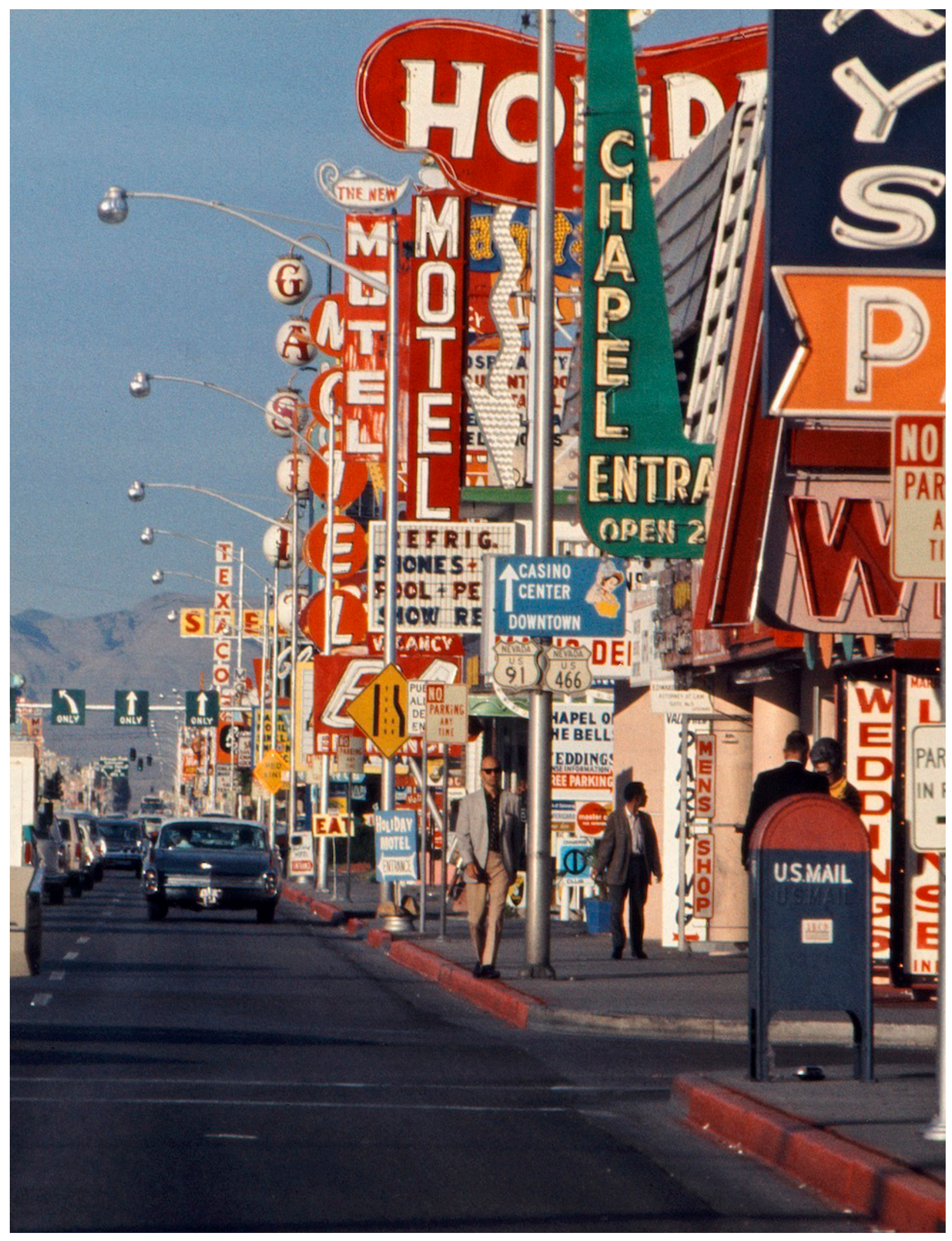


"My idea of vision is to see with more than just your eyes"

- Chris Downey 


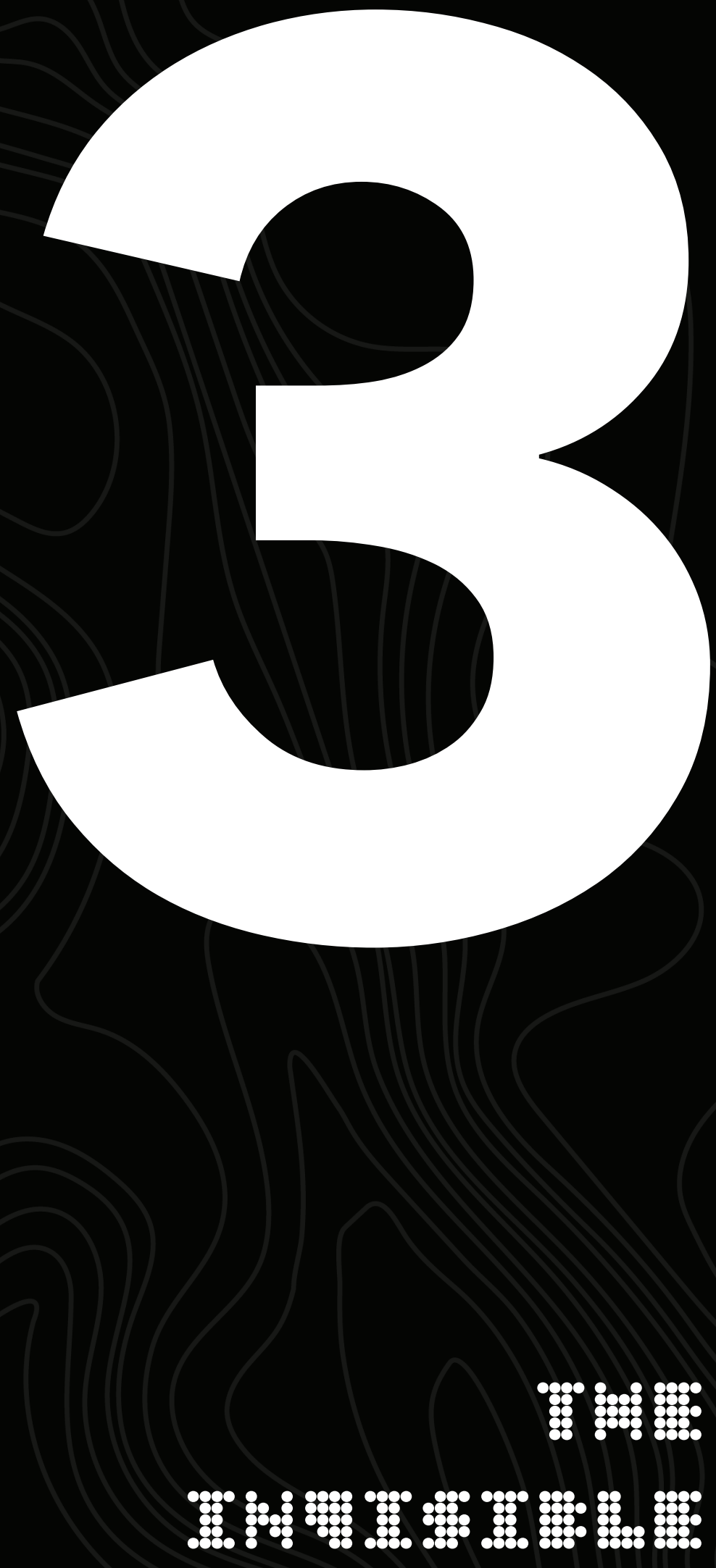





\subsection{INTRODUCTION}

In speculating on an invisible architecture, we are not inherently saying that architecture should not be seen to be understood. Instead, advocating for an invisible architecture addresses the prioritizing of the image in a contemporary framework, proposing instead that architecture reasserts the importance of a fully sensorial reaction to spaces. As our senses serve as the connection between spatial occupation and memory, they mediate the relationship between the landscape and body in space, provoking new conditions, sensations, and artefacts - thus creating a sense of place (Rossi, 1982, p. 130). In the same way that we can only understand the true power of music with silence, light in architecture can only be known through an understanding of the darkness it frames through a contrast of shade and shadow.

The physicality of architecture must act as a form of matter, one that contains gradients of energy in our lived experiences aroused through the senses. Since "we are not just a pair of eyes floating through space; we have bodies, senses, emotions, expectations, and memories," an invisible architecture is necessary as an antidote to ocularcentrism (Ursprung \& Goodwin, 2014, p. 47). As philosophers of phenomenology like Maurice Merleau-Ponty critiqued our fascination with the visible they saw the need for not a superficial surveying of distant objects, but rather "a fundamental reversible relationship between the seer and the seen, the visible and the invisible, and an intertwining of all sensory perceptions" (Belova, 2006, p. 94). Through 
the concept of phenomenology, the holistic sensorial perception of the world through bodily experience can be achieved where its meaning is derived from its context. An invisible architecture asserts the need for the practice to communicate itself through its sensorial experience and the bodily responses it provokes. As the senses in our digitized and urbanized lived experiences continue to privilege the visual, a phenomenological understanding of the body's sensory apparatuses and their interaction with a geography is necessary in creating meaningful architecture once again. 

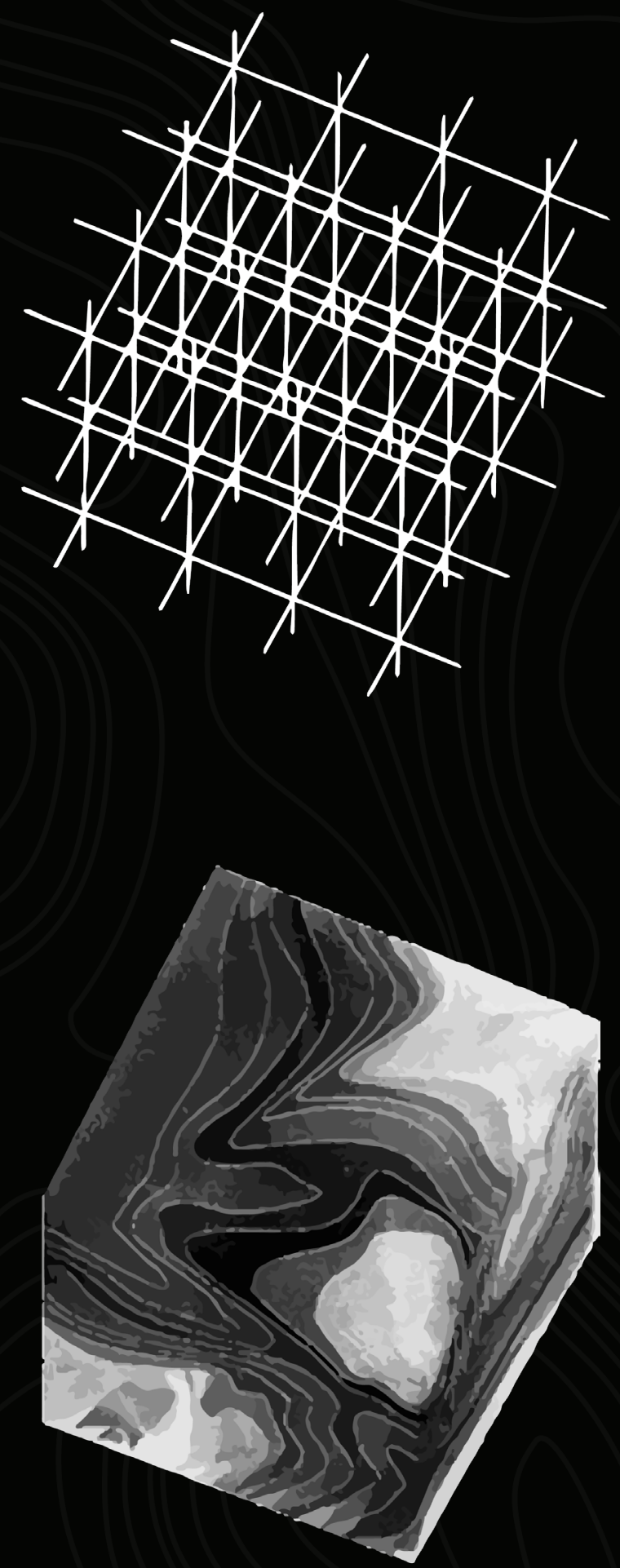

Figure No. 18

Mattervs. energy

The Invisible | 37 


\subsection{THE SENSES}

In further contextualizing the invisible within psychology, we must first investigate the body's sensorial envelope and its relation to the external environment. As the body responds to external stimuli, the senses function by transitioning information between the environment and the body. The senses play a pivotal role in the understanding of one's own place within space and as such, determine the emotional or reactionary response of the individual. The senses exist as a gradient of bodily awareness, ultimately resulting in the consciousness of the sentient being. As the body is subject to various intensities and types of stimulation, we are constantly knowingly or unknowingly evaluating our environments in an attempt to make sense of its geography and the body's place within it. In the Eyes of the Skin, Pallasmaa postulates that the inhumanity of most contemporary architecture is a direct consequence of the neglect for the body and senses in design, leading to a clear imbalance in our sensory system which creates this psychological sense of alienation and anxiety (Pallasmaa, 2012, p. 21). In this disregard for the entirety of the senses in our architectural experiences, the individual becomes disassociated with their environments as interior lived experience, further reducing architecture to a visual and often unmemorable object. As the dominance of the eye in the contemporary framework increases with its digital dissemination and the short attention span culture emerging from the proliferation of the image, it creates further detachment and isolation in our lived experiences (Pallasmaa, 2012, p. 21-22). Pallasmaa argues that the senses are one of the most fundamental ways we are able to assess risk in our environments and are arguably the most critical method to situate the human condition within it. It is only after understanding and re-incorporating the other senses into architecture - the invisible ones - that we can truly begin to operate meaningfully to address the alienating nature of these non-places we occupy. 


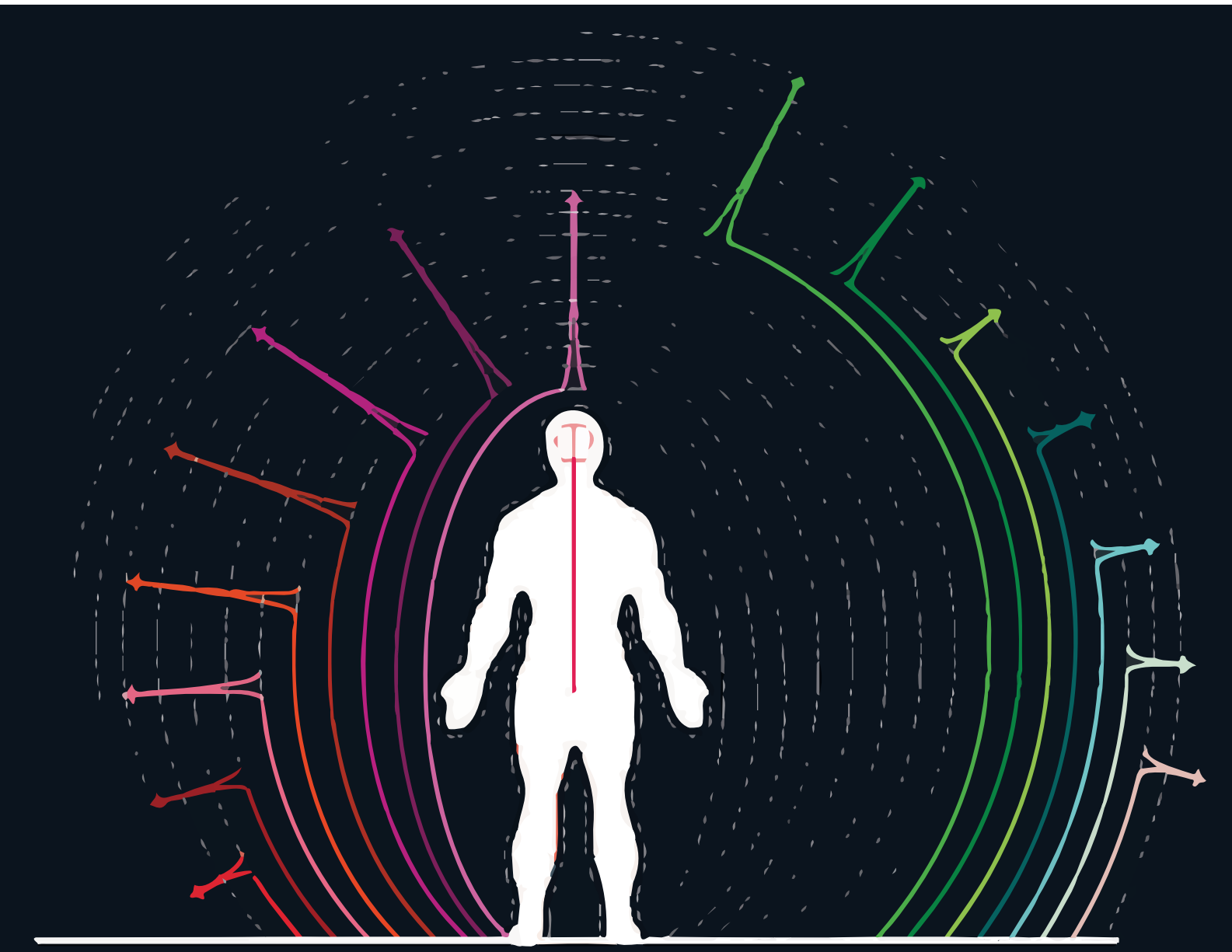

\section{Human Senses}

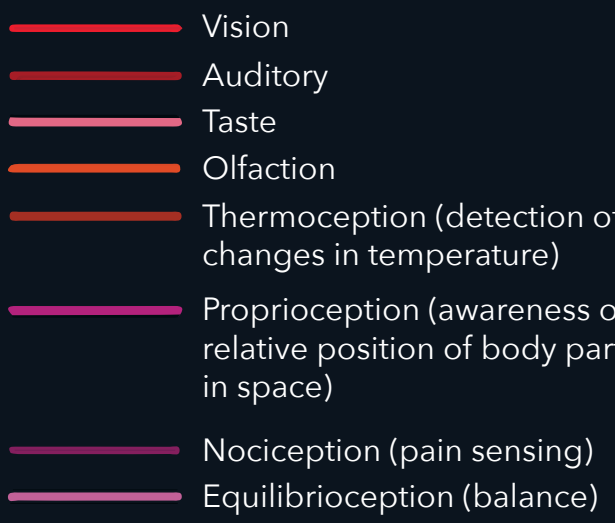

\section{Interoception}

Senses found within the body that involve sensory receptors in internal organs.

\section{Artificial Senses}

(analogous to human senses)

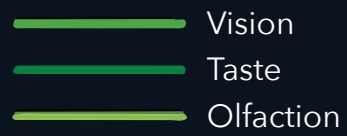

\section{Artificial Senses}

(seen in other species)

$$
\text { Echolocation (sonar) }
$$

\section{Electroreception}

(detection of electrical fields)

Magnetoception (detection of Earth's magnetic field)

Vibrational

\section{Central Nervous System}

\section{Pharmaceutical}


Today, our engagement with our senses in architecture places an emphasis on the ones furthest away from the body. The sense of sight projects the body to great distances. Vision has become the primary tool for navigating the human condition, dominant in our built landscapes and in the geography of the city. Today, our obsession with pictures and the image both in architecture and society as a whole intensifies. As we receive sensory information through our eyes, our gaze flattens the world onto a plane that is projected on the surface of the retina. As a result, instead of experiencing our being in the world, we tend to behold it from the outside as spectators (Pallasmaa, 2012, p. 33). In our increasingly digitized and ocularcentric society, vision alone fails to include the body in an authentic dialogue between space and self.

Contrary to the distancing effects of sight, touch is one of the closest senses to the body, both physically and psychologically. According to Pallasmaa, the skin is the oldest sense, one that has the innate ability to physically connect the body to its surroundings

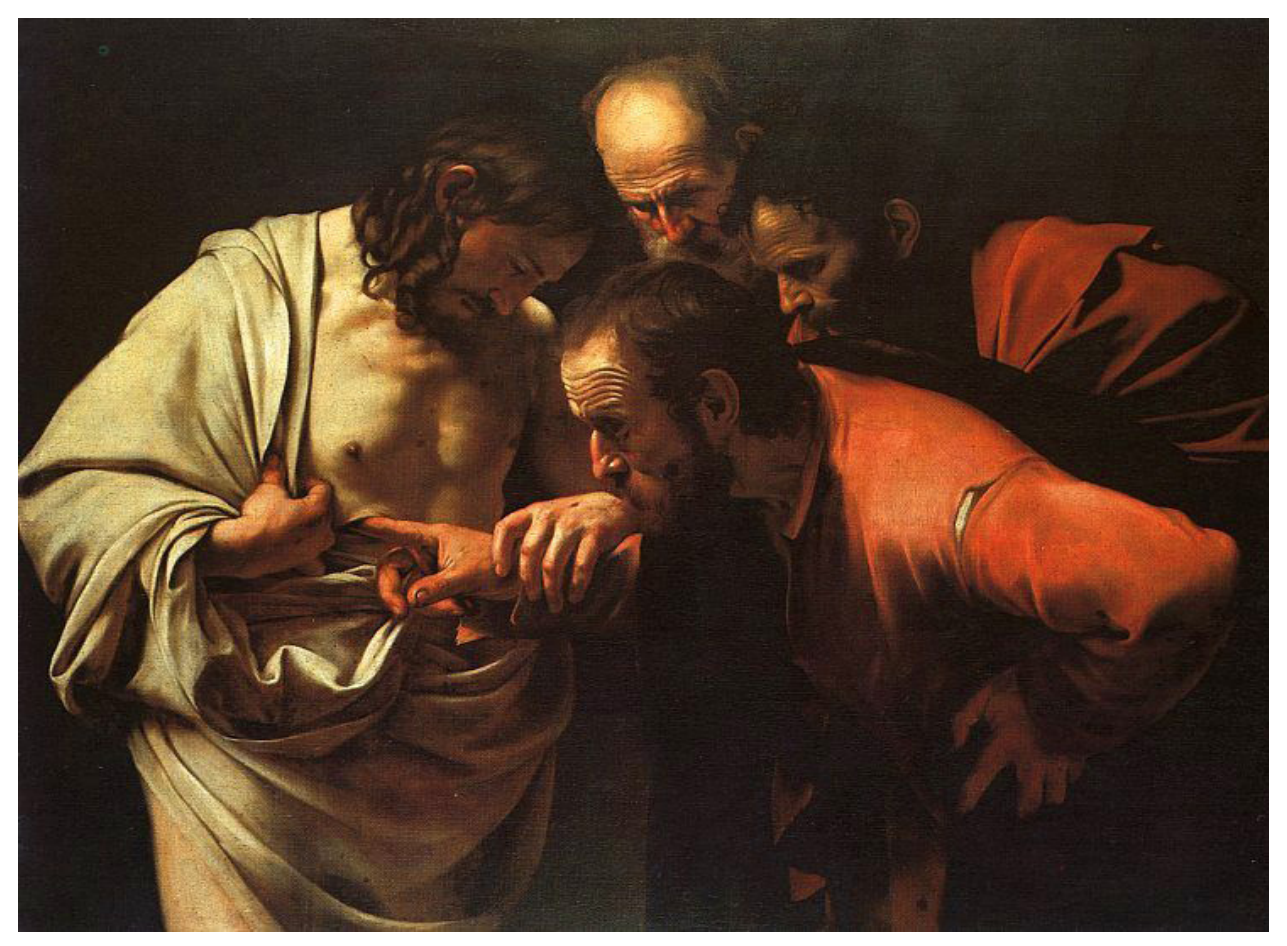


(Pallasmaa, 2012, p. 12). Through touch, we evoke intimacy and attachment, as the closeness of the sense cannot be ignored like closing one's eyes. We validate what we believe to be true with haptic confirmation, as we refer to things that are real and definitive as tangible. In the field of psychology, touch therapy involves grounding the senses through contrasting touch sensations, serving as a means in addressing a variety of different mental states within patients (Vaucelle, Bonanni, \& Ishii, 2009, p. 467-468). The body can detect even minute differences between a variety of surfaces, textures, and finishes, all attributing to our orientation and understanding of a specific sequence of phenomena. The haptics of the body make the human experience in space real - as opposed to the imagined or simulated geography much of the contemporary environment creates in spaces.

Touch, however, can be broken down into a number of more specifically targeted sensorial perceptions within the mind. Temperature, the degree or intensity of heat present in a substance or object, is detectable through the tangible interface of the skin and

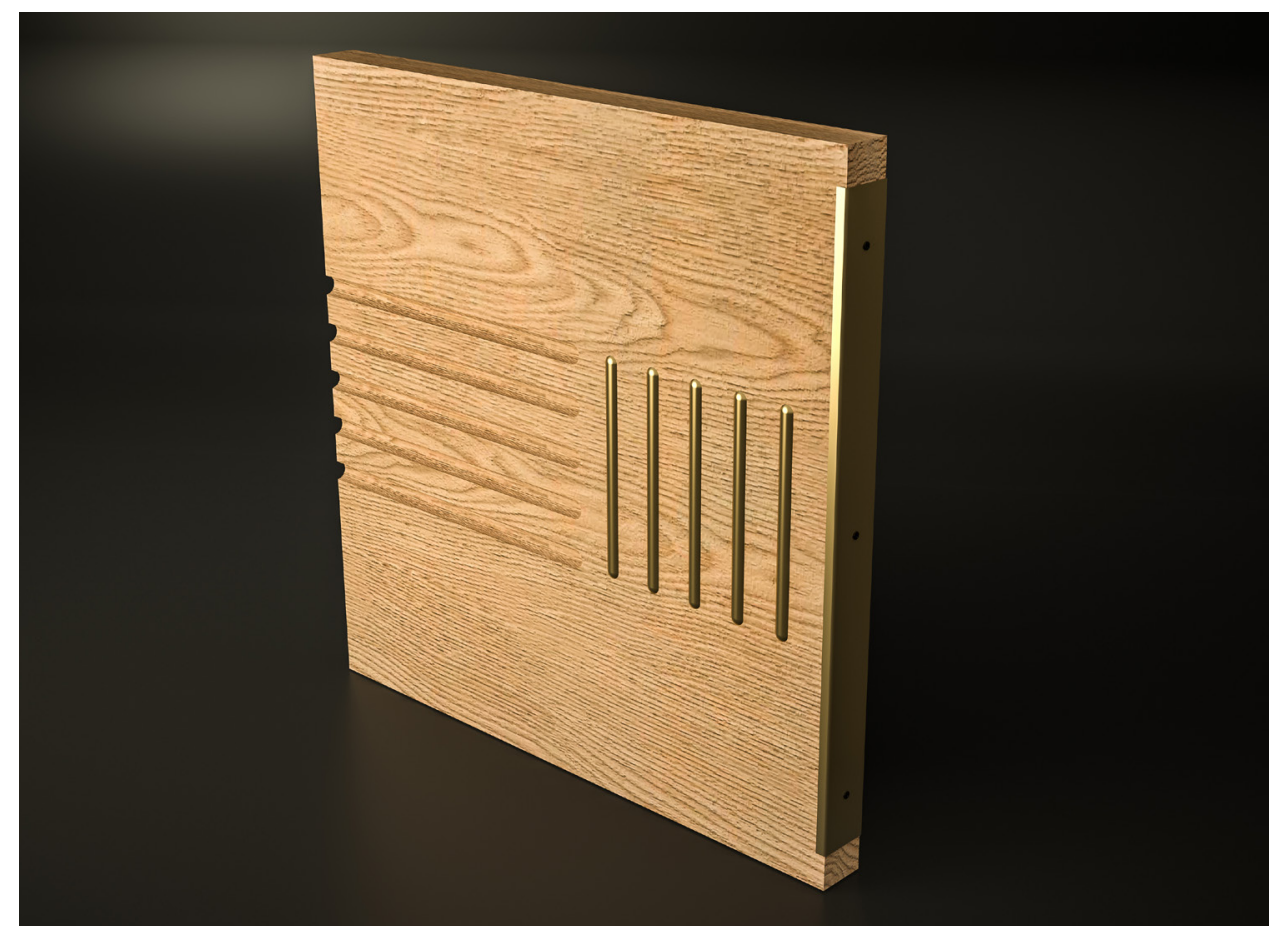


a surface. Thermoception, in a similar way to a building envelope, uses the skin as a boundary between the body and an atmosphere, separating them and clearly defining its outer most layer of protection. Perceiving temperature can go beyond the measured temperature of various objects. Thermal conductivity between objects and the skin can also be perceived as drastically different in temperature, when there are no measurable differences. This phenomenological aspect of a material and its thermoception through the sensorial envelope results in both a physical and mental understanding of a material and the way it feels. Thermoception's place within the sensorial envelope further conveys haptic information to the mind, ultimately continuing the understanding of the body in space.

Sound plays a significant role in the understanding of a space's volume in relation to the body. Both visual perspectives and the incomprehensibility of the whole through touch can exaggerate or diminish the actual qualities of a space. The auditory sense not only allows for an understanding of volume, but also of its hardness,

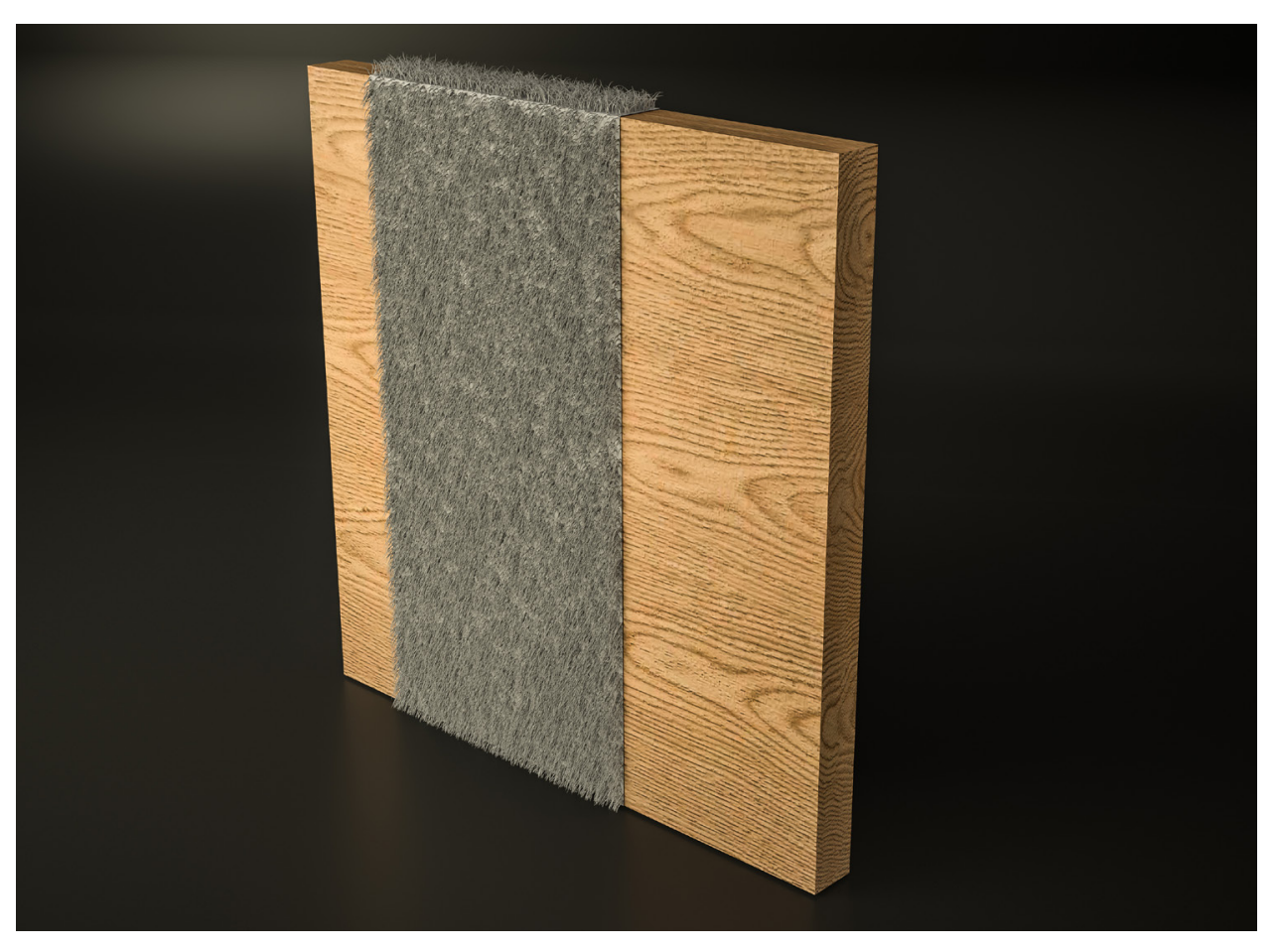


roughness, softness, and other material qualities. Sound can be powerful in understanding space, even when the presence of the other senses are reduced. In Pallasmaa's writing on the sensory stimulation of sound, it is evident that the ear has the extraordinary capacity to carve a volume of space into the void of darkness within the interior of the mind (Pallasmaa, 2012, p. 54). Today, however, our hearing has become suppressed as an indirect result of the presence of mechanical hums, mundane materials, and an overall misunderstanding of the auditorial potentials of architecture.

Upon immediate consideration, the olfactory appears to be the sense least considered in contemporary architectural expression or experience. Smell, however, is often considered one of the senses most prominently linked to our individual memories and experiences. Environmental stimulation in the form of aromas, atmospheres, and scents agglomerate within the nose to form immediate and concrete connections between a person and their memory and experience in a particular place. It is for this reason that more natural settings

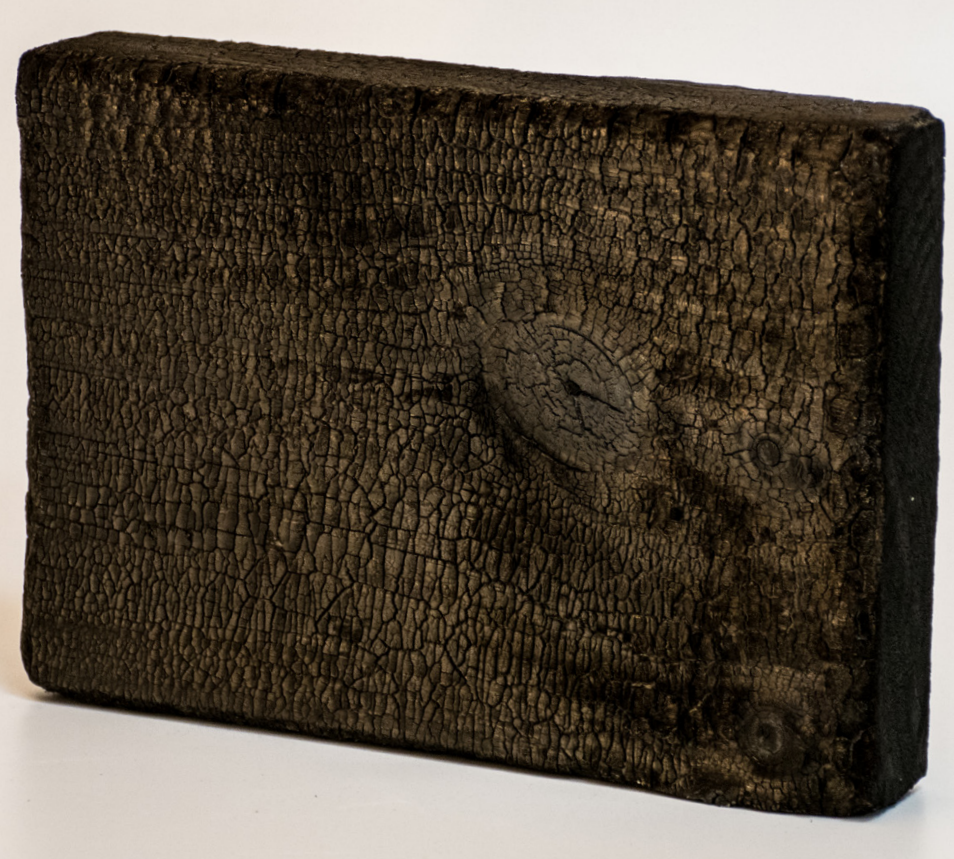


like forests hold strong calming sensations through their ability to integrate the senses in their experiences of place. The sense of smell in contemporary architectural non-places has been completely sublimated through the overabundance of chemical and artificially derived materials for their cost efficiencies or visual impact. Many of these inorganic materials bring with them harmful volatile organic compounds which, in contemporaneity, we have grown accustomed to masking with cleaning agents or other artificially derived 'natural' scents. The architectural potential of smell in our digitized society remains one of the most powerful and under explored characteristics in the built environment of the non-place.

The human senses are critical to engage with in order to derive meaning from architectural expression. The senses produce knowledge and an understanding of place, ultimately forming the most critical component of what it means to be human. The majority of contemporary spaces today have ignored the other senses, instead focusing on the easiness and pleasure provided through the eyes. Our vision has become overwhelmed by the over proliferation of the image in architecture while the other senses have been forgotten. As a result, architecture today is understood as merely a visual tool for aesthetic expression. 


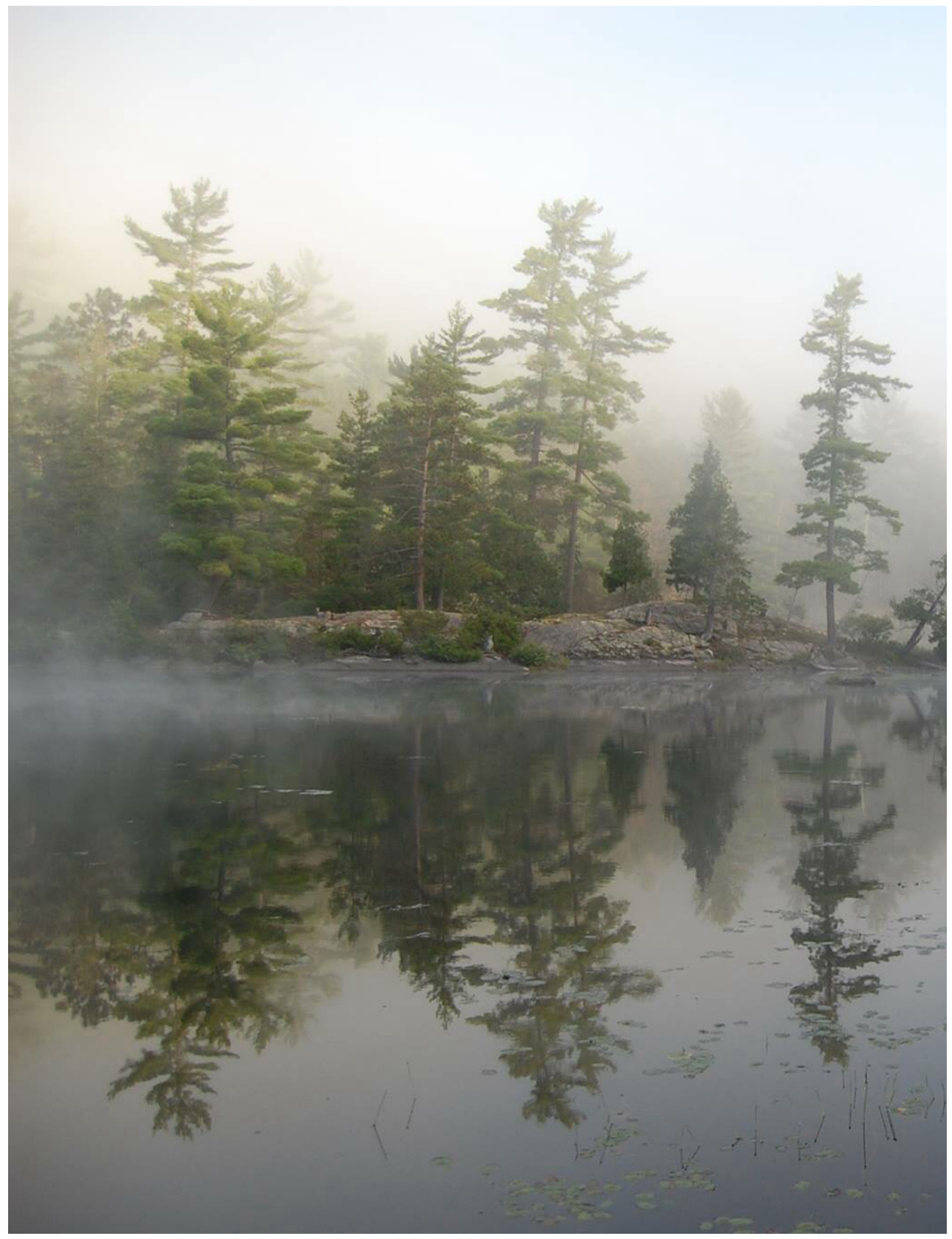




\subsection{PROXEMICS AND THE HUMAN SCALE}

In cultivating an understanding of the intimacy of the senses within architectural space, one must investigate human scale and the proximities of the body in space. The body's understanding of an occupied space is a direct result of our own embodiment at the human scale. This becomes problematic in the contemporary spaces we transit today, as their size and lack of understanding of the human scale creates spaces where the body cannot relate to, comprehend, or understand. This territory is where, in the 1960s, American anthropologist Edward T. Hall introduced the idea of proxemics and human interaction. Proxemics can be defined as the "interrelated observations and theories of [the body's] use of space" (Marquardt \& Greenberg, 2015, p. 33). Proxemics involves the measurable distances between people and objects in space. Hall's findings on personal space went beyond mere protective measures however, as he conceptualized personal space as a form of non-verbal communication, a type silent language developed between people and objects (Marquardt \& Greenberg, 2015, p. 33). From Hall's analysis of the interactions of body and objects, we can begin to formulate an understanding of social and physical distances between the two. Hall categorizes these varying proximities into four discrete distance zones, directly linking

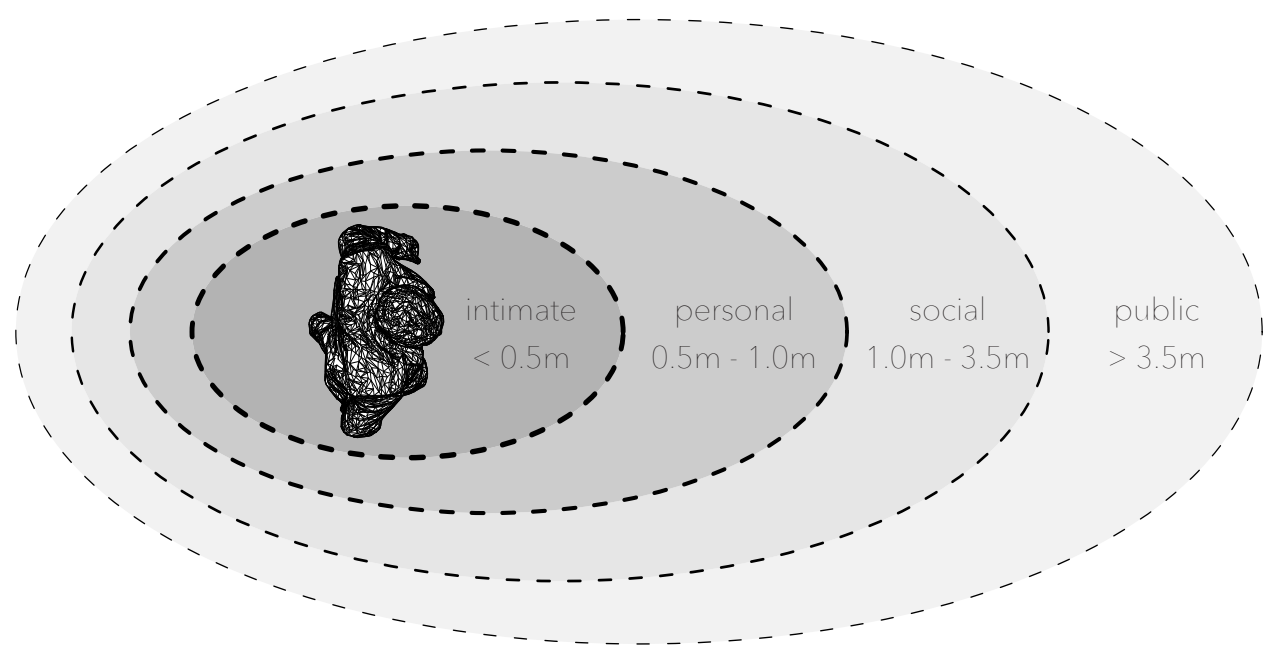

Figure No. 25 
them to people's perceived sensory information. Firstly and located most closely to the body is the intimate. Distanced approximately from the boundary of the skin to fifty centimetres, this zone is for close relationships. This distance addresses the most sensory inputs, as people can see the other close person, hear a whisper, and feel their heat (Marquardt \& Greenberg, 2015, p. 33-34). The next zone is the personal, spanning between half to just over a metre. This zone is for interacting with friends and family. At this distance, people and objects are within an arm's length and it is still possible to touch and speak at a lower volume (Marquardt \& Greenberg, 2015, p. 33-34). Continuing our journey outward from the boundary of the skin, the next zone is the social. Occupying the distance between one to three and a half metres,

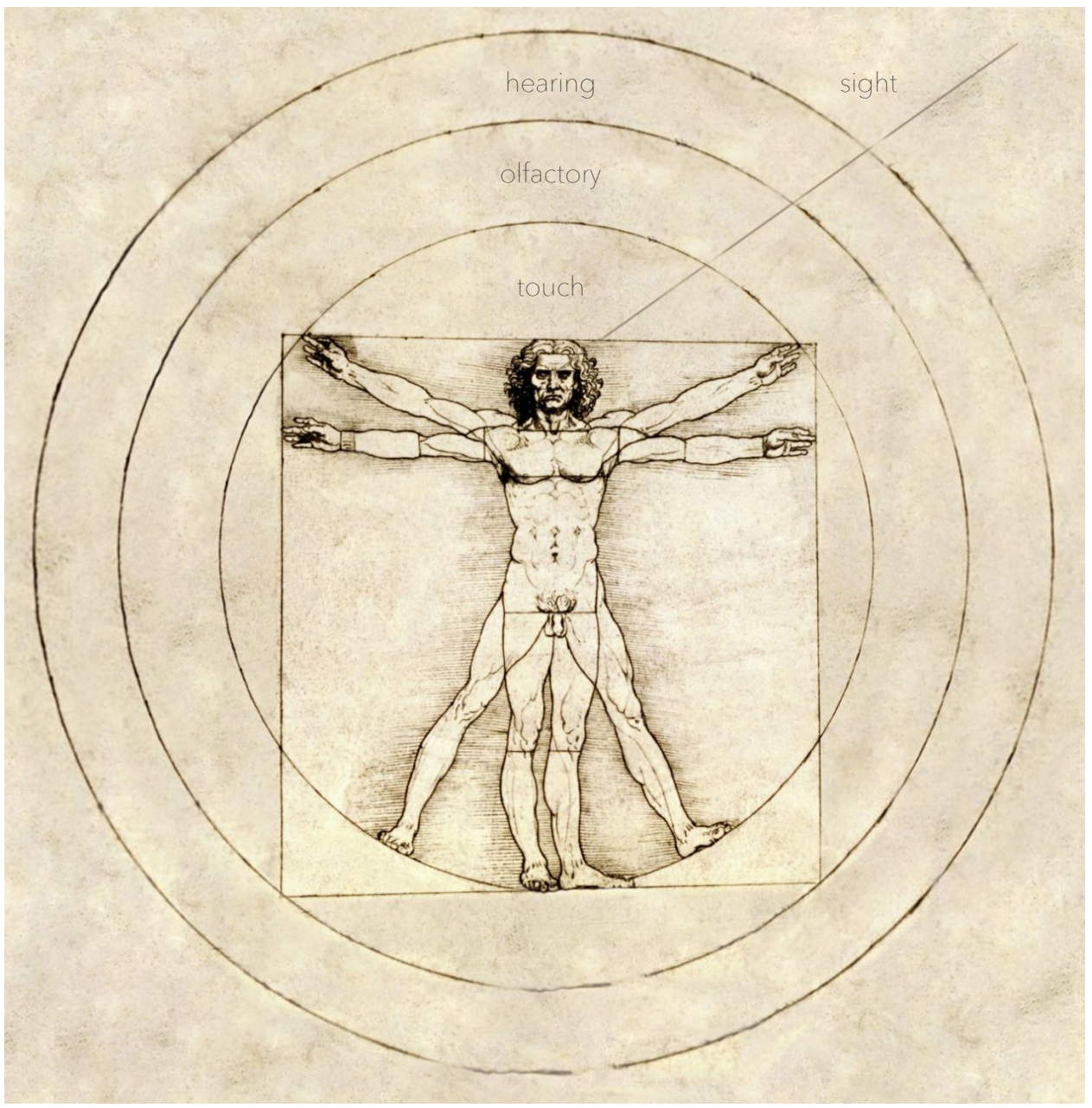


this zone is where interaction in more formal settings occurs. At this distance, it is harder to reach out to touch and voices become louder as a result of increased distance (Marquardt \& Greenberg, 2015, p. 33-34). Lastly, Hall introduced the public zone. This zone is the furthest from the body, at least three and a half metres from the boundary of the skin. This zone is the least personal, and where senses like sight take over as the primary sensory input. Here, it is nearly impossible to touch and one must speak loudly to address others (Marquardt \& Greenberg, 2015, p. 33-34). An architecture that attempts to incorporate a multiplicity of senses in an attempt to promote intimacy and meaning in the landscape of the mundane must first understand the fundamentals of proxemics and the proximity-behaviour relationships between objects and people. Hall believed that the theory of proxemics not only contributes to the interaction between people, but also in "the organization of space in... houses and buildings" (Marquardt \& Greenberg, 2015, p. 33). Instead of the privileging the senses farthest way from the body like sight, we should be focusing on the intimacy of the other senses and their closeness to the consciousness of the body. In order to create an emotional relationship in architecture at the human scale, we must design through the senses so as to operate more meaningfully within the non-place-ness of the contemporary city. Bringing architecture to the level of the material, transition, and detail brings the traditional outsider of the non-place to a more intimate proxemic relationship with a space. In doing so, the entirety of the senses become closer to the things we produce, benefiting both the understanding of an architecture as well as psychologically grounding occupants in a place. 
Figure No. 27

Proxemics: rail + guard study [1:1]

Figure No. 28

Proxemics: ending a material [1:1]
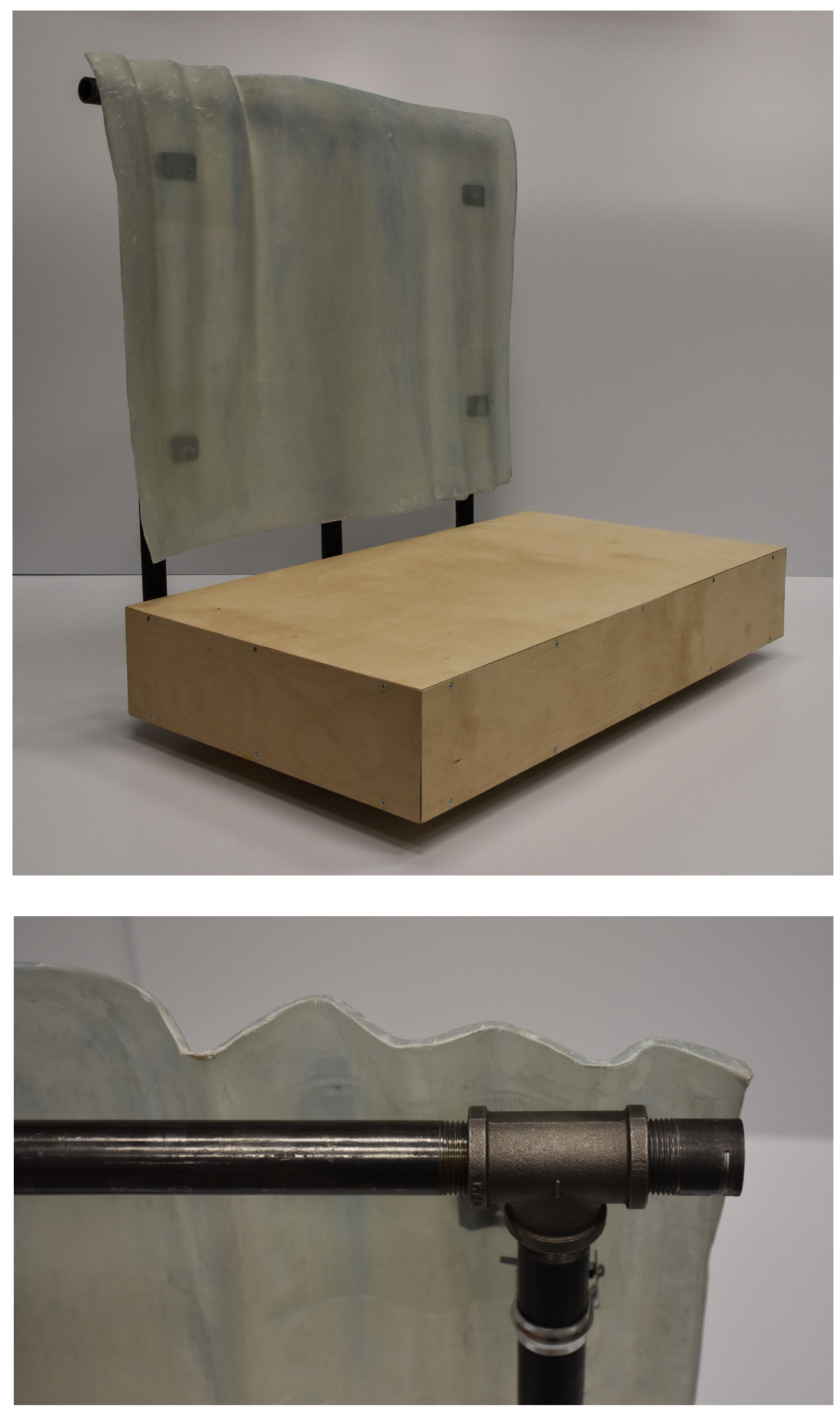


\subsection{CASE STUDY: CARLO SCARPA}

Through investigating the architectural detail and the human scale, it is evident that architect Carlo Scarpa was able to operate effectively within this territory as an instrument for producing meaning in his work. Scarpa's work involves the meeting of materials and takes a primary focus on the architectural detail and its relation to the overall tectonic experience of a space. Scarpa often breaks down even the simplest meetings of material or components, expressing their construction and allowing it to become the focal point of a users experience. Relying on the serendipitous encounters between the individual and the object, his work hardly ever uses off-the-shelf hinges or hardware. Rather, he directs the operation and function of a detail and turns it into an event that adds to the overall engagement between person and architecture. Though Scarpa's work creates an undeniable aesthetic through this detailing - and with it a strong image presence in his spaces - the ability for a user to experience the building in parts rather than the whole makes them incredibly understandable and relatable. The palpability of a users experience in his spaces, even to those with no formal understanding of architecture beyond their daily occupation of buildings, make his work so powerful in integrating the senses in his architecture. Similar to the way a geographer might map a landscape and break its geography down into understandable parts and components, Scarpa uses the concept of stratification both spatially and with materials in an attempt to provide a clear language

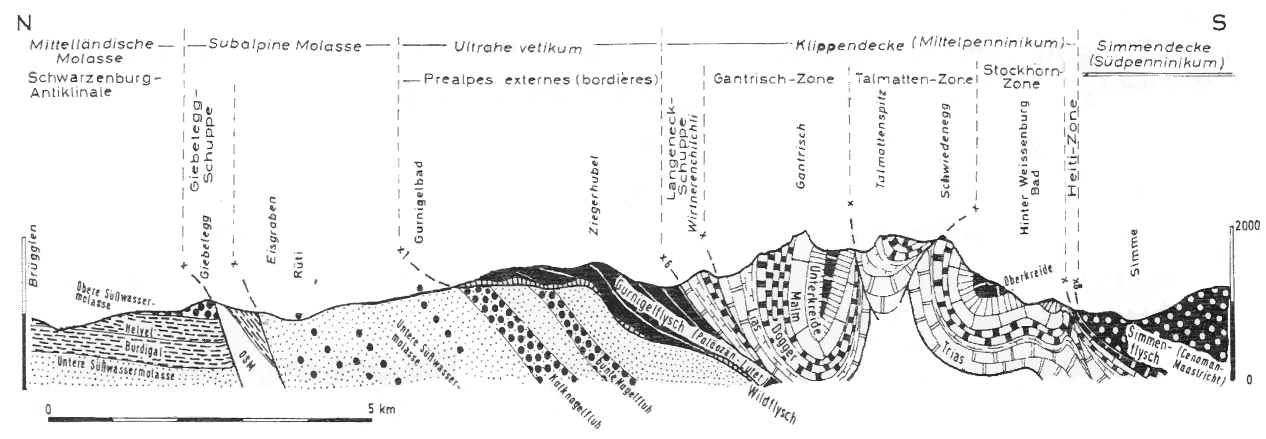


to its making (Schultz, 2007, p. 9). In doing so, Scarpa's details become the result of the use and memory of the organs of touch and sight, referencing their making to stimulate the using of his architecture. As a result, the architecture of Scarpa is never fully rendered, as it only exists in fragments and parts through the users' interaction with them throughout time (Nesbitt \& Frascari, 1996, p. 508). In Scarpa's architecture "each detail tells us the story of its making, of its placing, and of its dimensioning" as the details play functional roles in narrating an architectural experience to the user (Nesbitt \& Frascari, 1996, p. 506). His use of pattern, patina, repetition, and the articulation of joints all cumulate into sensory moments that guide users on their journey through space and their interaction with it. It is this invisible element to Scarpa's work, one that is often unnoticed and secondary to his aesthetics, that provides the true story-telling power of Scarpa and his architecture. His constructions focus on experiences closer to the body

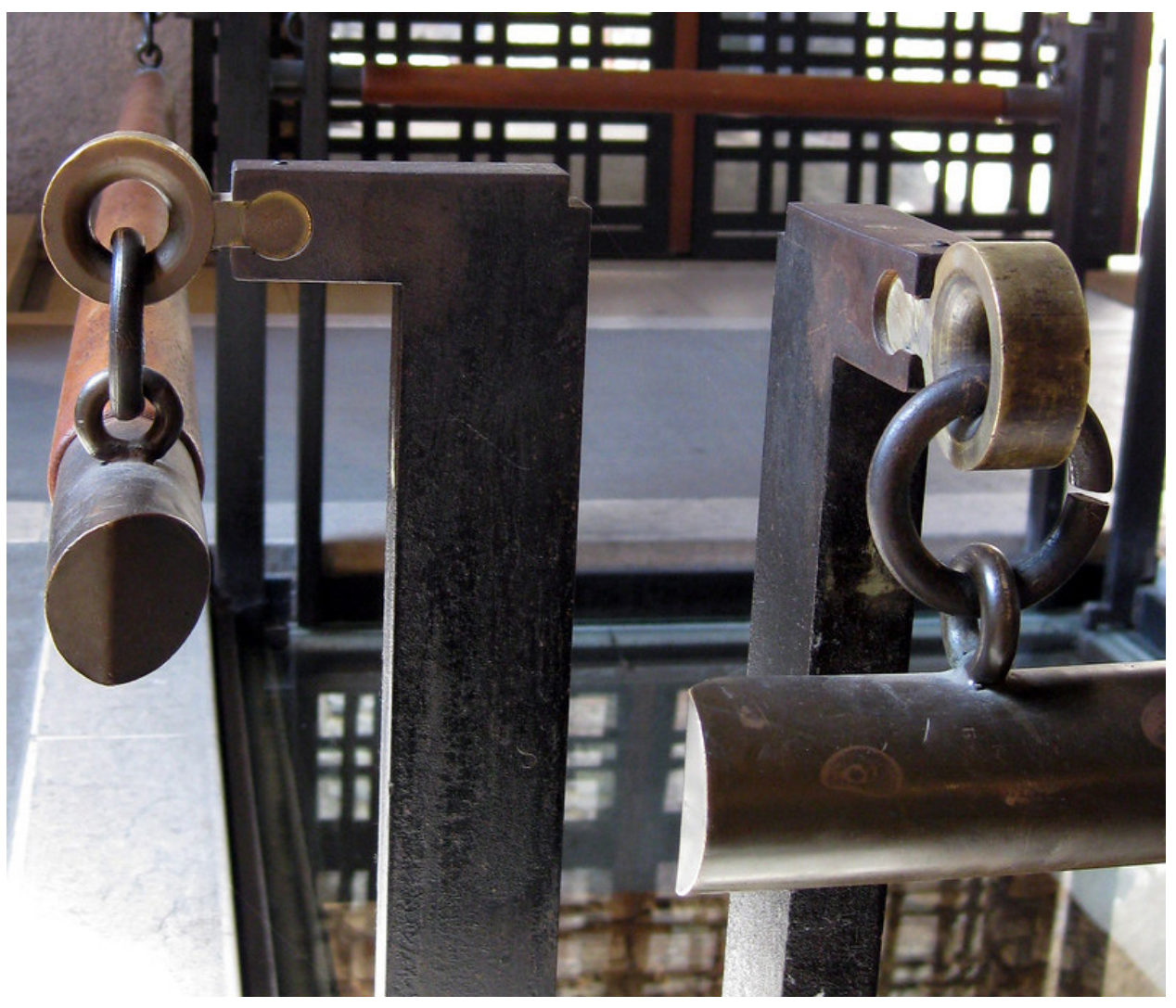


through the intimacy of touch rather than the projection of vision away from the body onto a surface. It is only through Scarpa's understanding of the sensory apparatuses of the body and the intimate possibilities of the tectonic that enables the experiences he creates to transcend the sterilized landscape, creating powerful and memorable moments within the perception of architecture.

Using the concepts and techniques of Scarpa in an attempt to further the discourse of this thesis through design research, a door handle was chosen to engage with the critical nature of the proxemic relationship between the architectural detail and the body. Just as Scarpa's work relies of the stratification of material and form to provide individuals with an understanding of the individual parts of his architecture, the door handle exploration seen in Figure 31 and Figure 32 explores the architectural detail and material. With much of contemporary architectural detailing focused on cold and sterilizing materials to deter interaction and touch, the wood materiality of this handle was critical in offering a form of comfort to the user interacting with it. Today, with contemporary digital technology, automated doors provide little to no meaningful threshold upon entering a space, quite literally stopping the user from actively engaging with architecture as sensors and motors detect and inhibit direct contact between the architectural object and the human. This has the effect of dehumanizing the architectural space, further alienating the individual from their environment. As Pallasmaa referred to the door handle as the handshake of the building, the 1:1 scale model of the handle explores the interaction between body and architecture through the kinetic movement and haptic feedback of operating the handle itself. The handle, proportioned and stratified to the dimensions of the human hand, operates on a pivot such that when it is pulled the mechanism transforms to the direction implemented by the user. The door handle study hinge operates a haptic knocking sound which reverberates 
though the hand. This auditory and tactile feedback is something present in the architecture and detailing of Scarpa, and is necessary in bringing architectural expression beyond the visual and into the invisible.

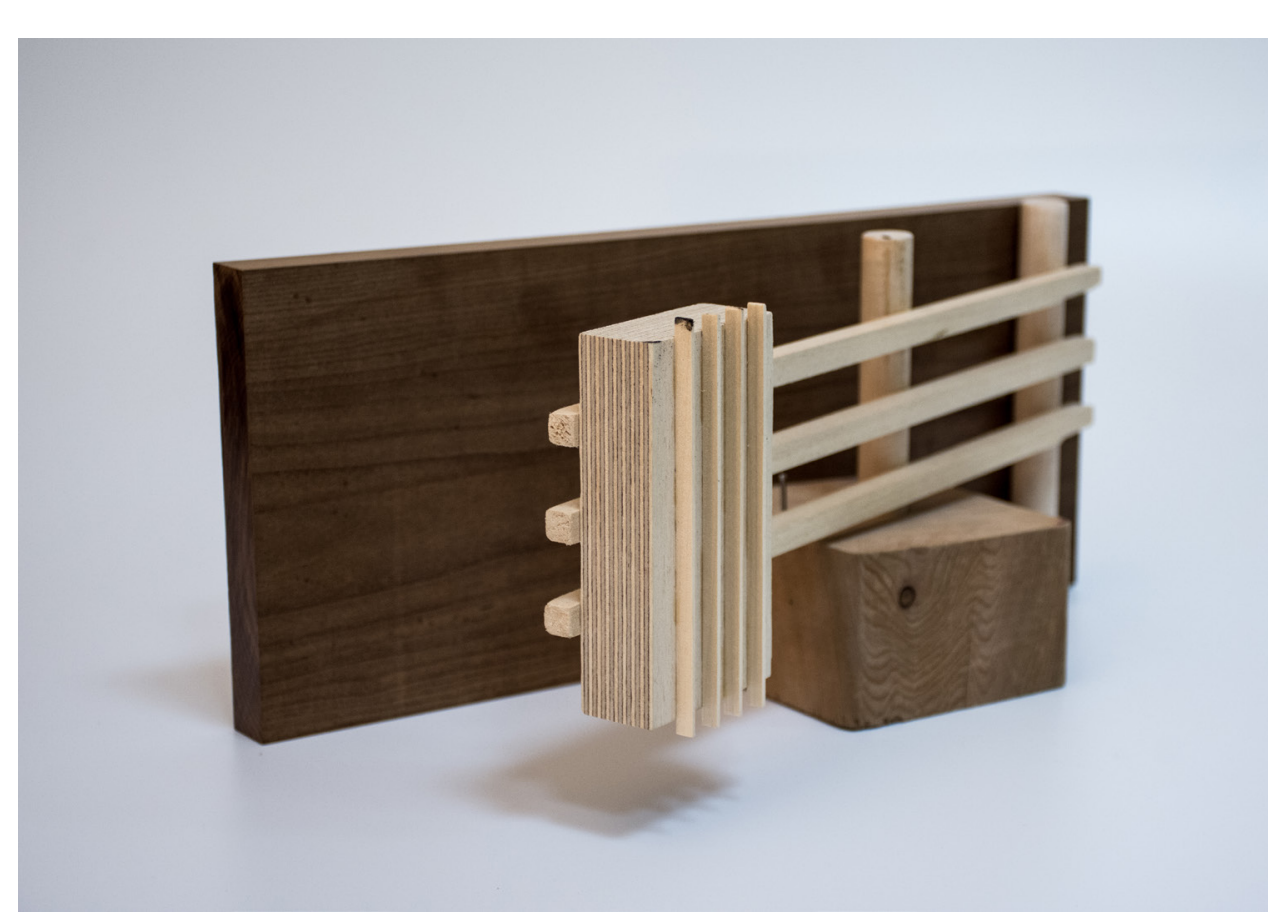

Figure No. 32

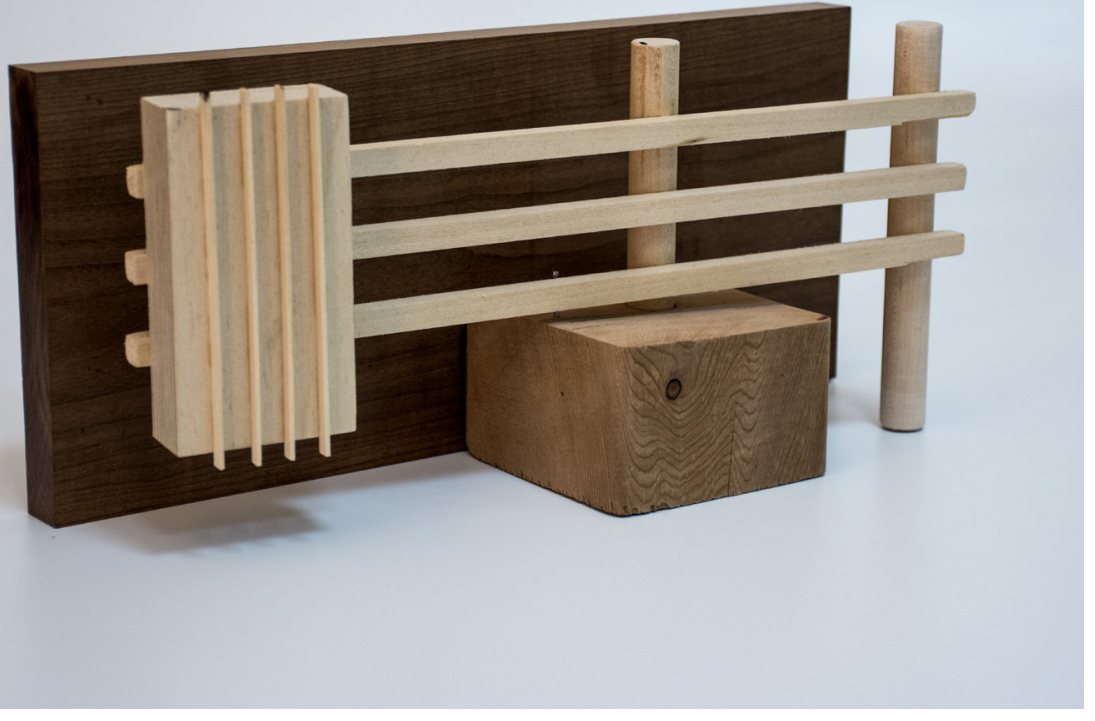




\subsection{ENVIRONMENTAL PSYCHOLOGY}

Just as the senses have many qualitative characteristics associated with them, they have also been observed to be subject to various quantitative intensities as well. As the senses directly affect the mind's perception of space, it is important to fully understand the psychological phenomenon traversing the environment, the body, and its psychology. Environmental psychology is concerned with the interaction between individuals and their surroundings, existing both physically in the way we use and move through space, but also through the senses and their interplay within the mind. As individuals, we are a product of our environments and of our unique experiences. Environmental psychology becomes critical to the understanding of the senses and their phenomenological effects of the person in space. Just as in the emergence of the metropolis in the late nineteenth century, sociologist Georg Simmel attributed behavioural pathologies in urban space to a type of sensorial overload, one that intensified the deterioration of social life in large urban areas (Bell, Greene, Fisher, \& Baum, 2001, p. 107). This phenomenon is still heavily present in the contemporary city today, as when we further analyze and critique the anxious geographies of built space, it becomes clear that the overstimulation of the environment causes a disconnect between body and environment through the limits of our own psychology. As late modern and contemporary architecture became hyper-expressive and large in scale, it further divorced itself from human-centric design, promoting a more visual-centric and anxiety inducing city. The environment-behaviour relationship between people and space is affected by the fact that individuals have a limited capacity to process incoming stimuli and can only invest a limited effort in attending to inputs at any one time. This overstimulation of the environment becomes problematic an individuals capacity for attention reaches its maximum, resulting in a reaction to overload and type of "tunnel vision" 


\section{ENVIRONMENT}

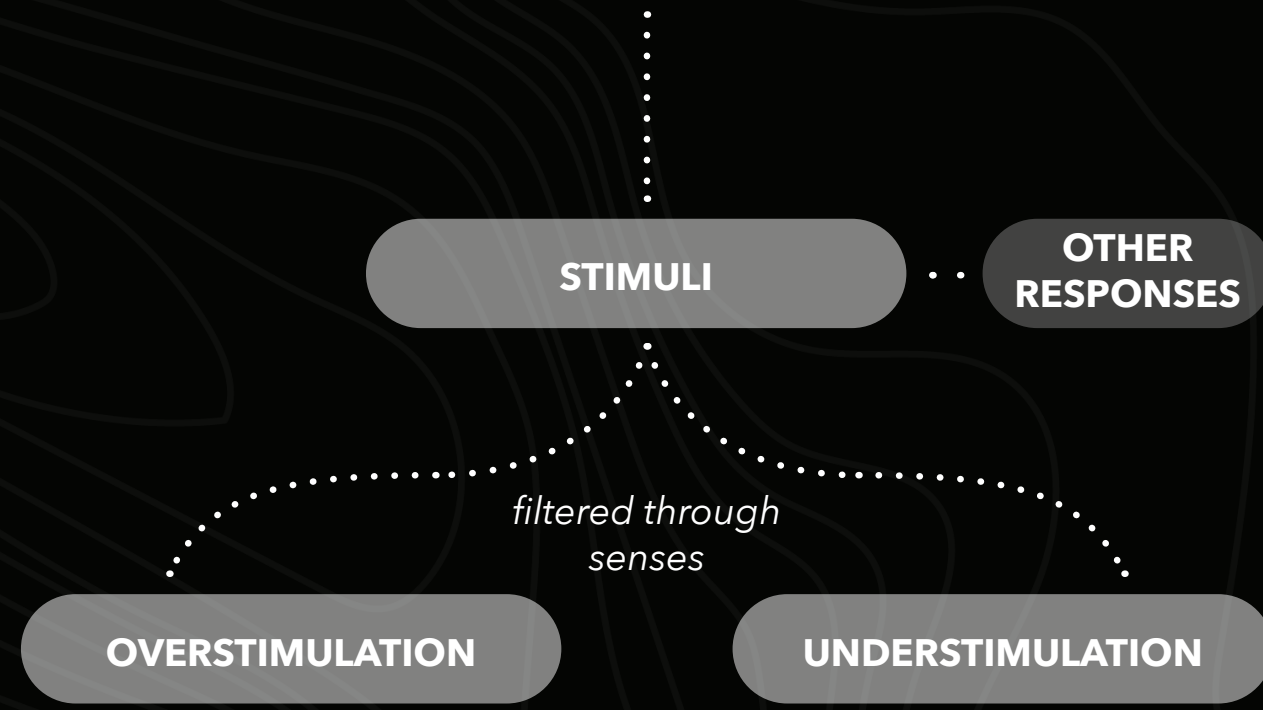

- ENVIRONMENTAL OVERLOAD

- TUNNEL VISIONING

- SENSORY DEPRIVATION

- ALIENATION

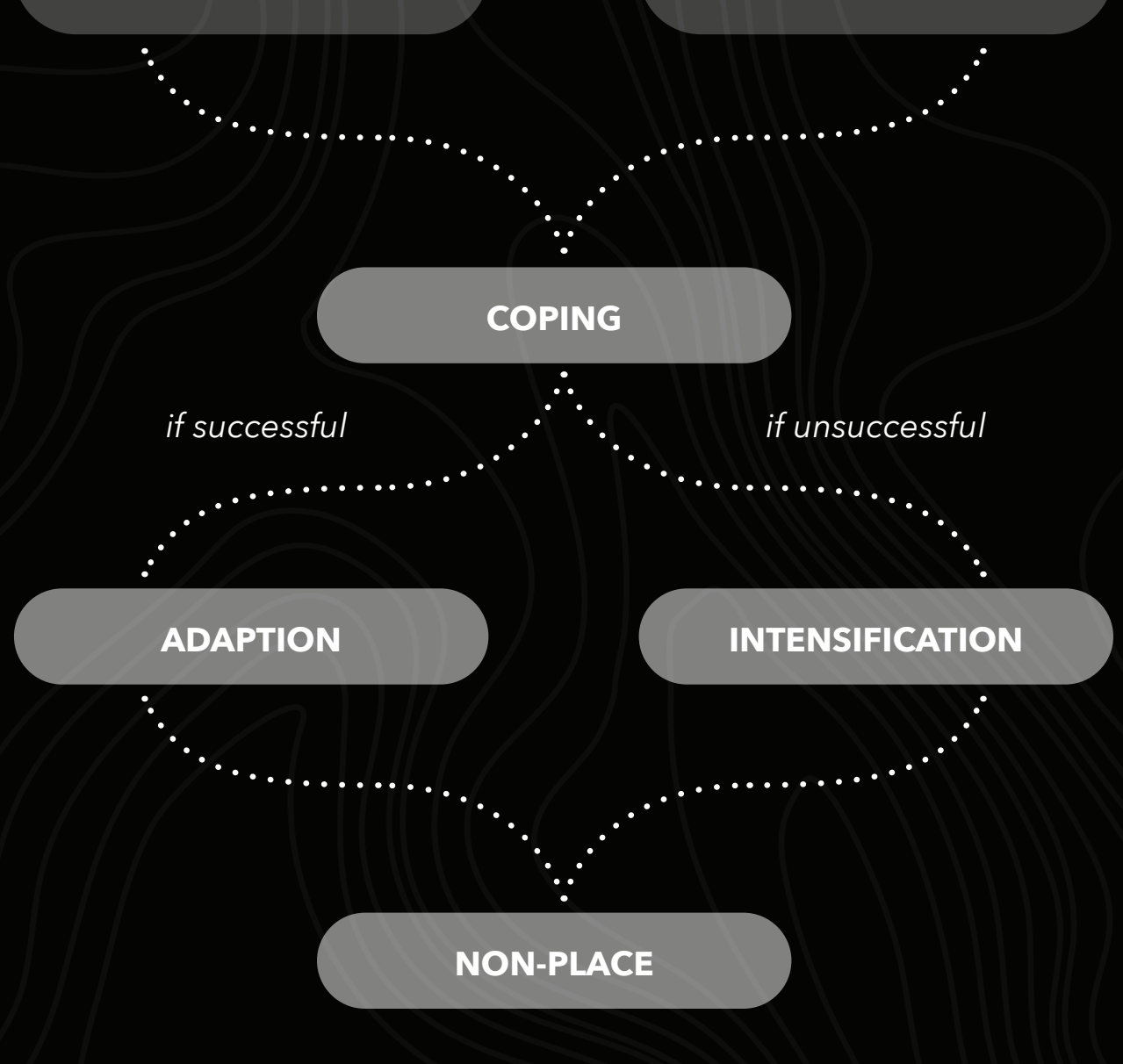


and alienation of the self in the occupied space (Bell, Greene, Fisher, \& Baum, 2001, p. 105-106). As the stimulating environment becomes increasingly more chaotic, the overstimulation of the contemporary landscape carries with it both invisible psychological and architectural issues.

The overstimulation of the contemporary landscape creates problematic relationships between people and architectural experience. Though this phenomena may be easily understood, it is not the only recognizable form of stimulation that can be troublesome. Environmental psychologists have also suggested that, like the overstimulation theory, the understimulation of an environment can cause behavioural consequences from a lack of mental engagement in space (Bell, Greene, Fisher, \& Baum, 2001, p. 108). Similar to the overstimulation of the contemporary landscape we have become familiar with, sensory deprivation studies suggest that "depriving individuals of all sensory stimulation can lead to severe anxiety and other psychological anomalies" (Bell, Greene, Fisher, \& Baum, 2001, p. 108). It is here where psychological studies also seem to indicate that, though extreme stimulation can be troublesome, the environment should "sometimes be made more complex and stimulating in order

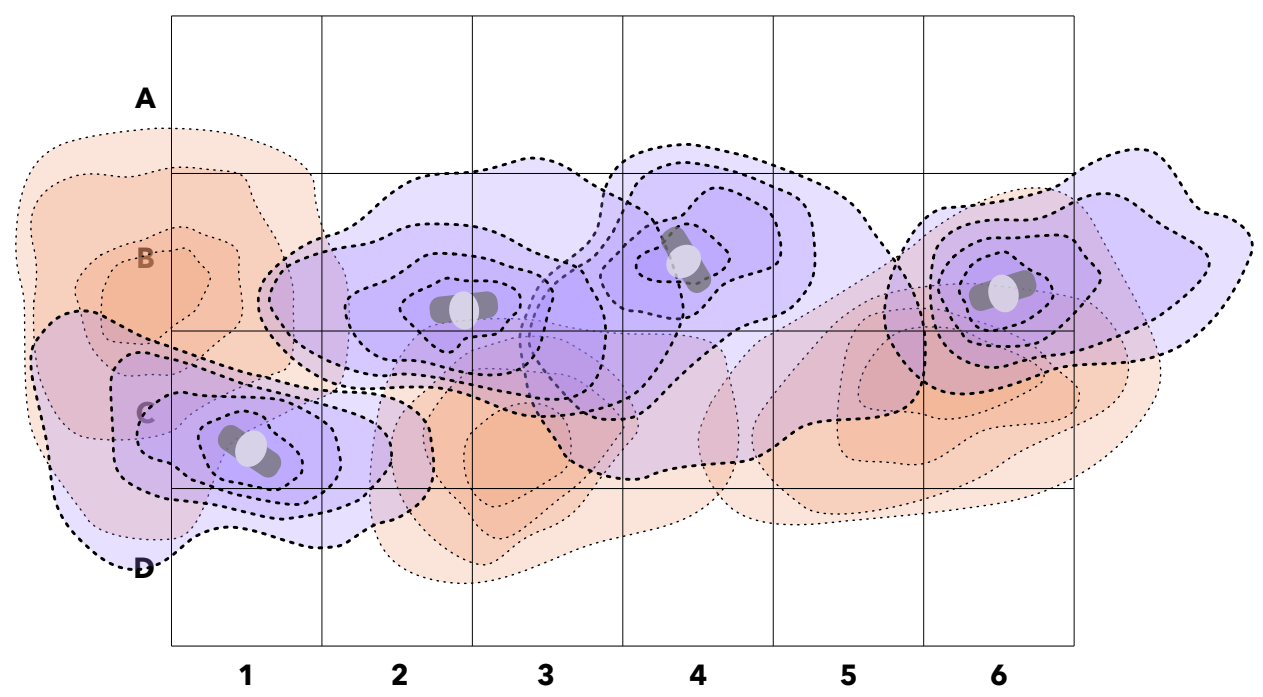


to restore excitement and a sense of belonging to individuals" in their environment," similar to the stratified details in the work of Carlo Scarpa (Bell, Greene, Fisher, \& Baum, 2001, p. 108). Urbanologist A. E. Parr added to this by stating that fields, forests, and mountains contain an unending variety of changing patterns and stimuli, a type of variation and patterning not found in the mundanity of the urban environment. In these urban interiors, "modern windowless structures install a sense of enclosure rather than a sense of being drawn to the next horizon" (Bell, Greene, Fisher, \& Baum, 2001, p. 108-109). Lastly, the stimulating environment again draws parallels to the adaption level theory put forward by psychologists. Adaption theory, after assuming the general rule that there are optimal levels of environmental stimulation, refers to changing the body's response to a given stimulus, rather than changing the stimulus itself (Bell, Greene, Fisher, \& Baum, 2001, p. 111-112). It is here that the architectural detail and material can be investigated in engendering new responses for environmental stimulus, furthering the discourse of the senses in an architectural language. In this new geographic territory of the contemporary environment and the individual's reaction to stimulus, architecture can explore new possibilities in a sensorially encompassing architectural experience beyond ocularcentrism. 


\subsection{CASE STUDY: PETER ZUMTHOR}

When the details of a space come together to target the senses, an atmosphere of place is created. The work of Peter Zumthor clearly demonstrates the creation of atmosphere through the material, tectonic, and formal arrangements of elements in provocative ways. Using his phenomenological understanding of human engagement with architecture, Zumthor is able to create both atmosphere and place-ness in his spatial constructions. His atmospheres incorporate the entirety of the senses, placing the individual and body within a space rather than outside of it looking in. This focus on the body and perception, rather than the simple visual aesthetic of a space, allows his work to permeate the emotional and psychological understandings of individuals, regardless of their awareness of what architecture is. Embodying phenomenology in his construction of place, Zumthor's work often embodies the very construction and making of his spaces. This has the effect of both orienting the individual in space, as well as actively engaging the user as an essential component to the architectural process. In projects like the Therme Vals Spa seen in Figure 35, Zumthor makes use of water, stone, and their interaction with the movement of the body through space in an attempt to provide haptic confirmation of the individual in space. Additionally, the Bruder Klaus Field Chapel seen in Figure 36 freezes its constriction so as to make it understandable and relatable to the overall architectural experience. The zinc floor is frozen in time, while the charred concrete walls allude to the spaces framing, burning, and making. The visual impact of his buildings is powerful, but even stronger is their simultaneous impact on the other senses like the olfactory and tactile, giving strong and unexpected sensory effects to individuals who encounter them. As such, the project is not so much about the materials themselves - as they serve no symbolic or historical meaning, but instead the materials "mediate [relationships] between 
Figure No. 35

Therme Vals Spa

Figure No. 36

Bruder Klaus

Field Chapel
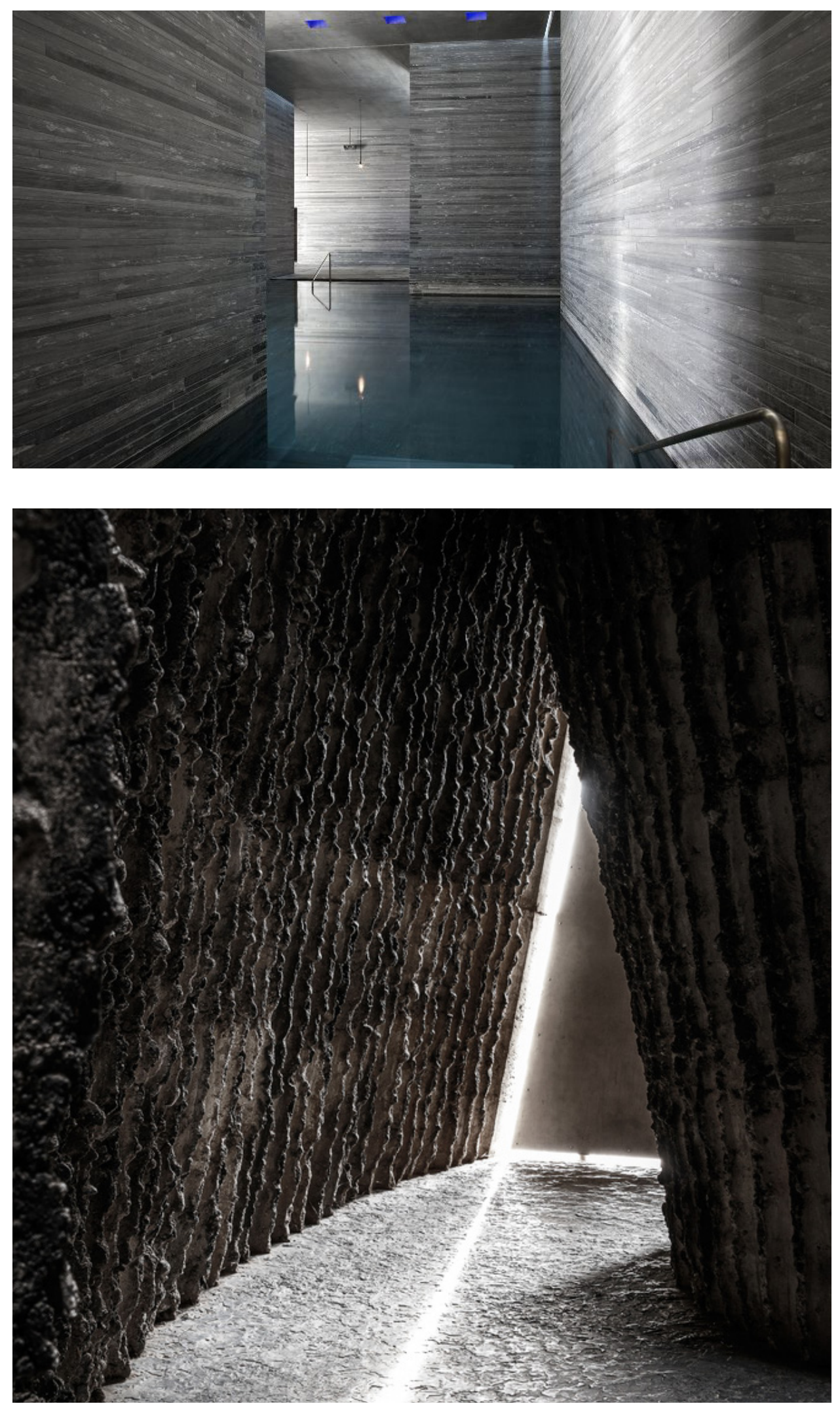

The Invisible | 59 
people... and their surrounds" (Ursprung \& Goodwin, 2014, p. 47-48). Moving beyond the visual, his spaces use a variety of carefully designed stimuli through the use of materiality, texture, light, echo, contrast, scent, and temperature to create a natural narrative to a space that evokes a sense of awe and wonder to individuals that make their journeys through them. As one moves through the spaces created by Zumthor, they are involving themselves in the very choreography of the space itself by "participating in its spatiality and materiality, literally activating the space" (Ursprung \& Goodwin, 2014, p. 48). Through creating a space that is not overstimulating, nor under-stimulating, Zumthor's work creates unique conditions within the understanding of individuals where they feel their experiences become part of the architectural narrative itself. Through carefully understanding materials, tectonics, and spatial perceptions, Zumthor is able to foreground a building's sensual qualities, allowing his work to transcend the non-place's of contemporaneity.

Using Zumthor's techniques, processes, and understandings of architecture and atmosphere, Figure 37 and Figure 38 shows a door handle study as part of the design research process of the thesis. The proxemic handle study attempted to use a unique architectural application for a contemporary material that would trigger a variety of different sensory stimulation. This reinterpretation of the material would thus have the effect of persuading individuals to reconsider the element they are interacting with. The chosen material was spray foam, exploring the potentials for the foam to physically engage with the hand through the actual process of making. By holding the block of wood with a glove and letting the spray foam cure around the hand, the foam dries and reveals an exact void of the human hand. Removing the formwork of the hand, the handle becomes an exact inverted copy of the human scale of touch. Displaying the highest level of intimacy through touch, the handle becomes a proxemic tool through which its architectural 
detail is understood, as well as the process of its making, ultimately using the construction of the component as part of the architectural expression itself. Similar in the way Peter Zumthor's architectural spaces display a quality of their making in an attempt to unite the user with the building process and experience, the handle study ultimately became a powerful tool in understanding both the scale of human interaction with a common architectural element, as well as the methods through which the building and the human can physically interact. Through the void left behind in the construction of this study, the individual has the opportunity to become an authentic part of the architectural detail itself through the intimacy of the hand and the door handle to the building. By embedding the construction process within the design of a building, the individual has the potential to become part of the architecture, ultimately making it more relatable and creating more powerful moments of connection between the estranged individual in the contemporary city and the spaces that make it. 


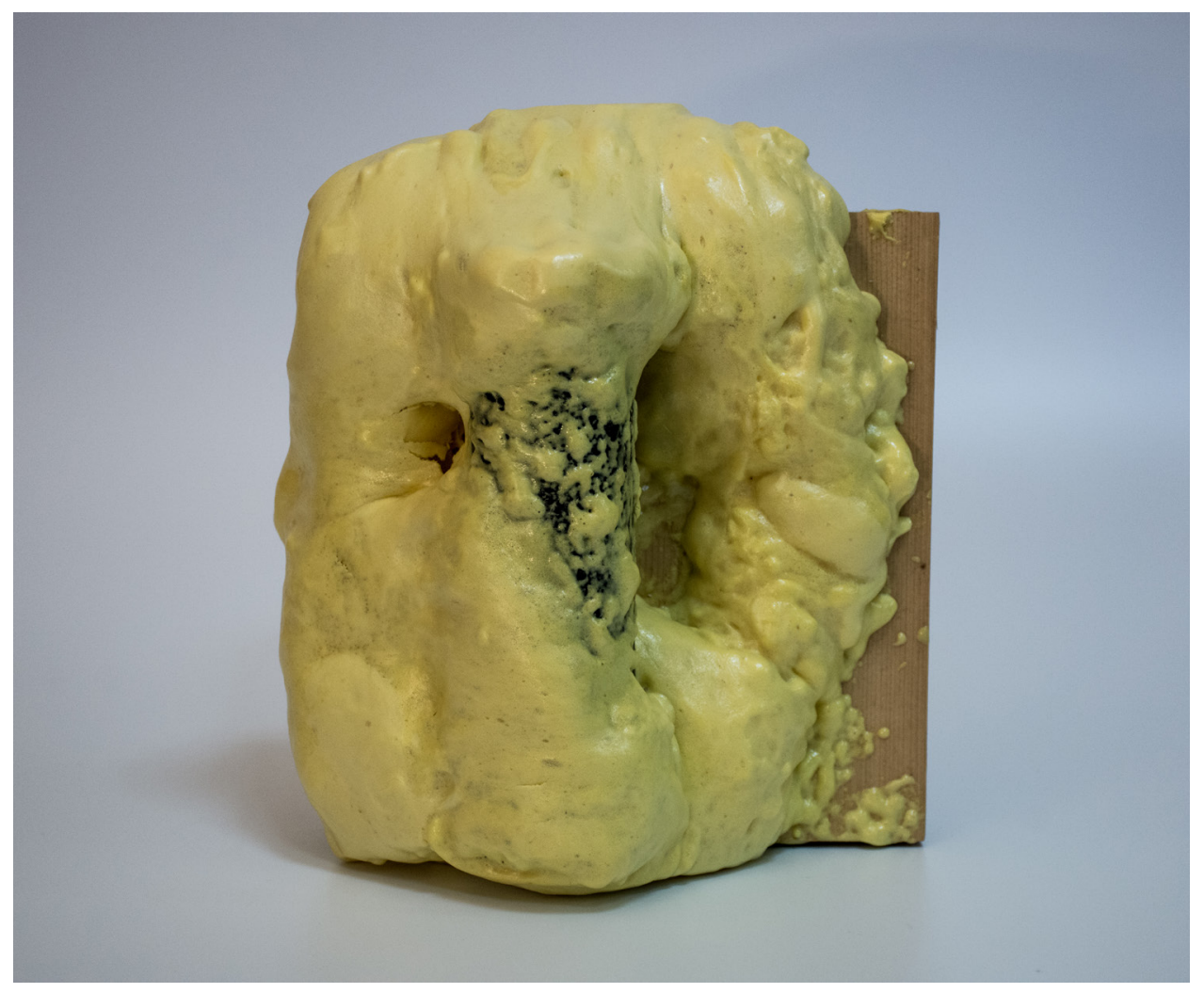

Figure No. 37

Proxemic handle study - front [1:1]

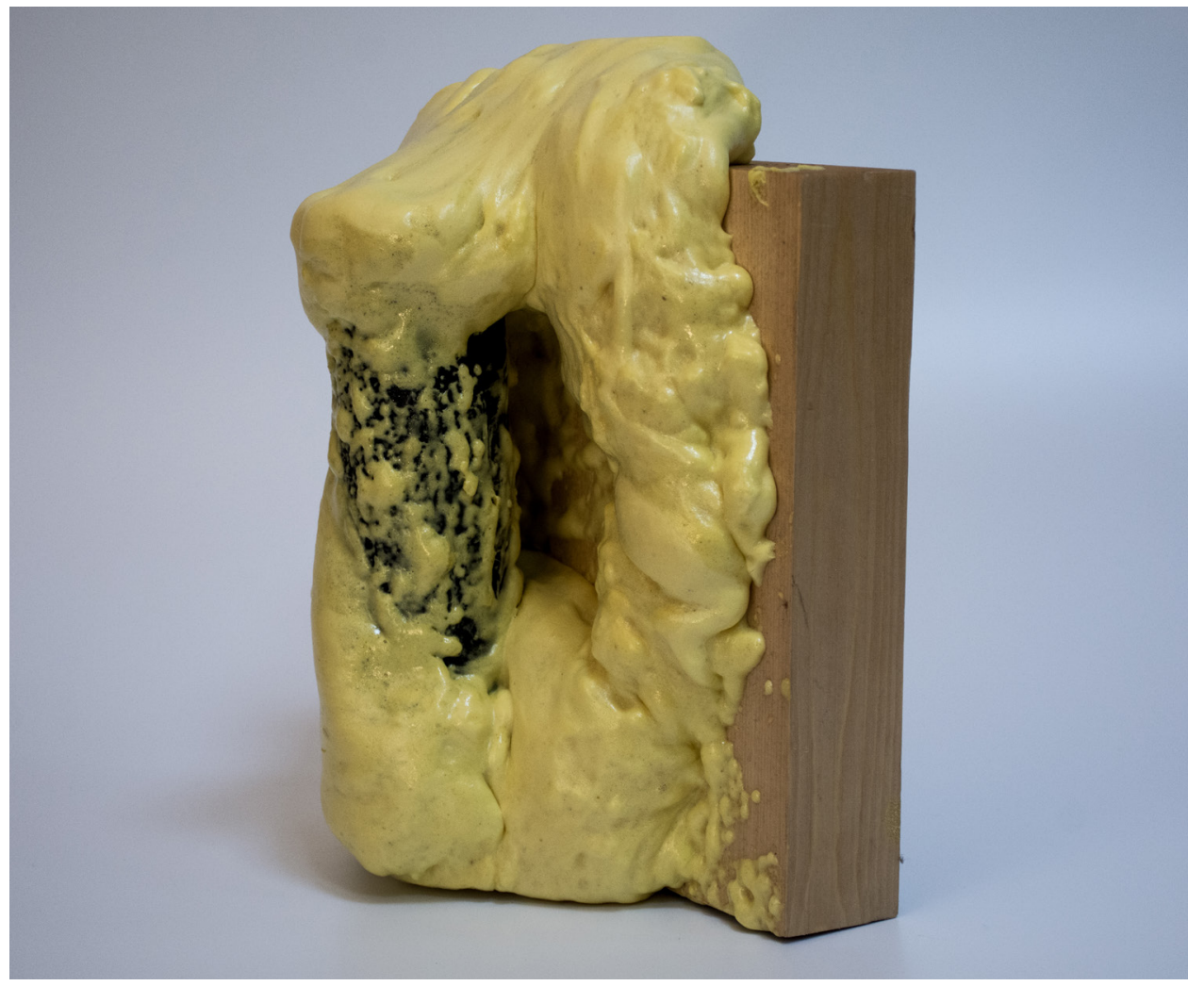

Figure No. 38 Proxemic handle study - side [1:1] 


\subsection{ON REINTRODUCING THE INVISIBLE}

Contemporary architectural thinking has been infatuated with the iconic image of the building, reflected through the ocularcentric society of digital dissemination and manifested in the many nonplaces of our current urban conditions. In doing so, we have forgotten the fact that architecture is not merely a building; it is a set of ideas, relationships, and narratives that formulate an experience to the user. By prioritizing visual aesthetics, architecture fails to engage the entirety of the senses - resulting in the distancing of oneself from an immersive urban experience and reducing architecture to an obscure commodity. Reintroducing the in-visible senses back into an architectural framework can address the geographies of both the over and under-stimulation of the contemporary environment while at the same time repairing societies damaged relationship with architectural experience and understanding. As such, the senses should be used as a stimulus for conveying necessary information about the body's geography within space, ultimately creating a narrative that communicates with the individual beyond what they see. Through addressing aspects of tactility, hapticity, juxtaposition, and contrast through the sensory apparatus of the body, architectural meaning and expression can once again begin to occupy the contemporary city. The senses provide a constant feedback loop between the body's current location and where it is going, allowing one to orient oneself while also connecting people with space. This, however, can only be possible in acknowledging the invisible aspects of architectural experience, namely in the way a space is perceived. In reintroducing the invisible, we are not simply identifying things that are missing from our environments, but rather we are enabling a broader understanding of spatial effects and the recognition that comes with it. The suppression of the other senses reduces the world to a plane of vision, one that remains a screen played out in front of us and ultimately, one that cannot be engaged with in any meaningful or authentic way. 


\section{"Without the senses we would}

have no true idea of space"

- Diana Fuss 


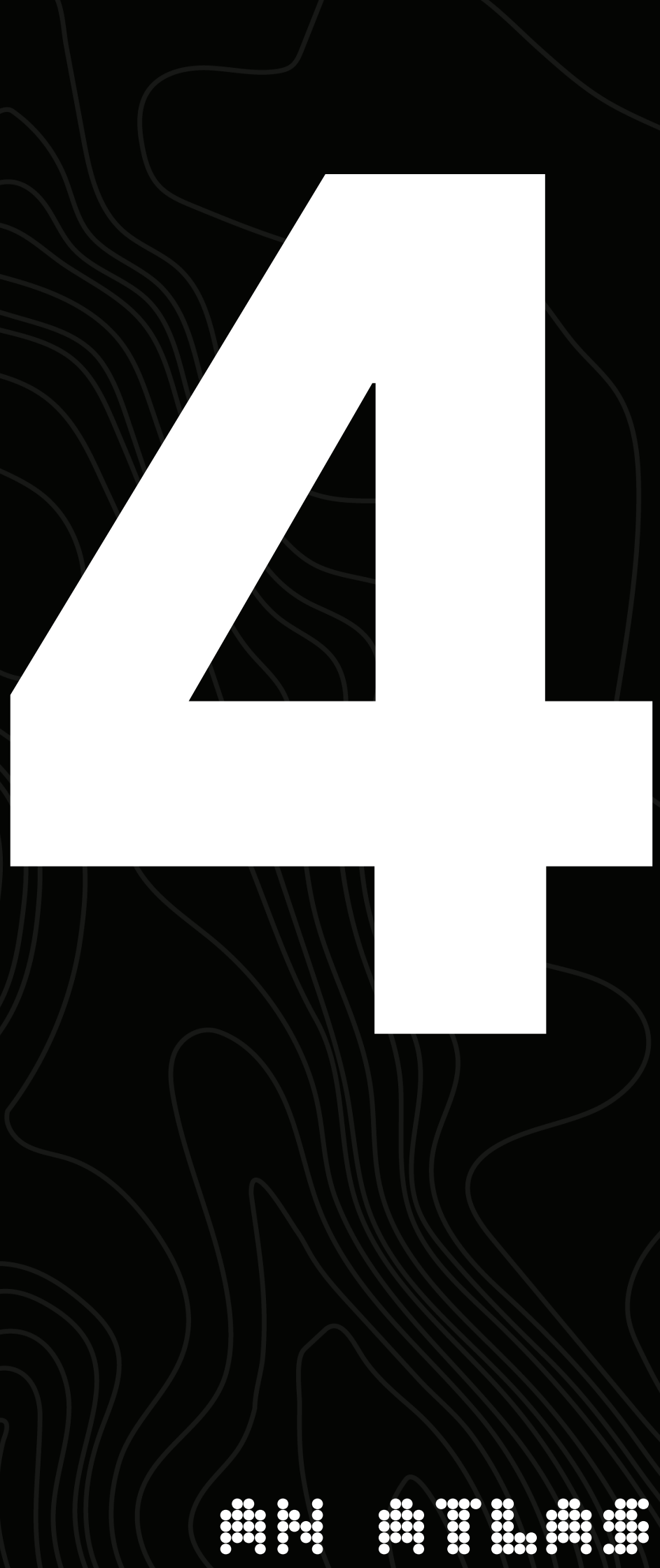

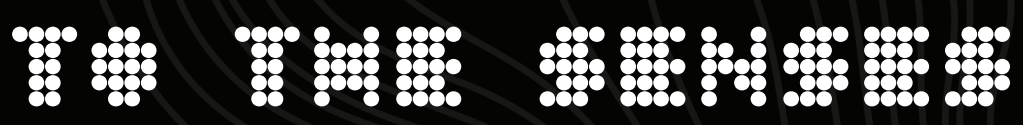





\subsection{INTRODUCTION}

An atlas for the senses is the thesis project undertaken and used as a vehicle for exploring the ideas put forward here. The proposal lies somewhere between a building, a piece of landscape, a pavilion, and a gallery. In order for the senses to be engaged within an architecture that exists in the digitized non-place of contemporaneity, the project must serve as an experiential machine that focuses on the relationship between the body and detail, internalizing architecture while at the same time externalizing the sensory inputs of the user. Through the use of spatial contraction and expansion, proximity and scale, sensory deprivation and release, material and tectonics, and a use of the unexpected, the project explores the ways a lived architecture can be used and engaged with in the twenty-first century.

The thesis project is an atlas, one that maps the relationships between people and space through defined architectural moments along the site, reintroducing individuals to an invisible understanding of both themselves and the spaces they may encounter. The project aims to push the boundaries of the majority of contemporary architectural practice. Today, as designers of the built world, we have more power in creating these relationships than simply through aesthetics. In Paul Rudolph's analysis drawings of the Barcelona Pavilion, it becomes clear the understanding of architectural expression and experience found in the form of energy rather than matter. Rudolph's drawings do not just convey the form of the building, but instead frame the levels of expansion and contraction through the use of gradient lines and how they are perceived through the individual's experience. By understanding the foundations of stimulation and the senses, we have the potential to create an architecture of the senses that becomes a part 

of our very memory of space, one that challenges our preconceived notions of the power architecture has over our perceptions. Through proposing an invisible architecture, we have the potential to turn the idea of blindness into vision, pinching the consciousness of the individual through the defamiliarized self in space, both creating a stronger architecture as well as generating memorable places in the landscape of the non-place.

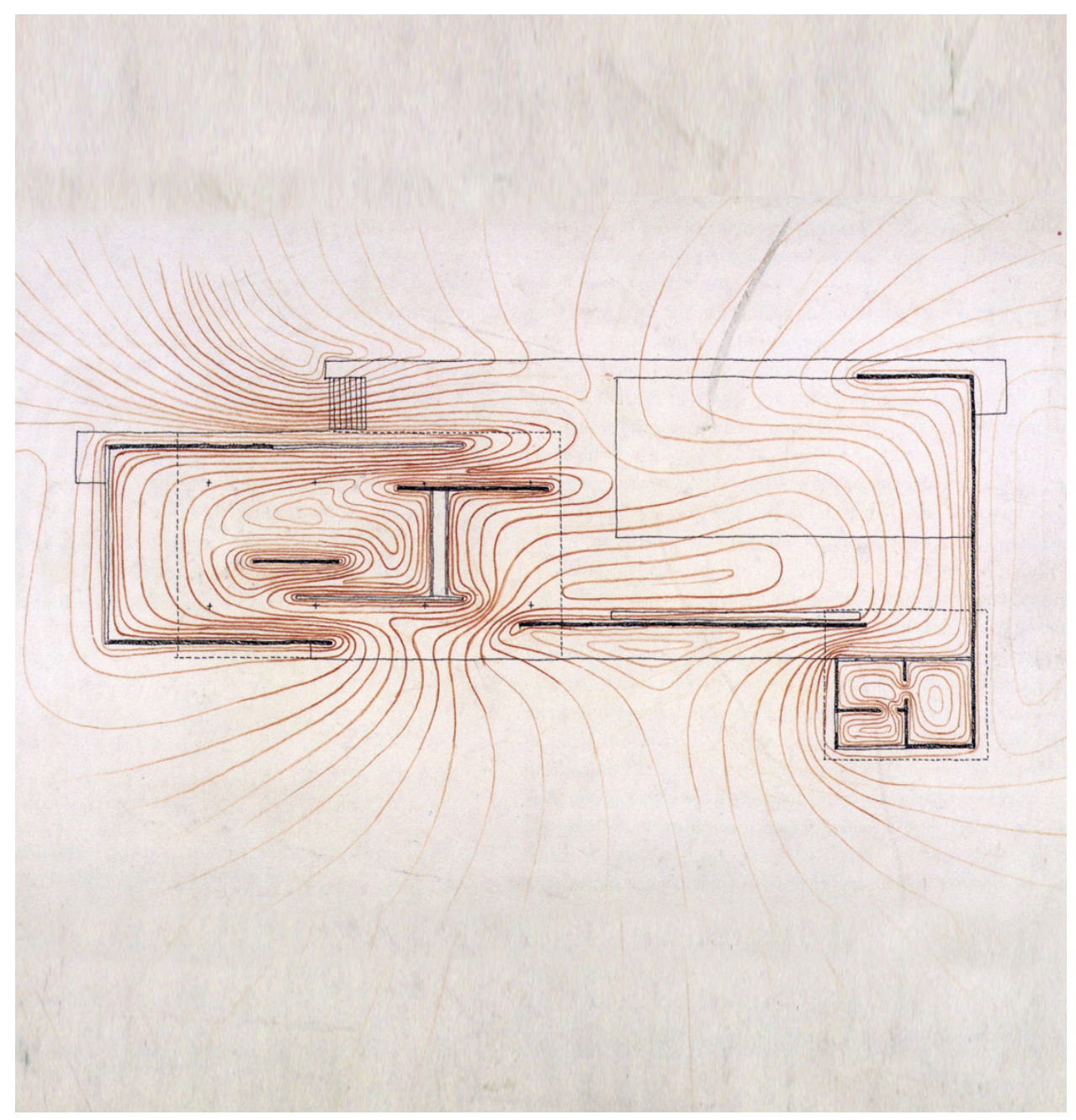




\subsection{DEFINING THE ATLAS}

At the most fundamental level, architecture is not about creating buildings. Architecture frames a set of ideas and values into a tangible and understandable manner. In the same way a musician frames silence and harmonic notes into a melody that provokes emotional responses by people, architects frame space through the careful manipulation of materials and details. Before the architect can begin to work with material, detail, tectonic, scale and otherwise, they must design for the very psychological responses they wish to employ. At the most fundamental level, the architect manipulates the senses. They provide a framework in the form of a map or journey through space and time that is meant to be experienced through one's own lived experience and by the temporal nature of life itself.

Today, the atlas has been misunderstood as a simple book of maps, yet historically it was attributed to much more. First defined by Gerardas Mercator in 1595, an atlas describes the creation and form of the whole universe, not simply as a collection of maps and images, but rather a collection of moments that represent the mappings of geographic, political, social, and other influential factors of a particular region in relation to the body (LeGear, 1950, p. 9). An atlas provides the very framework to which a map can exist. It reorients and furthers our understanding of a journey that goes beyond a mere book of maps. Much in the same way a geographer adventures to find new territories to document, the architect requires their own map; an atlas rather, one that provides an understanding for the psychology, senses, and emotions of the human consciousness and how they might formulate in new space. The atlas is thus important for both navigation, as well as for framing the relationships of objects outside the body and how they relate to one's own position in the world. 
Figure No. 40

The Atlas Minor

of Hondius by

Gerardus Mercator

Figure No. 41

The physical

atlas
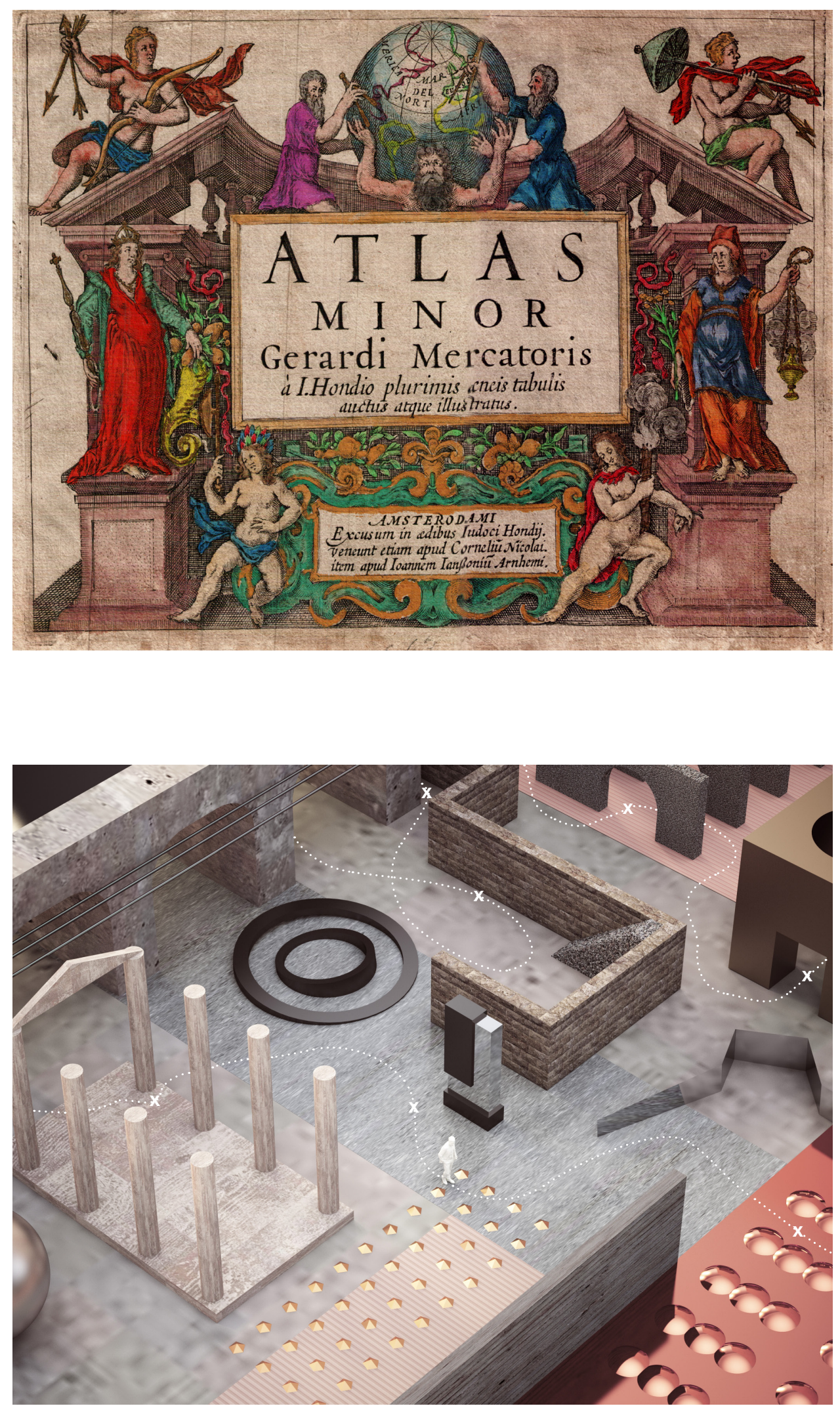


\subsection{THE SITE}

The city and the natural environment in contemporary discourse perhaps provide the most contrast in the mental and physical states they generate in human experience. As the city's construction formulated some form of order out of the perceived chaos of the natural world, so did it create the anxious and feverish populations and conditions analyzed by psychologists and geographers alike. This dichotomy of place within the fabric of Toronto exists across the expanse of the city, particularly in the moments where the natural world and the built world meet. Toronto's extensive ravine system forms branches of respite and retreat within the dense urban fabric of the city. A place where wilderness and wetland stretch deep within the built world, Toronto's ravines provide strong moments of juxtaposition between their forms, stimuli, and the perceptions and experiences they generate for the individual.

The proposed location for this investigative architectural construction will be located between Bloor Street East and a branch of

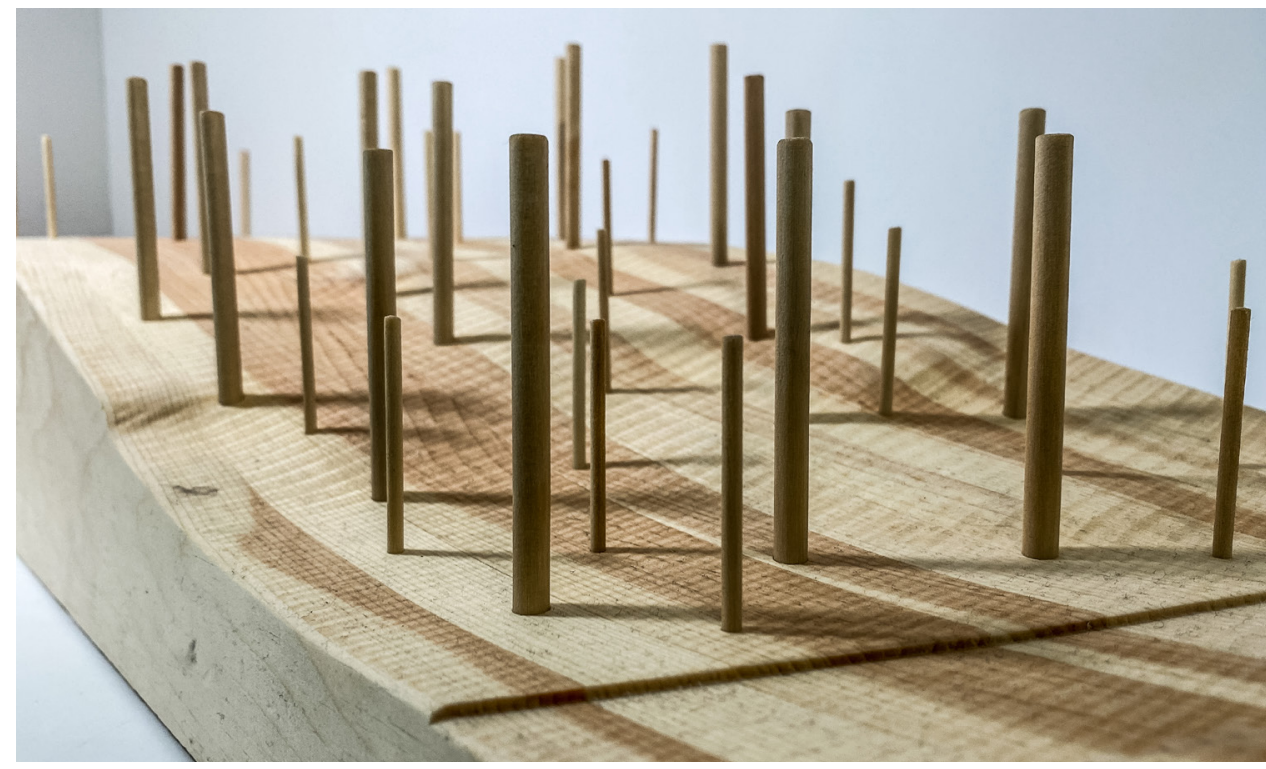

Figure No. 42 


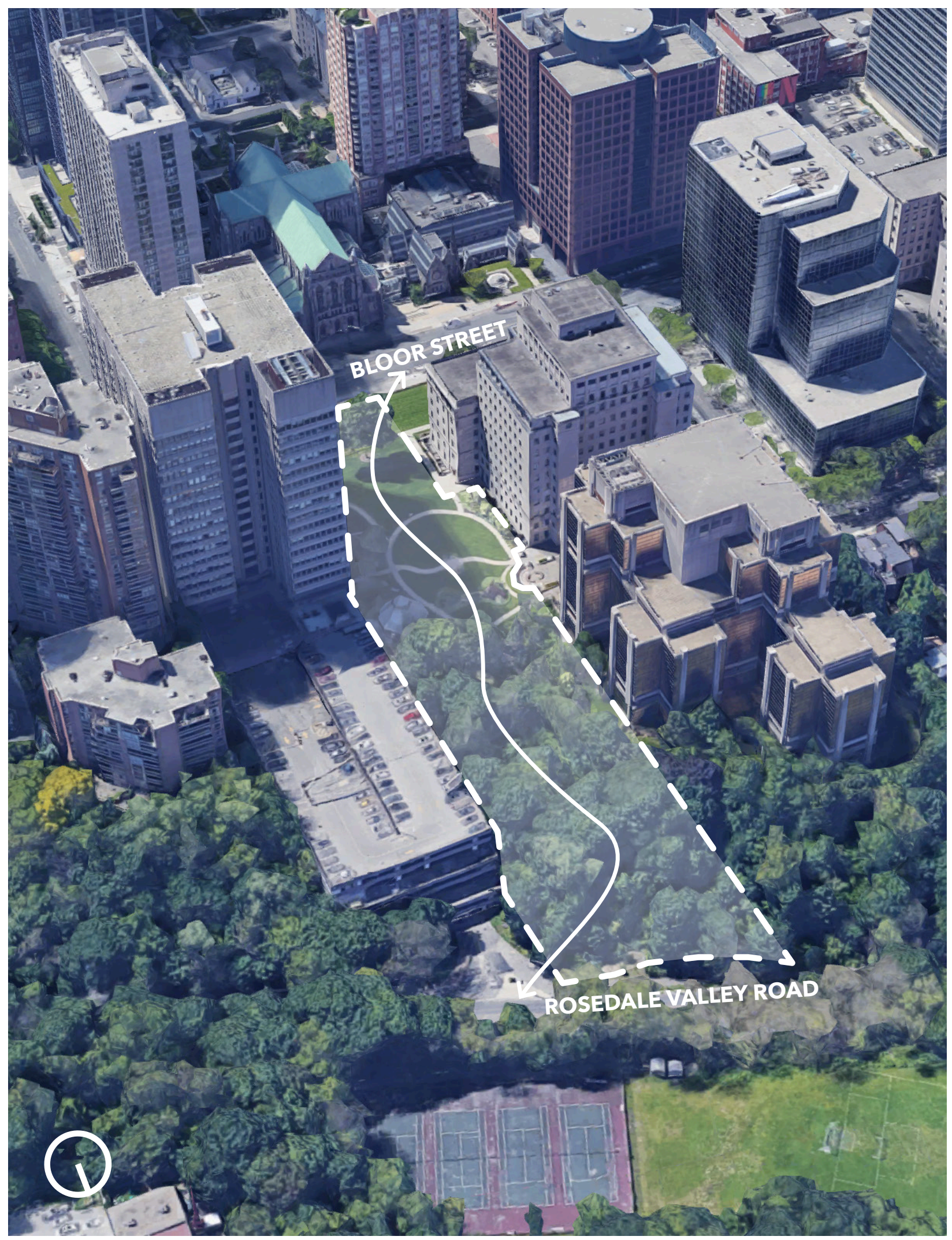



Toronto's Don River Valley, where the Manulife Garden exists today. To the south, the site exists as an urban non-place, where signs, generic buildings, lights, and icons agglomerate into a space where people seem to pass unaware of one another or of their very place within the flux of the city. Backing the north side of these buildings is Rosedale Valley - a branch of the Don Valley - a deep natural score in the Earth, invisible to the streetscape of Bloor. The juxtaposition between these two geographies provides the setting for an architectural investigation into the senses and the ways they might be used in grounding an individual in a full-bodied experience, ultimately designing a transitional space between the harsh contrast between the natural and the built worlds. The site's progression from natural space to urban provides the users with a sensorial experience, offering to them an atlas to the senses to be drawn upon in both present and future spatial situations. Ultimately, the site will offer a new territory for people to explore their senses in an architectural experience, allowing them to recognize the transformative potential of design. 


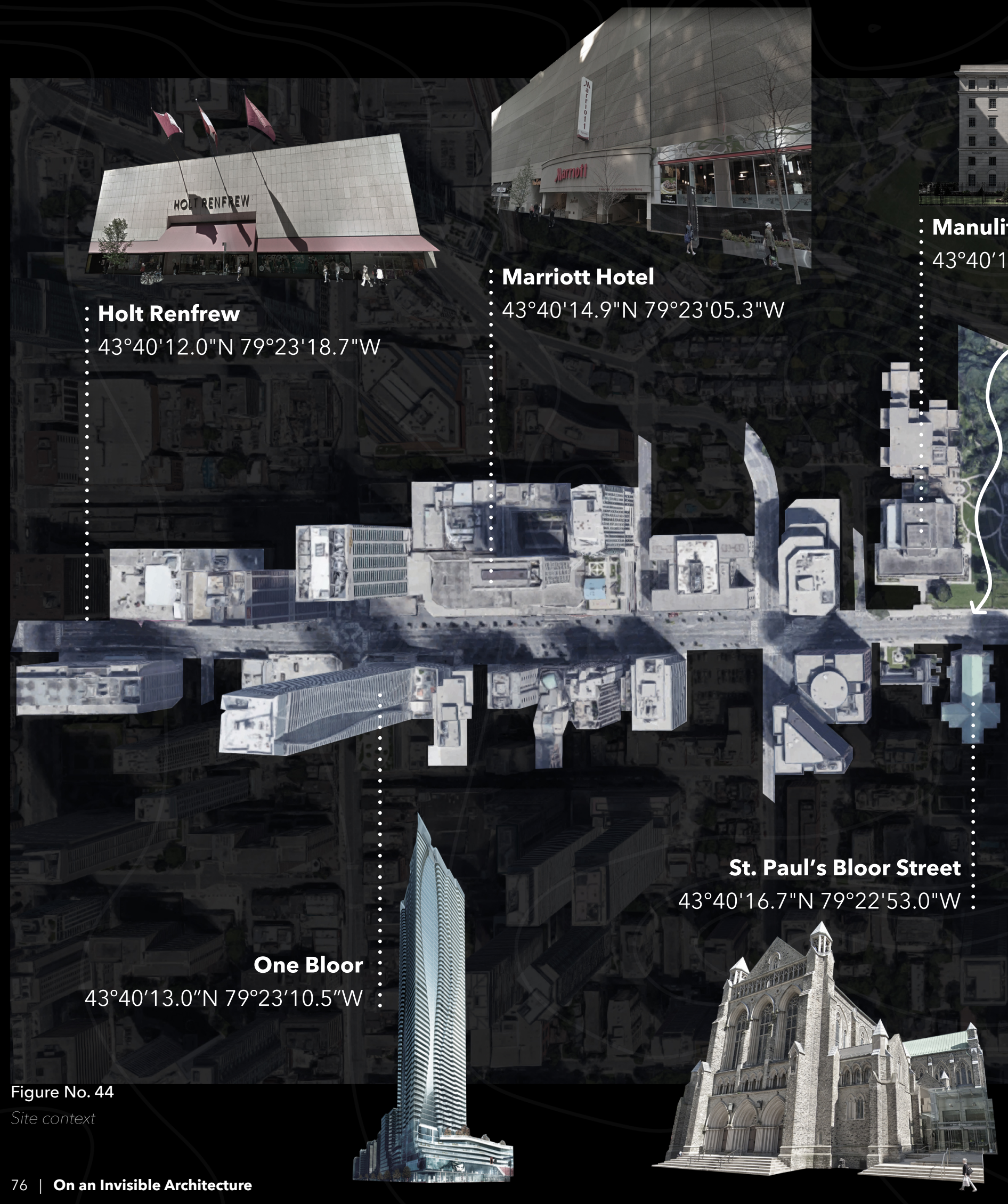




\subsection{NARRATIVE AND EXPERIENCE}

The atlas takes users on a journey, one that is equally as psychological as it is physical. Throughout a sequence of details, materials, and spaces, individuals encounter a series of moments linked to their experiences in space both through the intimacy of their sensorial envelope as well as their individual experiences in space.

The experience of the spaces becomes a narrative, one that illustrates both the current misuse and the immense potentials the senses have in promoting and creating a sense of place-ness. It enables individuals to re-evaluate their own understandings of the relationship formed between the boundary of the body and the spaces it occupies. As the boundary of the body moves through this gradient of spaces, key relationships between the physical world and the physiological one are formed, offering moments of understanding and confusion as well as heightening and deprivation. This contrast of sensorial applications forcefully engages individuals in the architecture itself, not as a visual journey but as one that creates varying emotional responses to the physicality of the spaces. The atlas attempts not to simply form a building, gallery, or pavilion to amuse and arouse people along their journeys, but it attempts to provide an atlas or map to allow for a richer and deeper understanding of one's own sensorial envelope and the ways it might be used in understanding the built form around us. As "the mind is part of the physical apparatus of human beings," it must be engaged with thoroughly in order to form any sort of meaningful experience in architecture (Olgiati, 2019, p. 60). It is only after truly understanding the environment that surrounds us that we can begin a dialogue that critiques and questions the conventions of architecture in the city today. 
The spaces are not meant to individualize and isolate the individual senses. In teaching and understanding our senses, we are taught about them as separate instruments that work on their own rather than in conjunction with one another. This, however, in the reality of spatial occupation is far from true. Our senses are almost never isolated or individualized in a true lived experience. The senses work in concert with one another, as some pick up where others are ignored. Given the senses encompass a full-bodied experience in space, Maurice Merleau-Ponty hypothesized that perception is "not a sum of visual, tactile, and audible givens," but due to the fact we perceive in a total way with our whole beings we "[speak] to all [our] senses at once" (Merleau-Ponty, 1964, p. 50).

It is only possible to understand the fullest extent and power of the senses in architecture through not isolating and individualizing them, but rather through incorporating their power in an agglomeration of neural connections that exist to form a strong memory of place. Additionally, not every moment or experience within the atlas for the senses narrative will be visually clear or coherent. This is intentional, as with the entirety of our senses we can never perceive a building as a homogenous whole. Instead, through the senses we experience snapshots or moments in space and time through which our body receives signals from the environment to comprehend. Through this formal design strategy, an individualized story and experience can unfold through the body's senses in hopes of discovering new sensorial engagements and relationships between the individual and a space. Through inverting the contemporary proxemic hierarchy of privileging vision over the closer senses, we will begin to focus on the closeness of interaction between the body and architecture. The intimacy of the 
senses allows one to become closer to architecture, both physically and psychologically, providing an atlas to the senses upon traversing the narrative experience from the natural geography of the ravine to the built geography of the enervated city. Through challenging the atmospheres created through the creation of spaces, architecture has the potential to reconnect with the body in more intimate and personal ways. It is only after understanding ourselves in the darkness, through a framework of the invisible, that we can begin to understand the light. 
Figure No. 45

Entrance model [1:200]

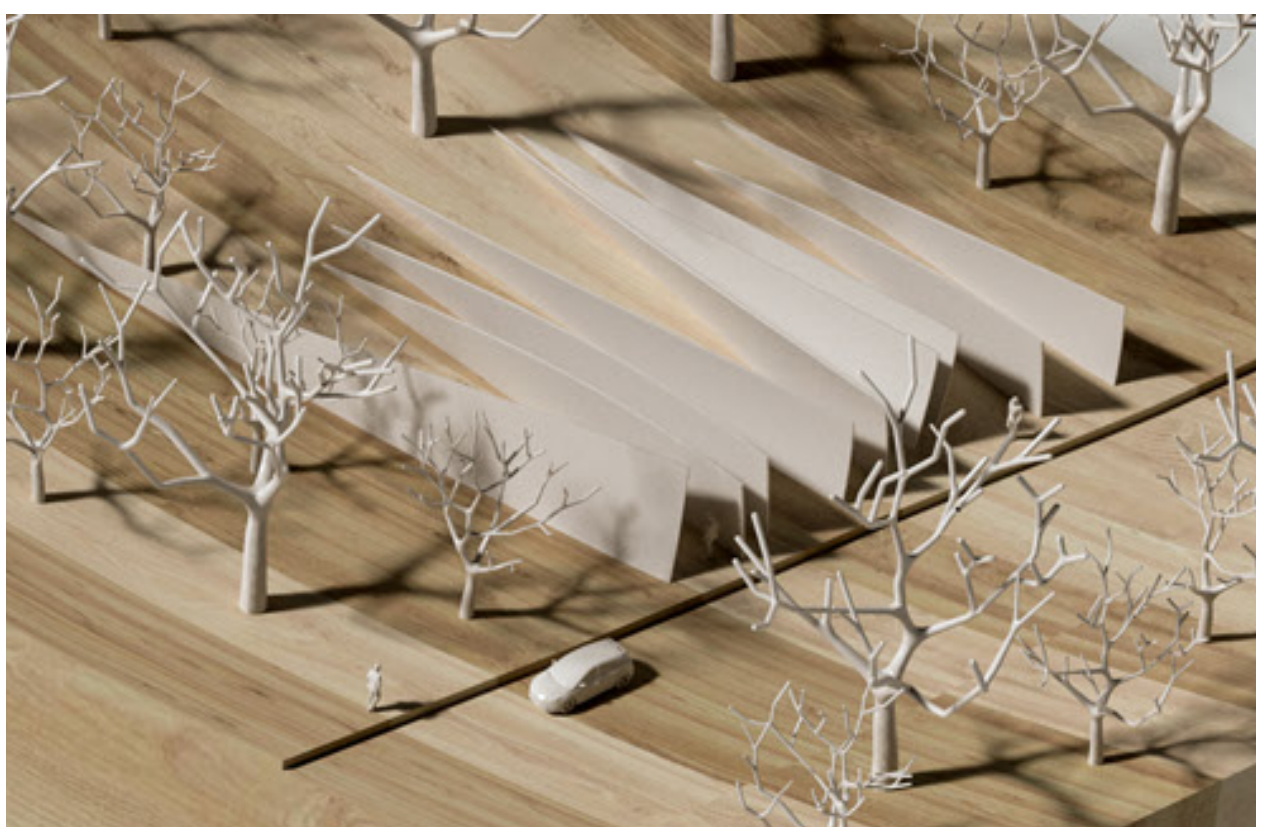

The experience of the atlas mediates the landscape and offers an understanding of the body in space as it traverses through the geography of the natural world to the urban one. The building has no traditional facade, only an interior skin that interacts with an individual throughout their journey. The building exists not as a homogeneous whole on a site, but rather as a series of moments between body, space, and atmosphere. Spatially, these moments exist as apertures in the topography, caught somewhere between a building and a landscape, architecture and sculpture, macro in scale yet also micro. In defining an atlas for re-learning the senses in spatial occupation, three events must occur. Through absorption, dislocation, and restitution the progression through space will narrate an experience of newly generated understandings between people and space.

Walking along Rosedale Valley Road, the heavily forested hillside provides a level of seclusion to the natural geography of the ravine, hidden away from the city above. As the individual walks, they are gradually struck with a variety of changing acoustical, olfactory, temperature, and other sensory stimuli as a result of the entrance to 
the atlas. Made of a number of corten steel fins that provide paths to the interior of the building, the structure protrudes through the hillside, gradually encapsulating the individual at they begin their journey to the city. The fins not only provide the framework for travelling through the beginning of the atlas, but they also carry with them sensory information and stimuli through their form and materiality. The steel reverberates and resonates, radiates temperature, and transfers sounds and smells from a variety of different locations throughout the site, both urban and natural. It is because of this that each steel structural protrusion will have its own unique quality, not only between the different choices of paths, but also between the same path through the passage of time and the changes it brings to the surrounding environment.

Upon entering the atlas, the bodily senses are absorbed, beginning at the outer most projections of the body and working inwards. The steel tunnels becomes darker as users make their way into the hill side of the ravine. Though the space becomes filled with darkness, it is not empty. The subterranean form begins to muffle both noises of the natural landscape and the distant hum of the enervated

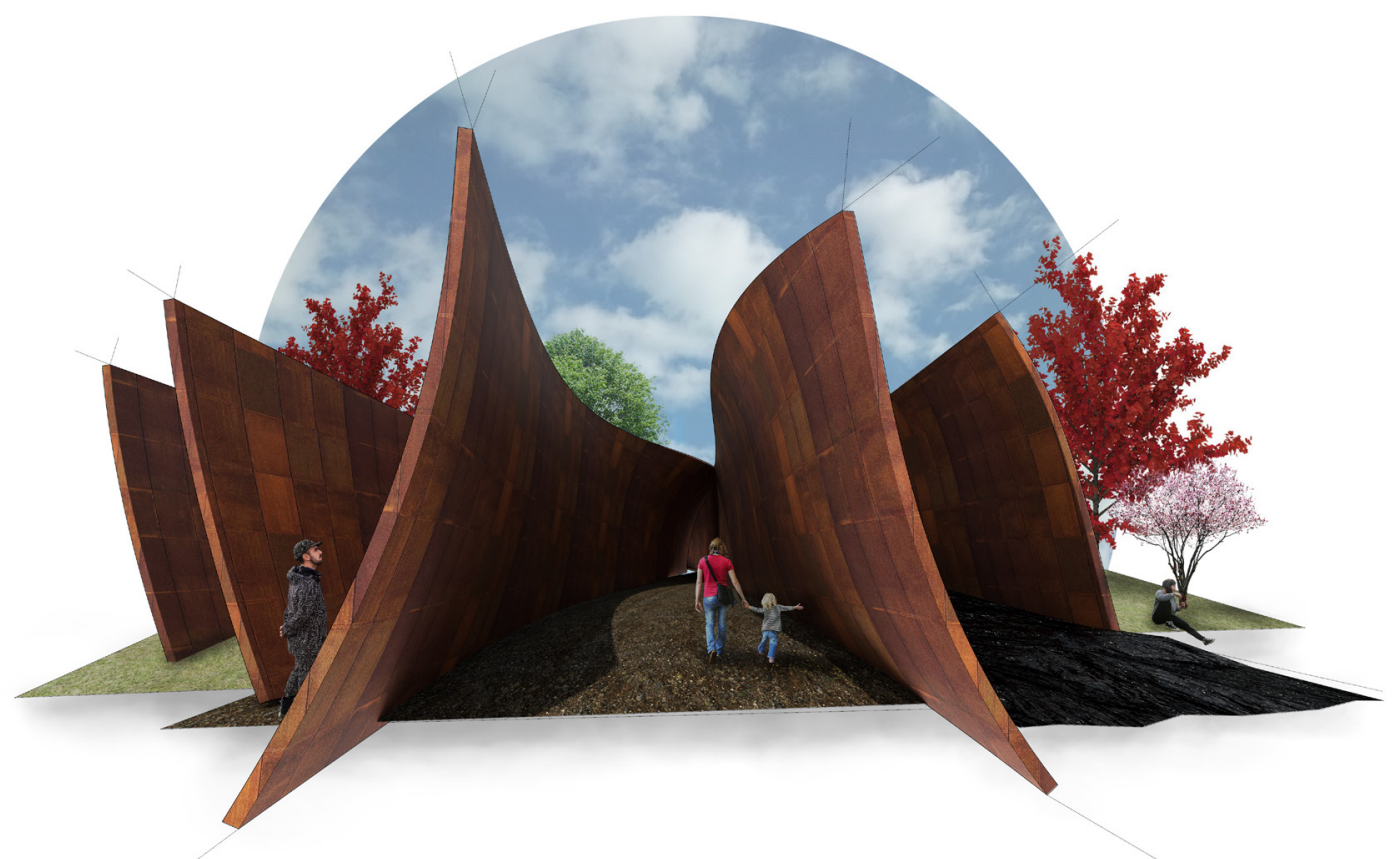


city. The steel, being naturally reverberant, begins to display a texture of patterned holes to form a gradient of sound and stimuli from reflective to absorptive. Here, individuals begin the journeys through the intimate encounters of touch and hapticity, the formal handshake between the user and the building as it opens itself up to the individual both emotionally and physically. Here, the familiar has no place as the strangeness and serendipity of the space and journey seems to provide some form of comfort.

Through this threshold, the first of the intimate spaces comes to life. This space again offers individuals the framework of an atlas, allowing themselves to make their own serendipitous encounters and journeys based on their own stimulations and memories. Encountering a variety of rooms, spaces, and experiences, this space acts as a

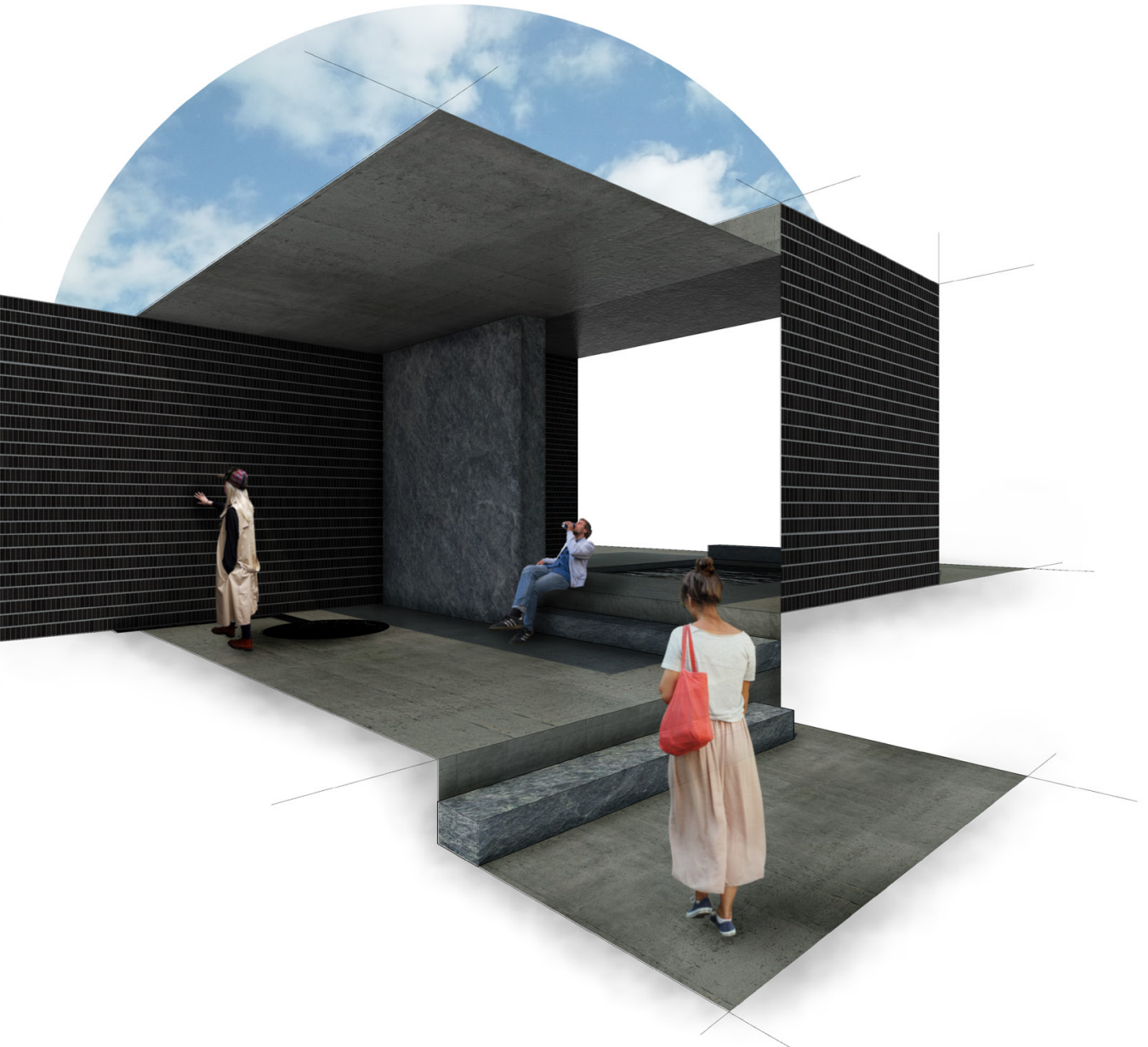


channel for both circulation as well as sensory stimulation. The space is filled with a number of apertures and wells, funnelling in a variety of stimuli from around the site, the subway lines, street traffic, as well as the natural world linking the city with the individual moment through its sounds, smells, textures, and temperatures. The space is made of highly polished stones, as well as having numerous reflecting pools and streams. The space is materially stratified to both add to the complexity of the environment, as well as to somewhat visually disorient the individual, as they must now begin to rely on the other sensory information present in the environment in order to not only navigate, but to fully make sense of their place within the complex labyrinth of the city.

The second event of dislocation involves the disruption of something seen as normal. Peter Eisenman believed that the paradox of architecture must involve the dislocation of the traditional interpretation

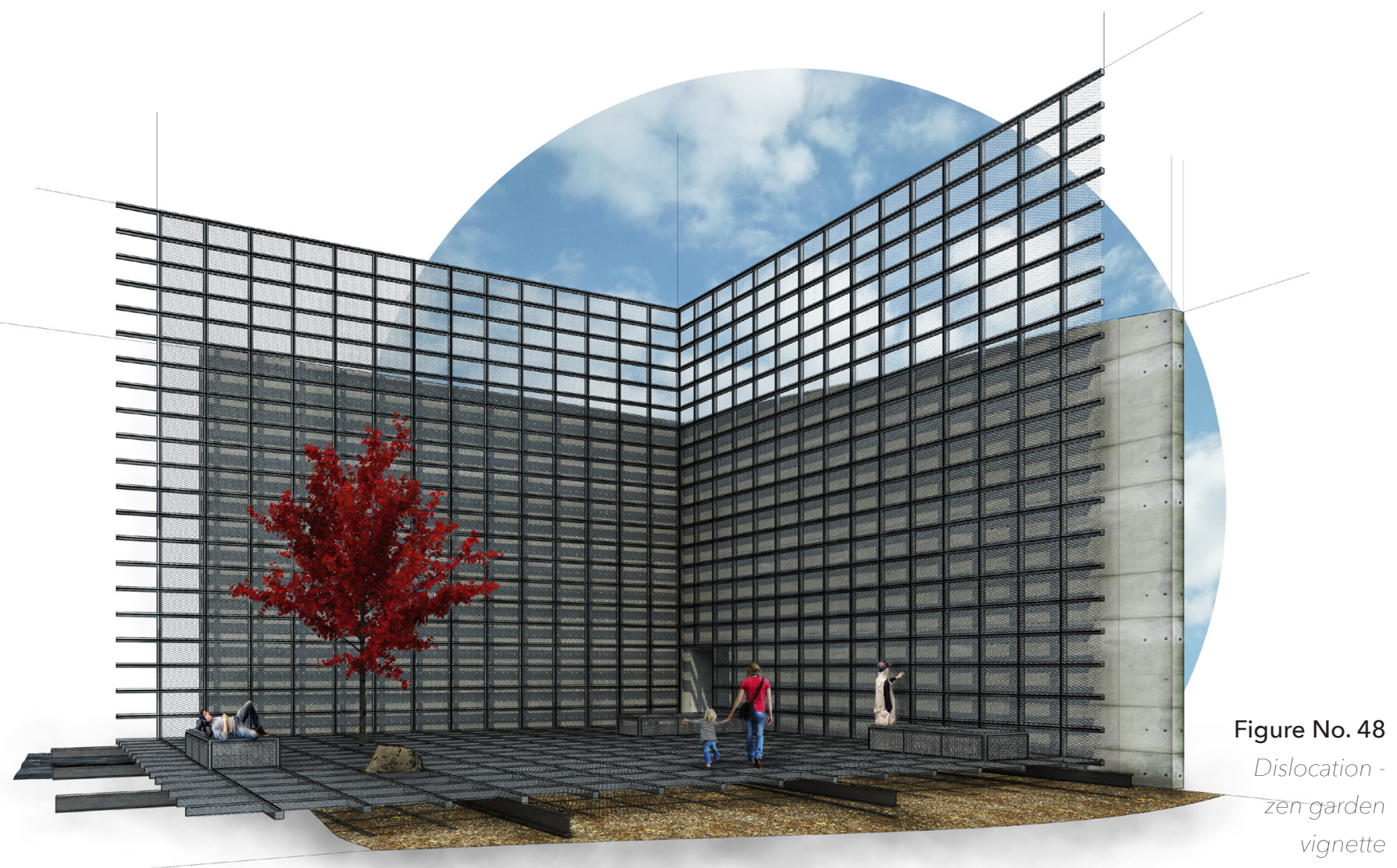


Figure No. 49

Zen garden model [1:50]

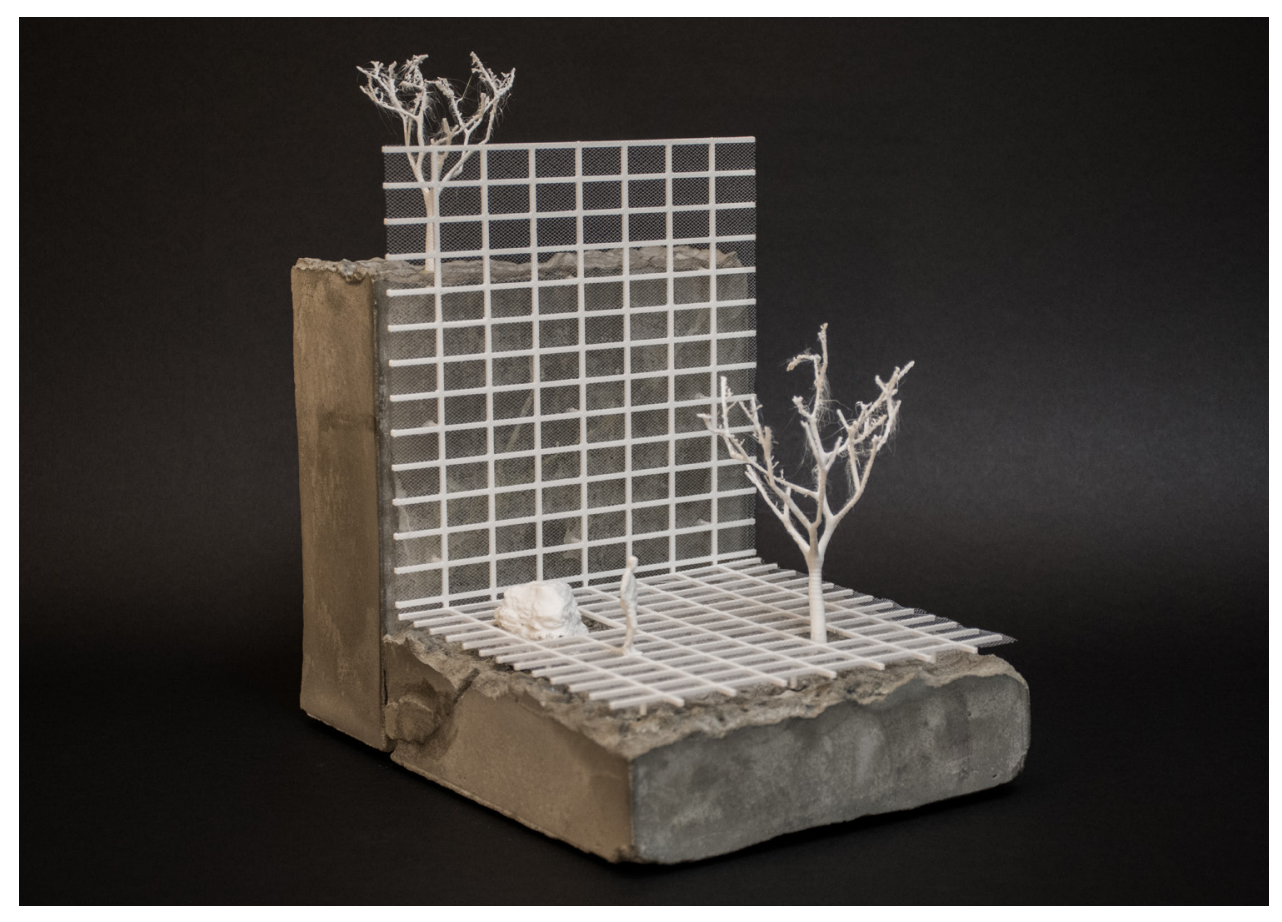

Figure No. 50

Zen garden model closeup [1:50]

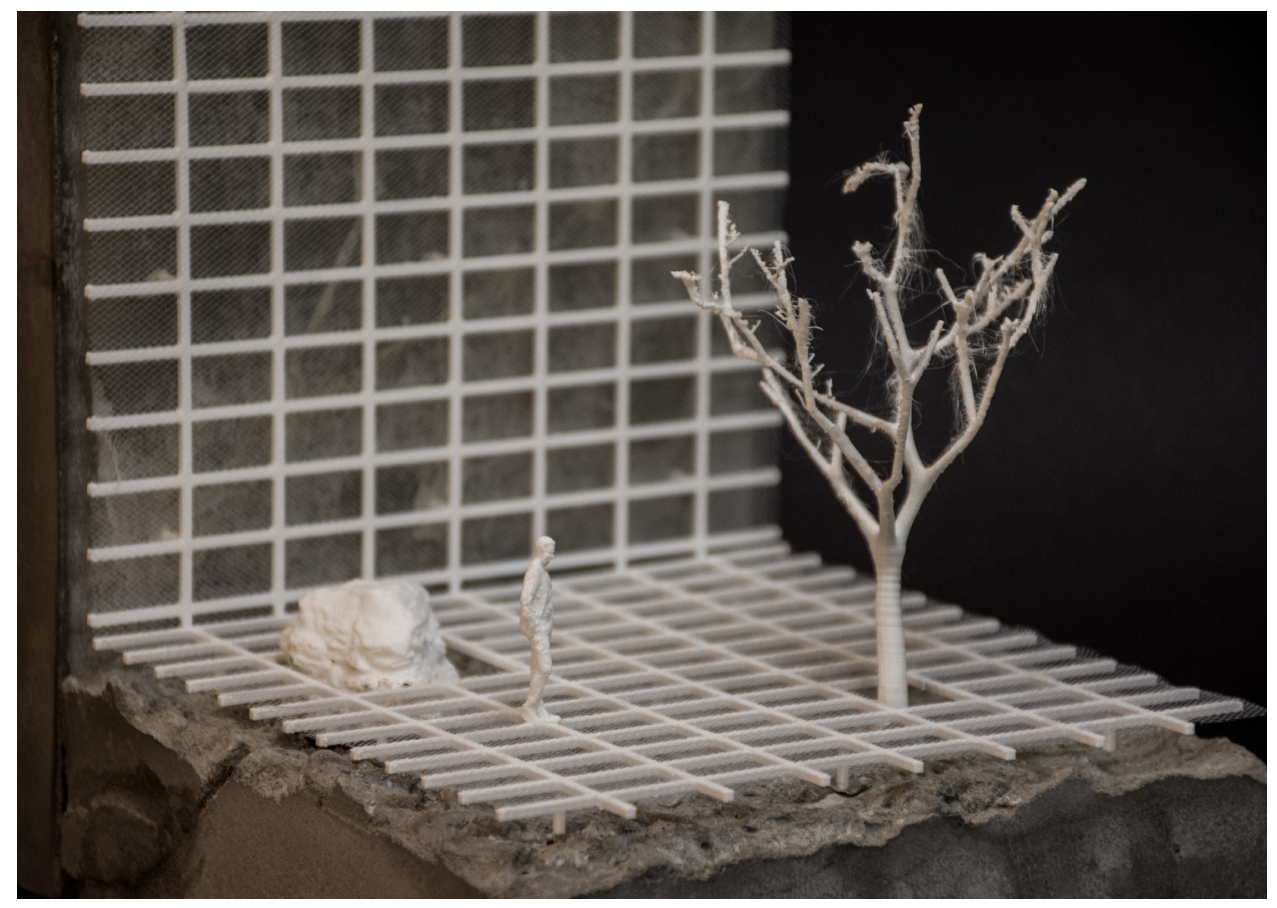


of its elements if it has any hope in reinventing a site, place, history or system of meaning (Goldblatt, 1991, p. 337). From here, the journey through the atlas can take on a number of different directions, but regardless the navigation of these spaces requires one to dislocate themselves from traditional spatial way finding and trust their other senses - the invisible ones. Here, individuals find themselves within a recessed courtyard. One of the apertures existing on the site the courtyard is inspired by the Japanese Zen garden, not attempting to mimic nature, but framing it in a space that is not natural, yet not entirely manufactured. The juxtaposition between metal grate and earth, sky and submersion, seeing and touching all contribute to the dislocative experience in this chamber. Extending above grade, the metal grate mesh aims to capture the wind on the site as it proportionally lines up with adjacent buildings to do so. This creates an ever-changing resonance and reverberation throughout the cage that changes with each season, day, hour, and minute, further stimulating the body with haptic confirmation of the self in space.

The atlas contains a number of places that promote movement, contemplation, lingering, resting, and congregating. In this hallway, seen in Figure 45, a number of these activities are accommodated, just one example of how the architecture allows itself to become part of a lived and used experience for the individual and not a simple place of passage. The hallway is sloped with a ramp to suggest movement and to allow the running of water along its side, containing a number of small cut-aways for resting, congregating, or contemplating. The spaces, though along a place of movement, offer an intimate moment for the individual to sit below a smaller circular aperture to the sky as they lean against a board formed concrete suggesting of the spaces making, while also thermally reacting to the temporality of season and atmosphere in the landscape. Along the other wall, vertically oriented wooded louvers provide the space with unique olfactory, texture, and 
Figure No. 51

Dislocation -

oculus hallway

vignette

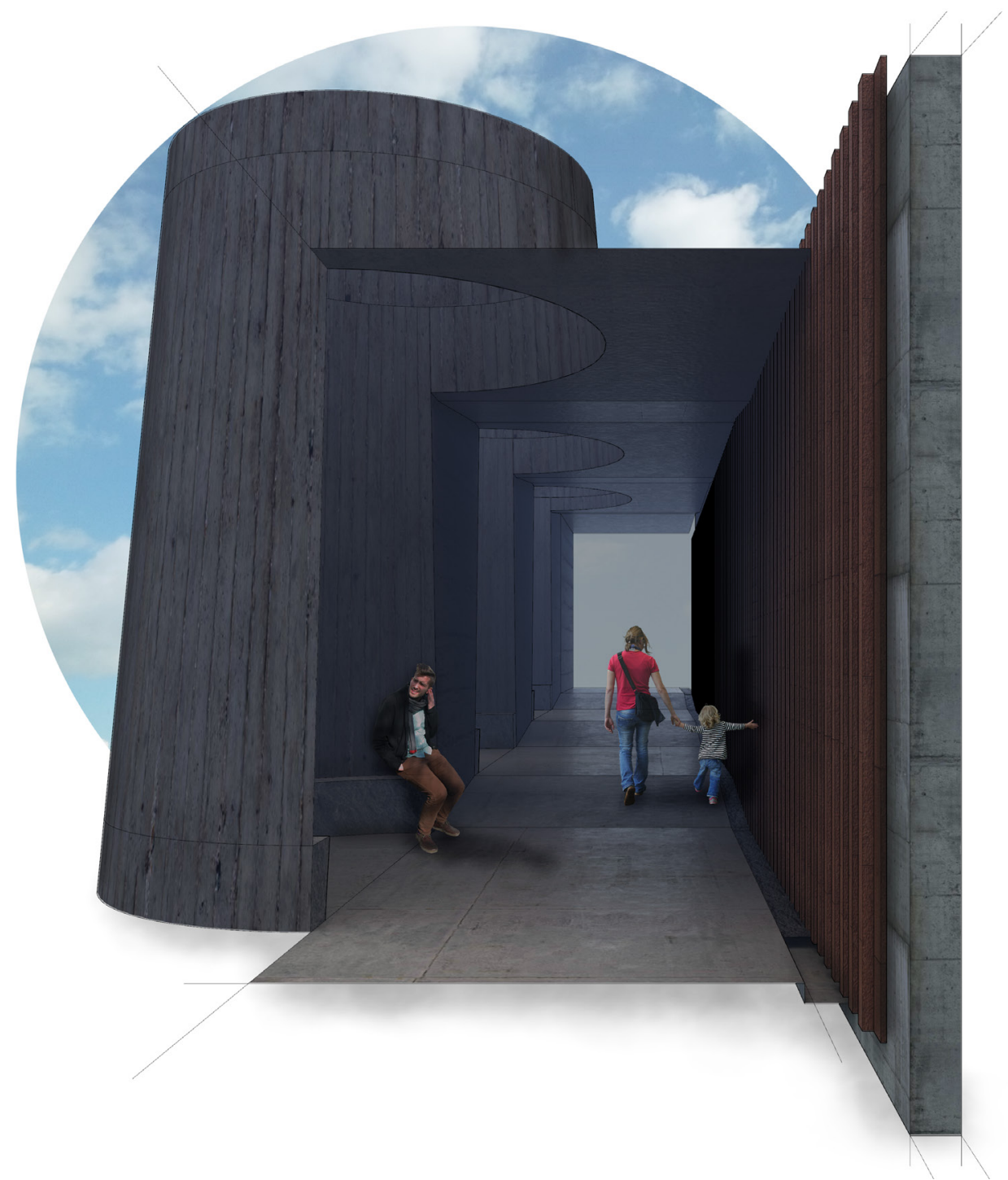

sound stimuli, as the wood reacts with the water running along its base. The space is in constant flux, both with the invisible stimulation from the environment as well as the passage of people through its corridor.

Moving through to another aperture in the site, the individual has another opportunity to sit, linger, and contemplate in this dislocative experience. This recessed courtyard is smaller in scale, offering opportunities for more intimate reflection to those who may stumble upon it on their journeys. The courtyard represents a juxtaposition between the natural and the built, as the a concrete hallway leads to a natural dirt and gravel ground cover, mediated by vertically lined 


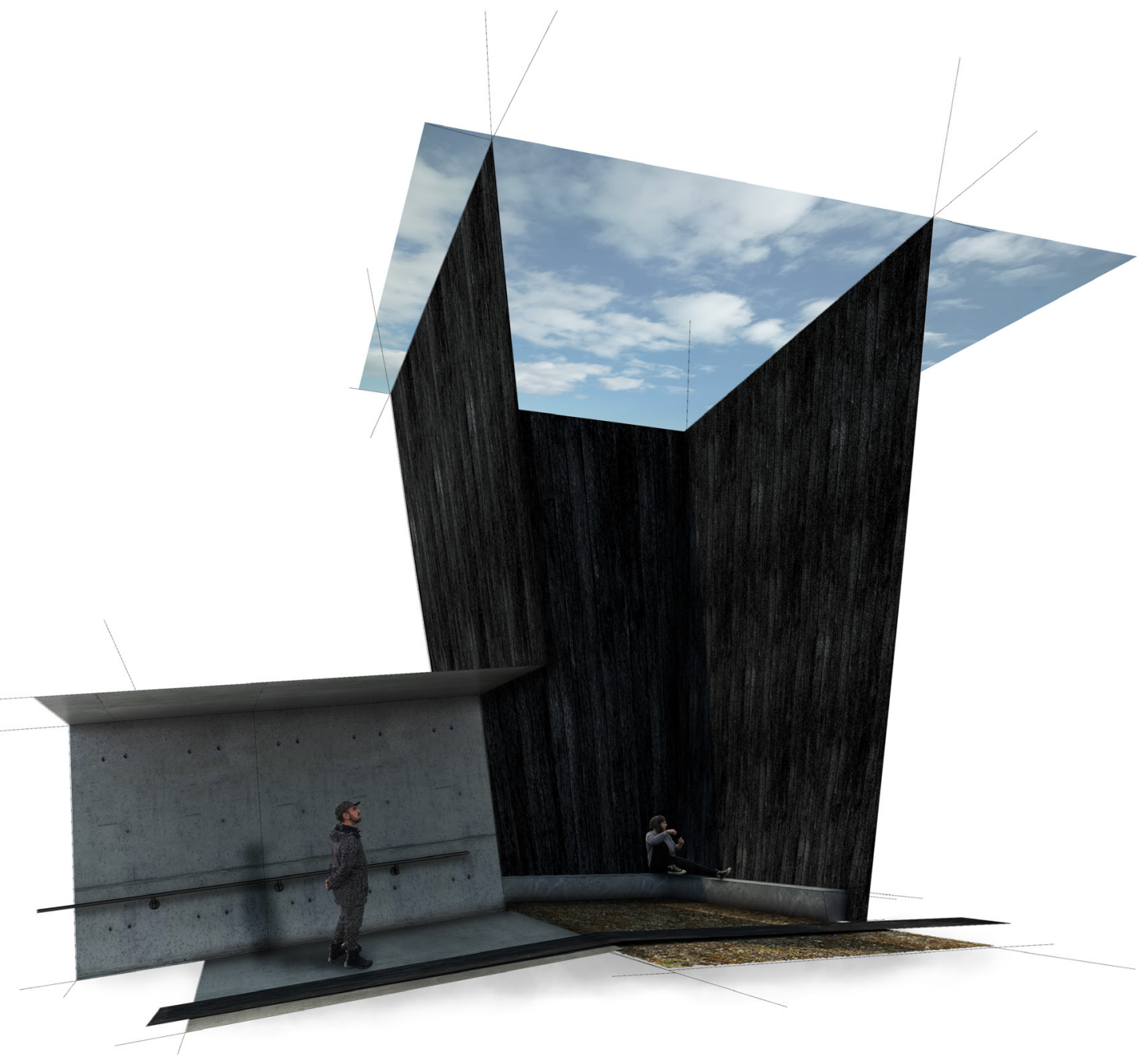

Figure No. 52

Dislocation

walls of scorched wood. The wood represents a fusion of both the natural and the built, as the technique for preserving the wood alters the material from its natural state. The walls angle obtusely, offering individuals the opportunity to lean and look up to the framed view above, again dislocating the individual from both their context within the city as well as their associations with traditional spatial occupation in the digitized city and what it means to navigate it.

Ascending a stairs serves as both a means for dealing with the grade difference present on the site, as well as serving an opportunity to engage the closeness of touch and temperature in the body. The interaction between the hands and the feet through the ascension of the stairs begins at the handrail. The handrail uses two materials, oak and brass, as it interplays with their unique conductance, texture, and 


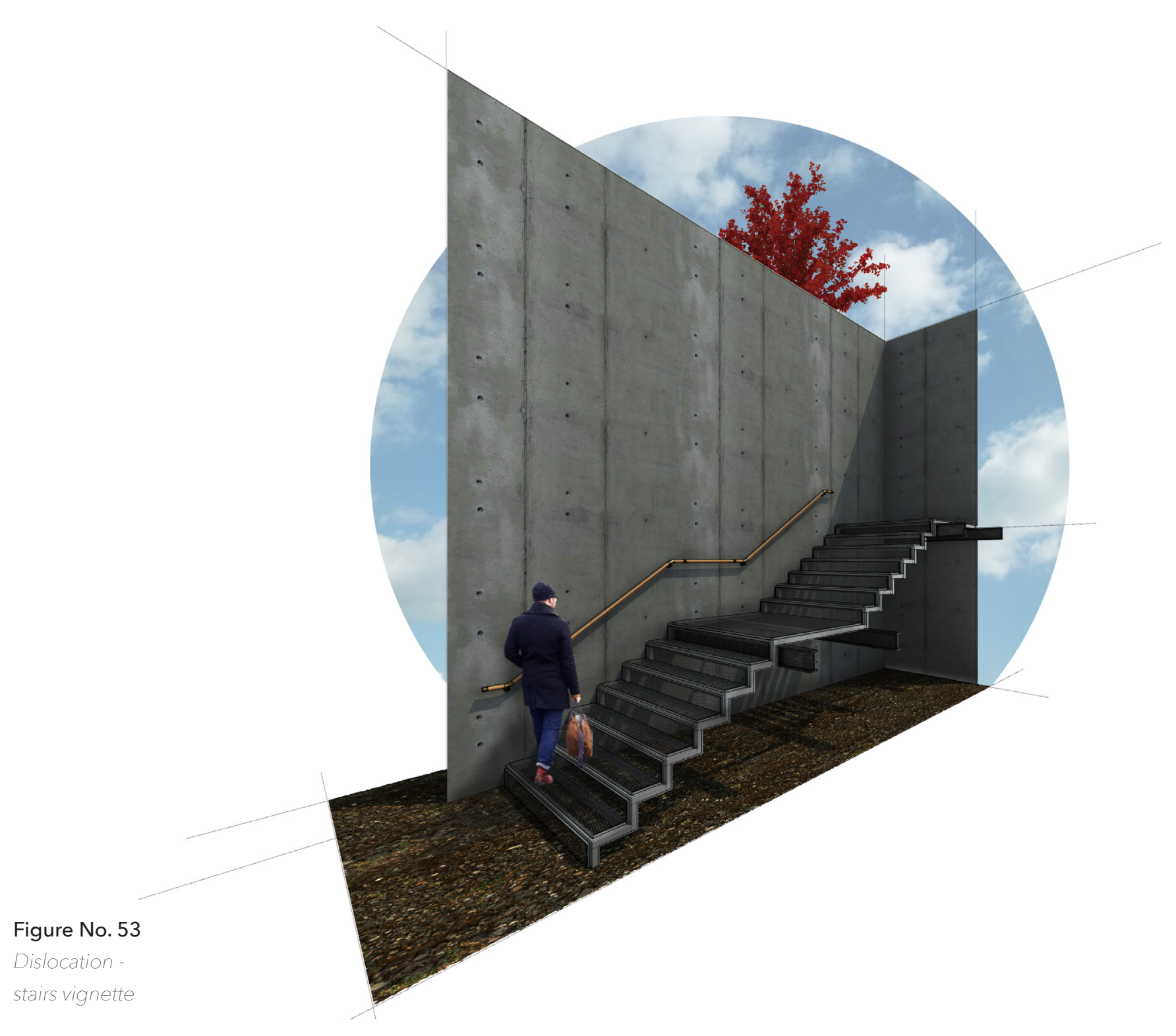

Figure No. 54

Dislocation.

railing detail

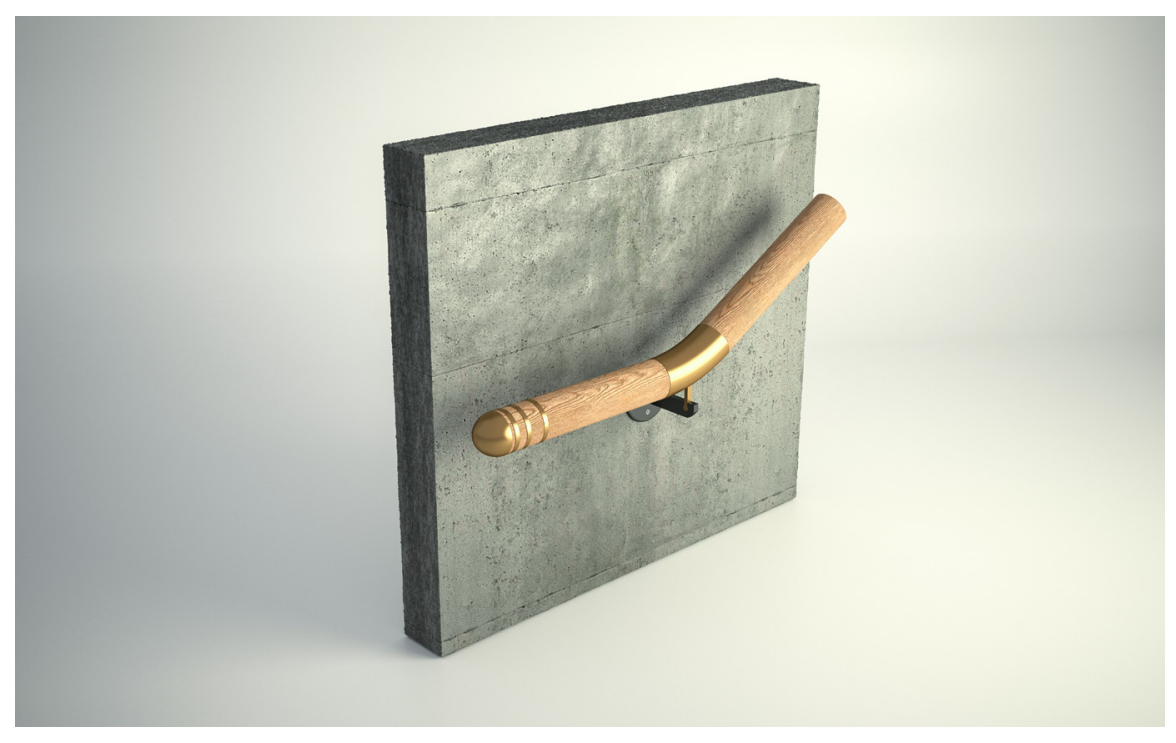


thermoceptive qualities in order to convey necessary information to the body in space through environmental stimuli. As the hand grasps the wood and begins to move up the stairs, sharp perceptible transitions in thermal conductivity trigger a sensory reaction in the body as the hand moves over the metal. Brass, having a high thermal conductivity amongst metals, transfers environmental information through the intimacy of the hand on the railing, signifying a changing in direction reflected in the movement of the feet on the steps. This transaction between body and architecture, though having an inevitable visual component, relies on the reactivity of the individuals sensory perception in order to guide and orient them through their journey in the atlas and the rediscovery of their senses in space.

The next space on the journey, framed by charred wood on its walls and ceiling, creates a dark atmosphere rich in smell and texture. Small and light metal chains hang down from the ceiling, creating a physical atmosphere within the space of the room. Being made of brass, their perceived coldness offers a shock to the body's thermal receptors.

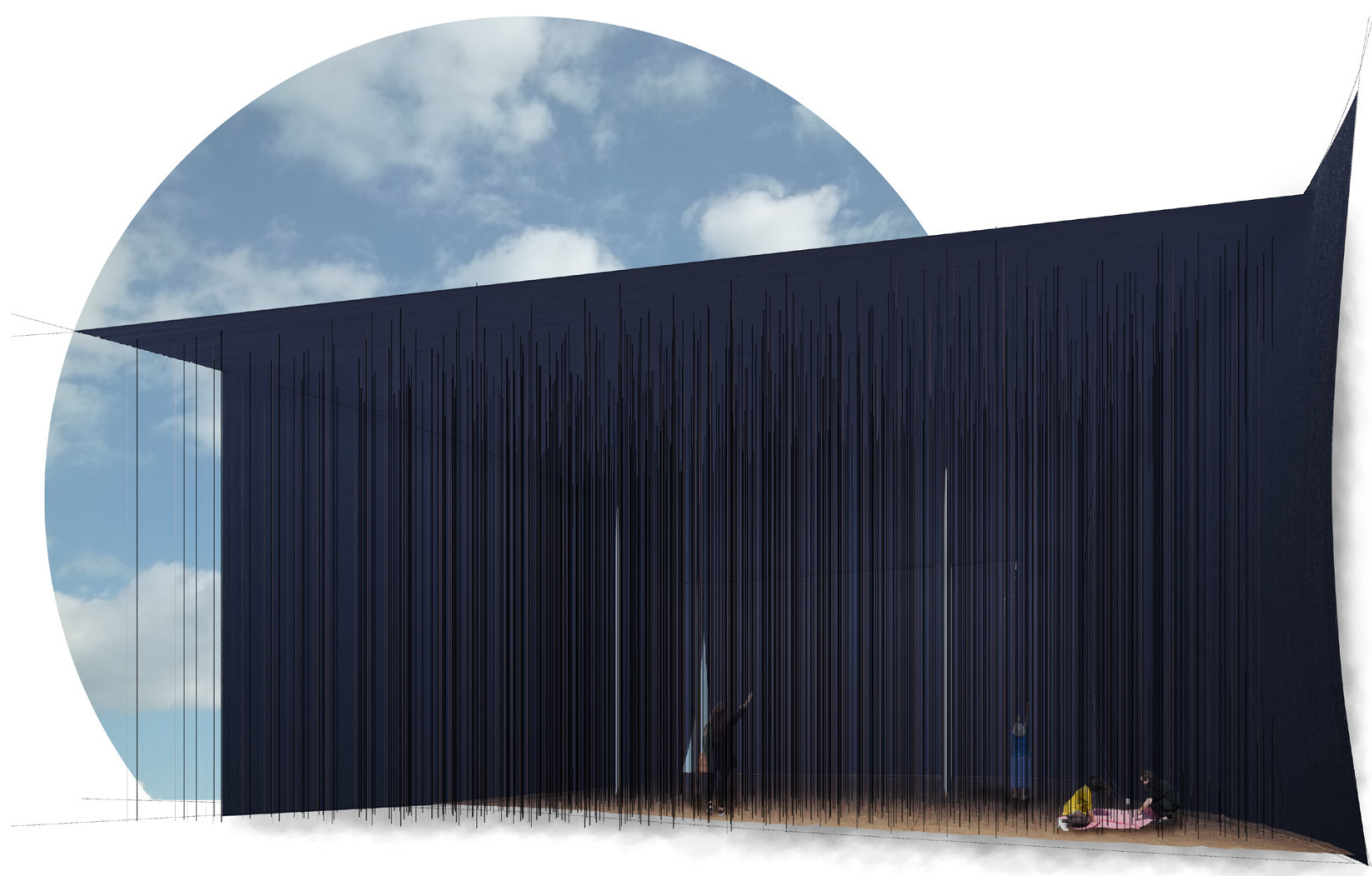

Figure No. 55 
Figure No. 56

Atmospheric void model [1:50]

Figure No. 57

Navigating the void [1:50]

Figure No. 58

Atmospheric void model-closeup [1:50]
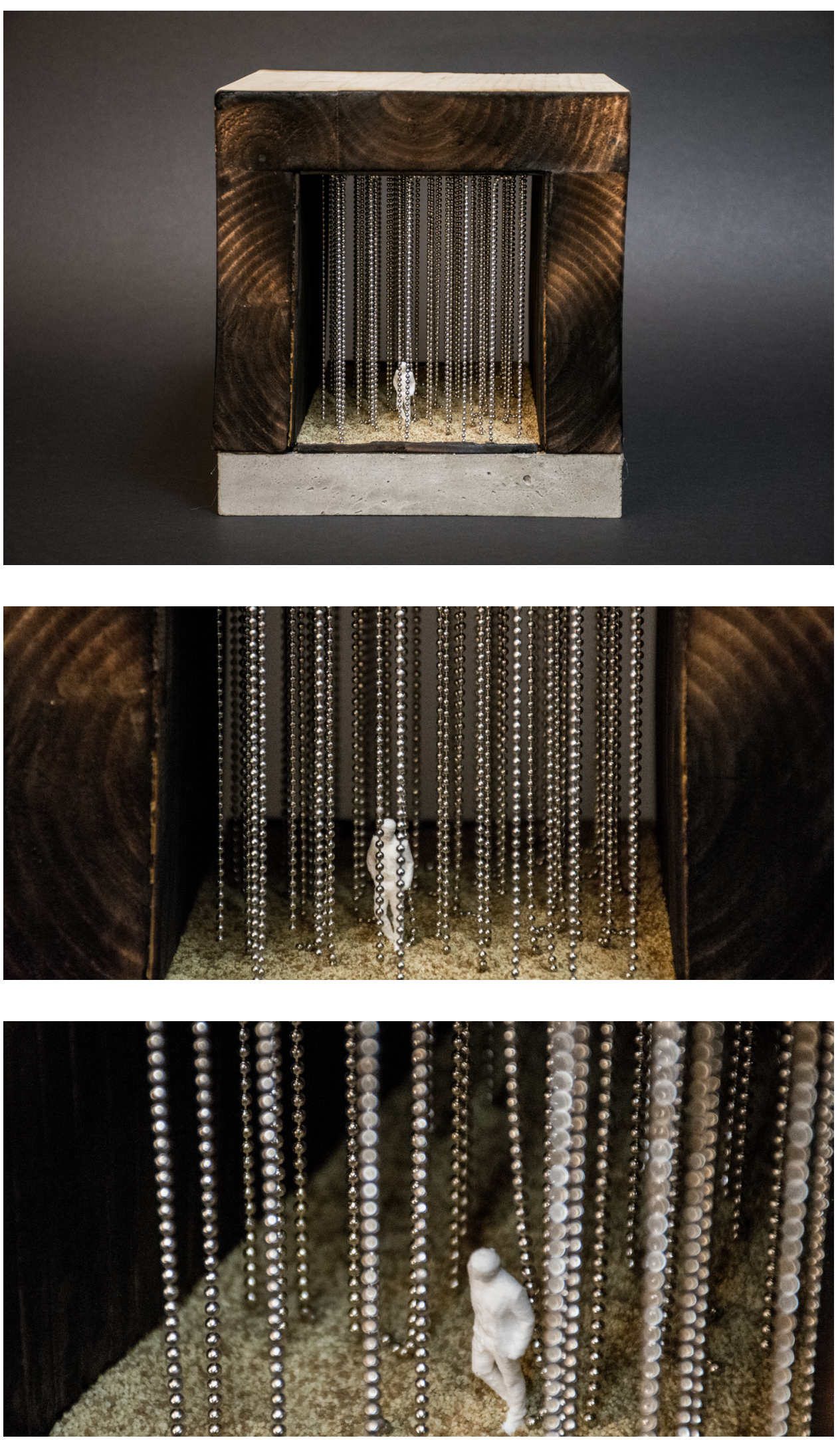

An Atlas to the Senses | 91 
The void thus becomes a fluid solid, allowing individuals to create their own path and journey through their ability to touch and feel their way through the void. Sand on the floor furthers the dislocative essence of the space while the displacement of the ground cover from past journeys alludes to a commonality between estranged people on their way to the city. Unable to be seen, a white noise of falling water grows as one traverses down the space, leading to a narrow sliver in the wall and into the final moments of the journey through the atlas - restitution.

Returning something that is lost or stolen, the atlas now attempts to reintegrate people within the framework of the urban geography. Here, the source of past stimulations become known provided by the structure of the architecture. The waterfall encapsulates this courtyard,

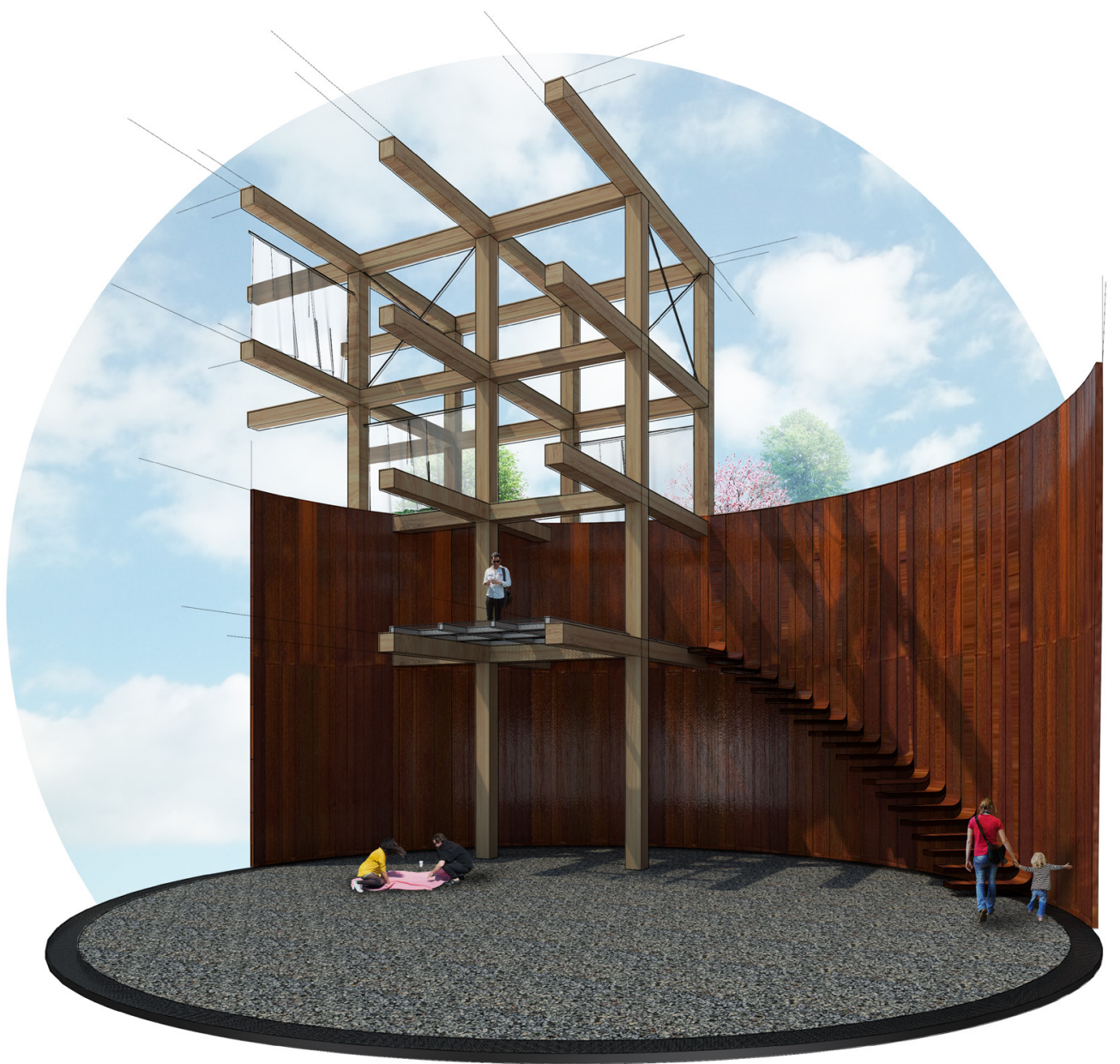


its energy and power felt deep within the body. Gravel lies beneath the feet and as one walks, it only adds to this white noise surrounding the body. The water falls along the vertical face of the corten steel, adding to its temporality and forming a patina of age over time. The water here falls into a grate and feeds the past spaces, constantly rejuvenating numerous elements of stimulation within the atlas. Here, water is used as not only a material, but as just one of the natural elements that flux between the natural geography and the building one in the atlas, helping to bridge the two environments together.

Ascending the stairs to the world above, individuals have the opportunity to touch the water-wall, to feel its temperature and to smell the interaction between the steel, water, wood, and mist. This moment continues as one climbs the stairs, ultimately leading to the other end of the atlas.

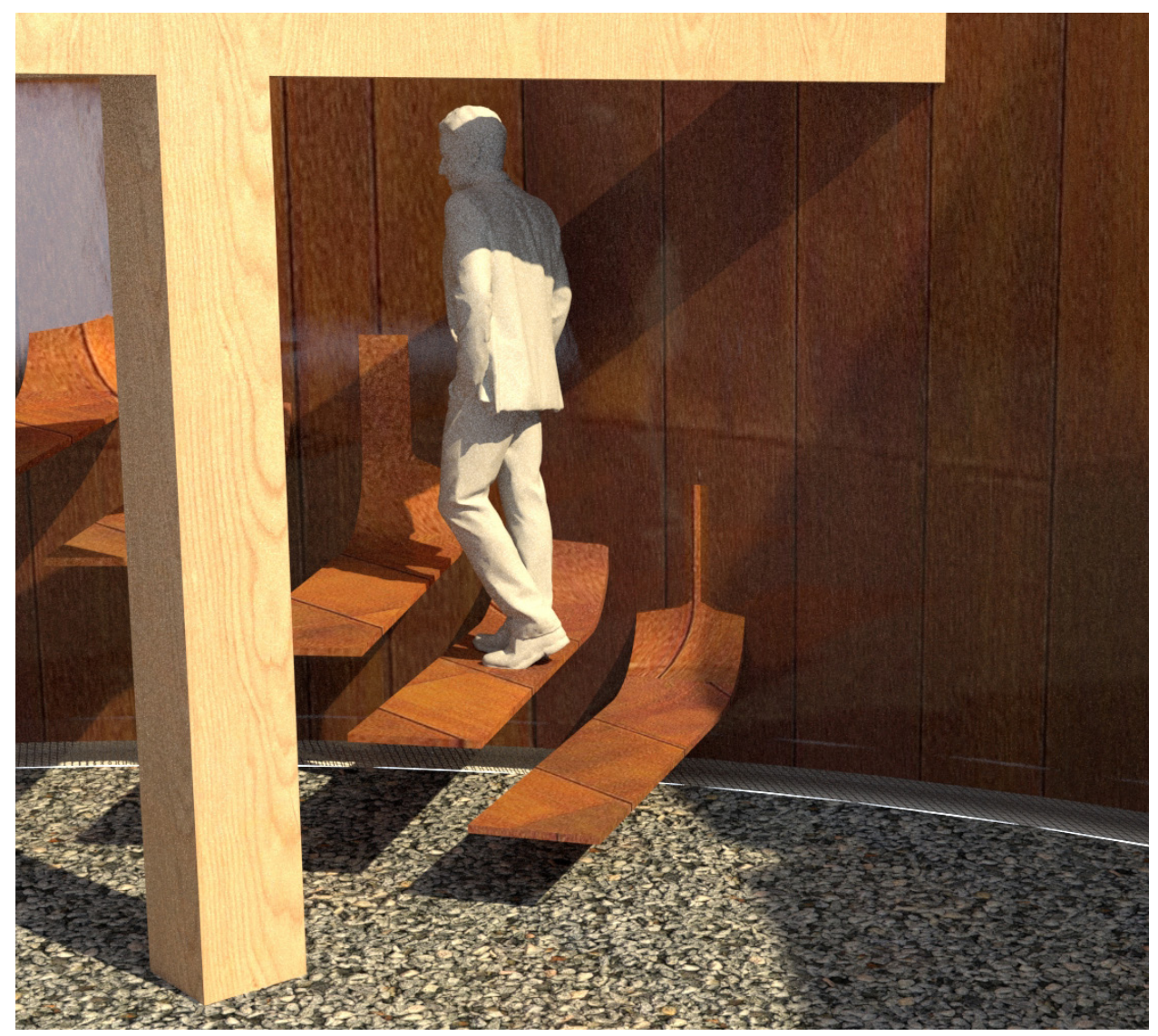




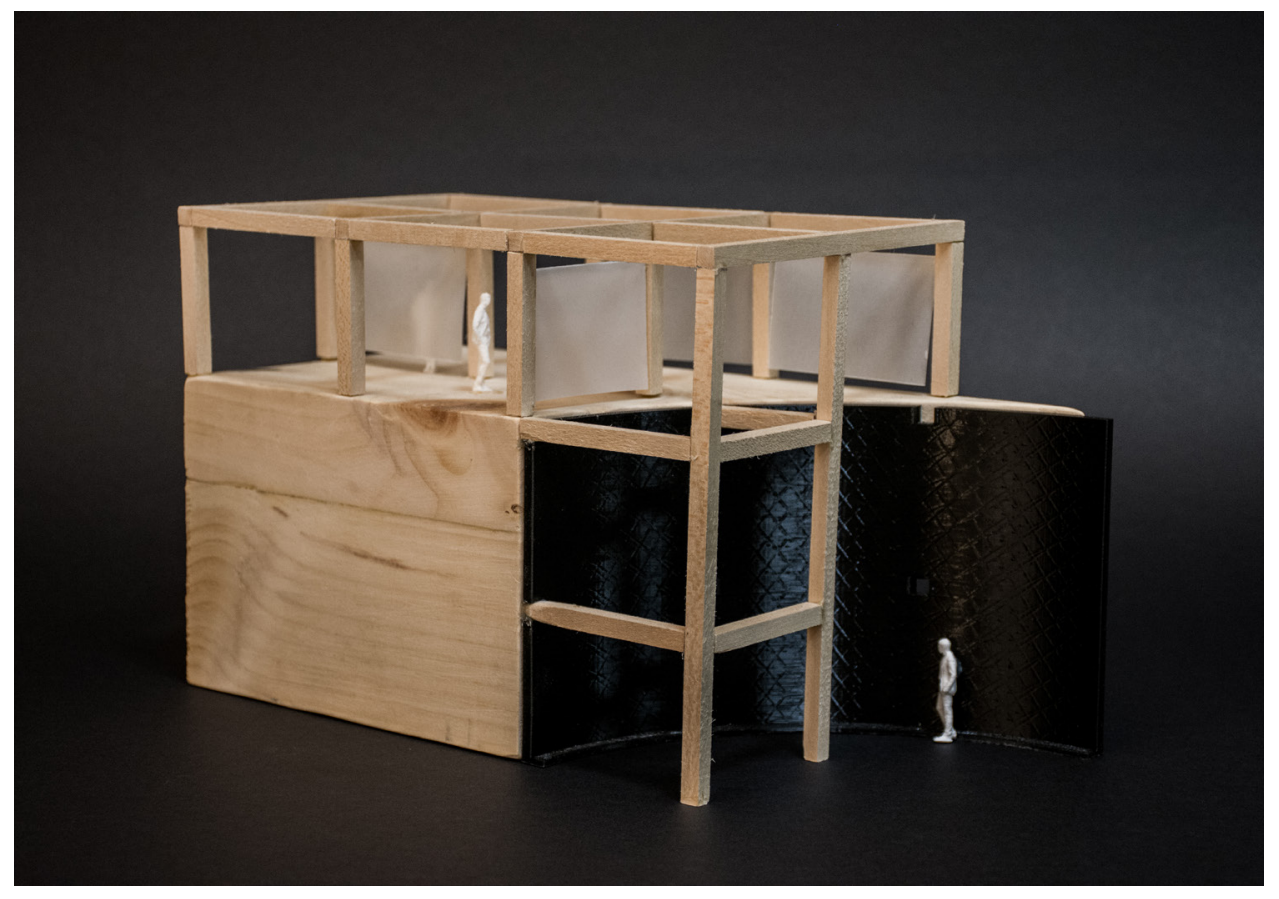

Figure No. 61

Waterfall

courtyard model

[1:50]

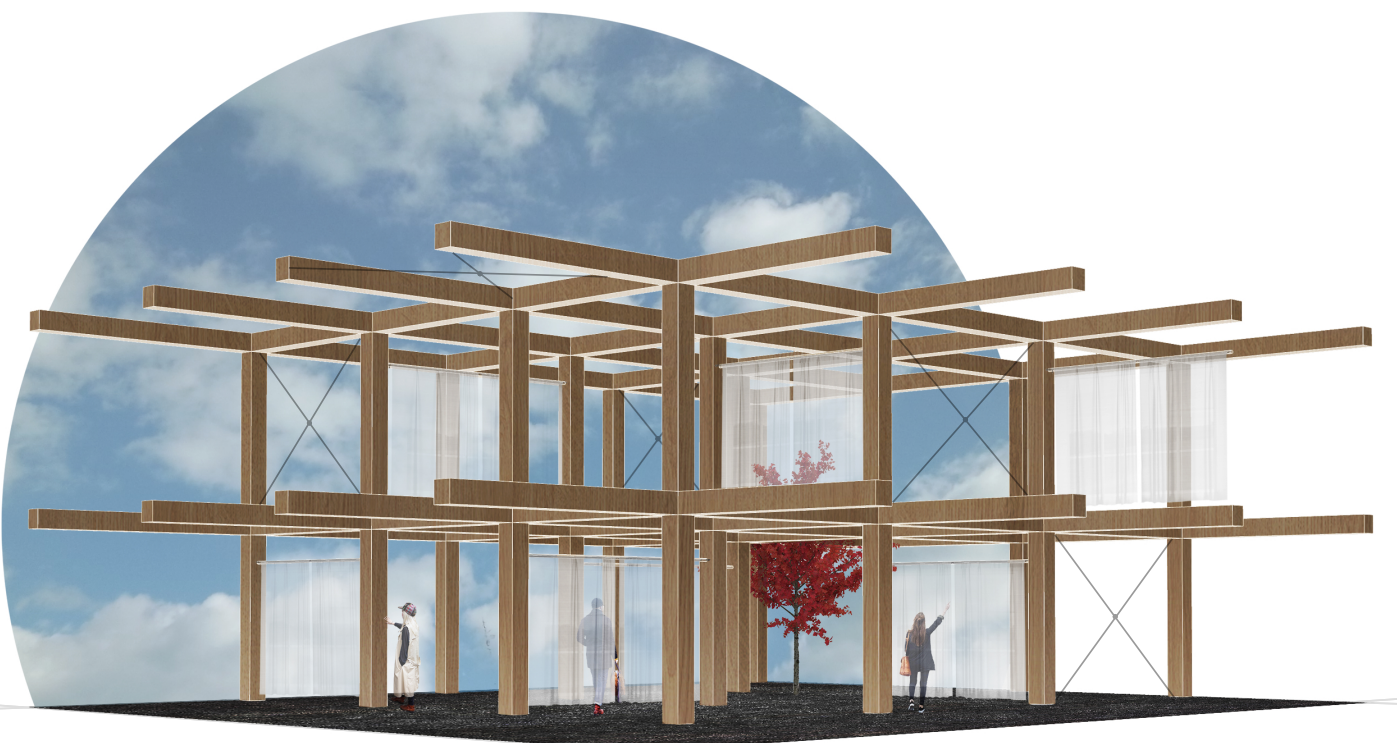

Figure No. 62

Restitution wood grid 
Finally, individuals find themselves at grade with Bloor Street East. The waterfall courtyard intersects with the grid of wood post and beam construction. The grid begins an urban dialogue between the form of the architecture and its relationship to its surroundings. The grid diffuses sound, smells, textures, and atmospheres through the wood grid itself as well as through the transparency of cloth diffusing individuals within the enervated city. As they meander through the lattice, the city becomes more clear while the white noise of the atlas fades away, completing one possible transition of the two geographies and with it, a new understanding of the sensory interactions of space and self.

Through this formal design strategy, an individualized story and experience can unfold through the body's senses in hopes of discovering new sensorial engagements and relationships between the individual and a space. Through inverting the contemporary proxemic hierarchy that privileges vision over the other senses, we can begin to focus on the interaction between the body and architecture. The intimacy of the senses allows one to become closer to architecture, both physically and psychologically, providing an atlas to the senses upon traversing the geographies of the human condition. In addressing our ocularcentric and digital society through spatial problem solving and acknowledging the potential for the senses to generate more relatable moments, we have the ability to create new spatial, perceptual, and emotional relationships within the memory of architecture. 


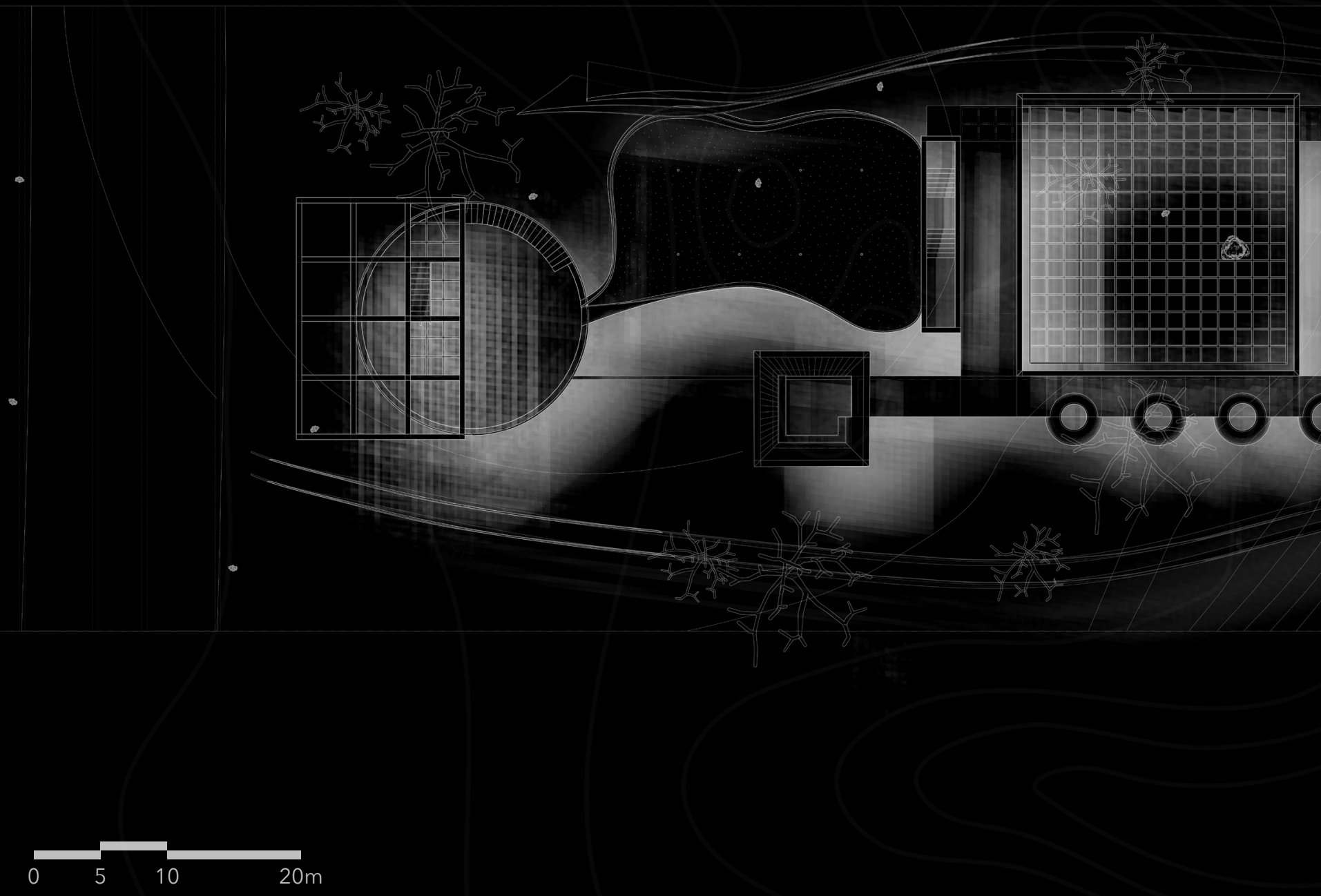

Figure No. 63

$X$-ray floor plan

[1:500] 


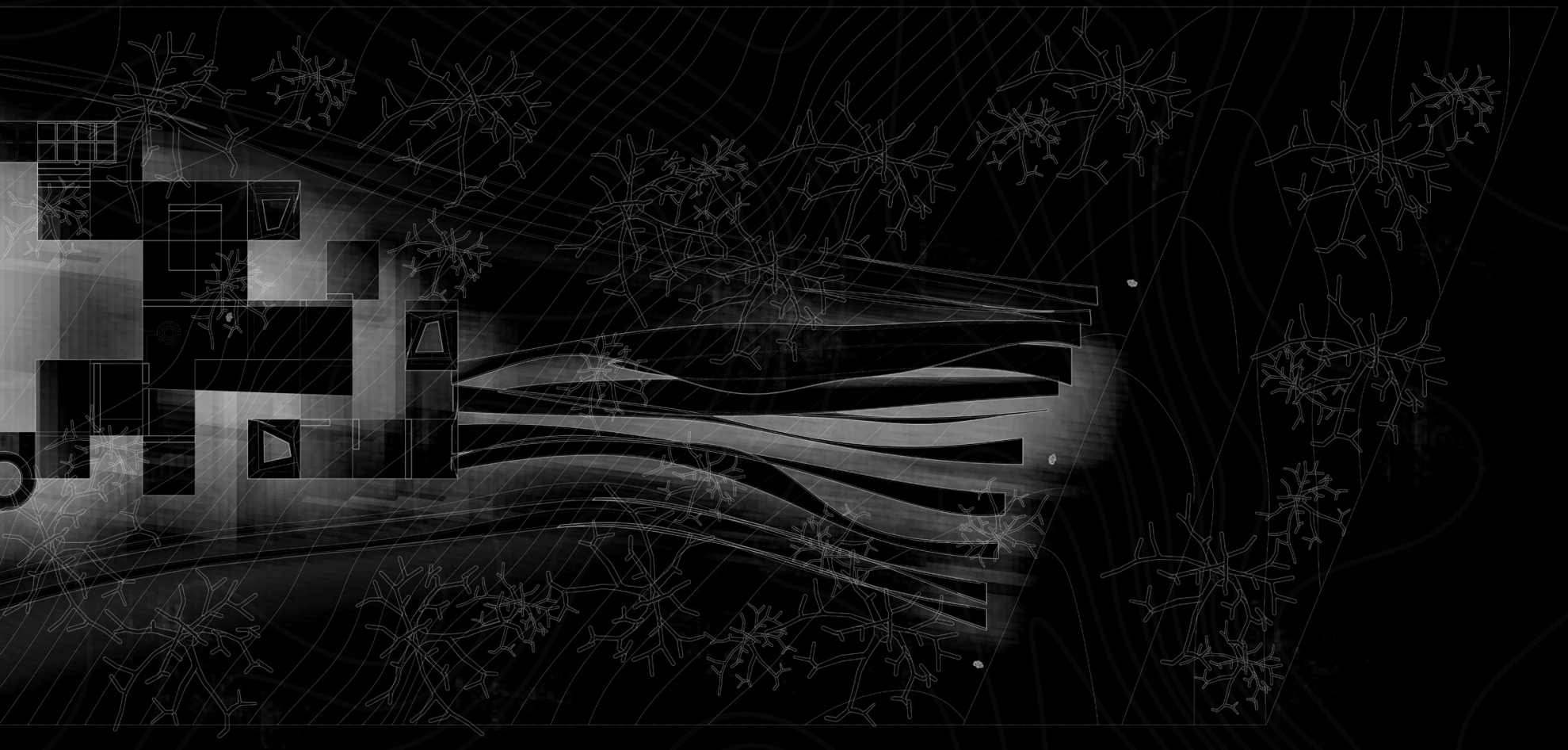

An Atlas to the Senses | 97 




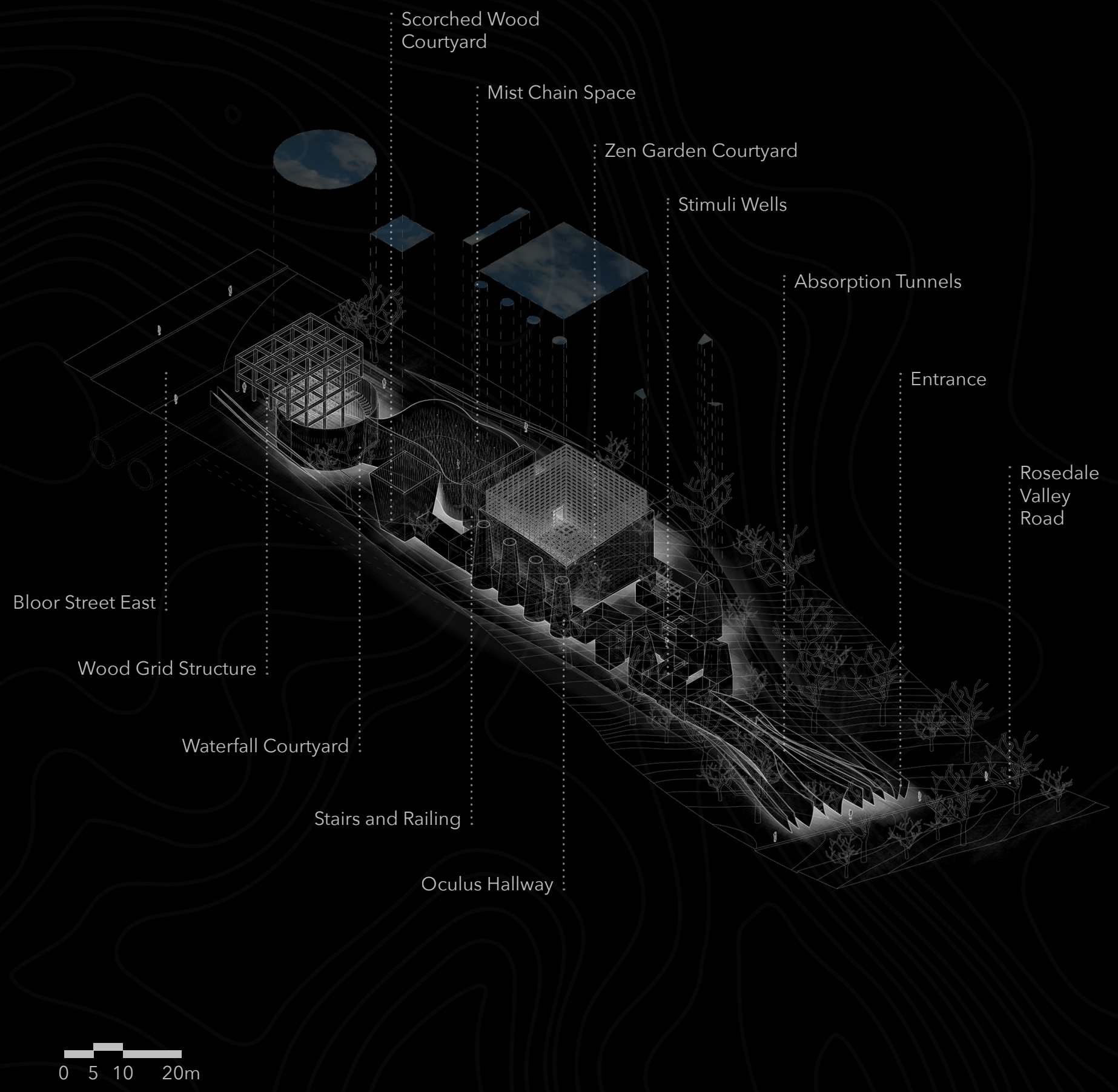

Figure No. 65

X-ray axonometric

[1:1000] 


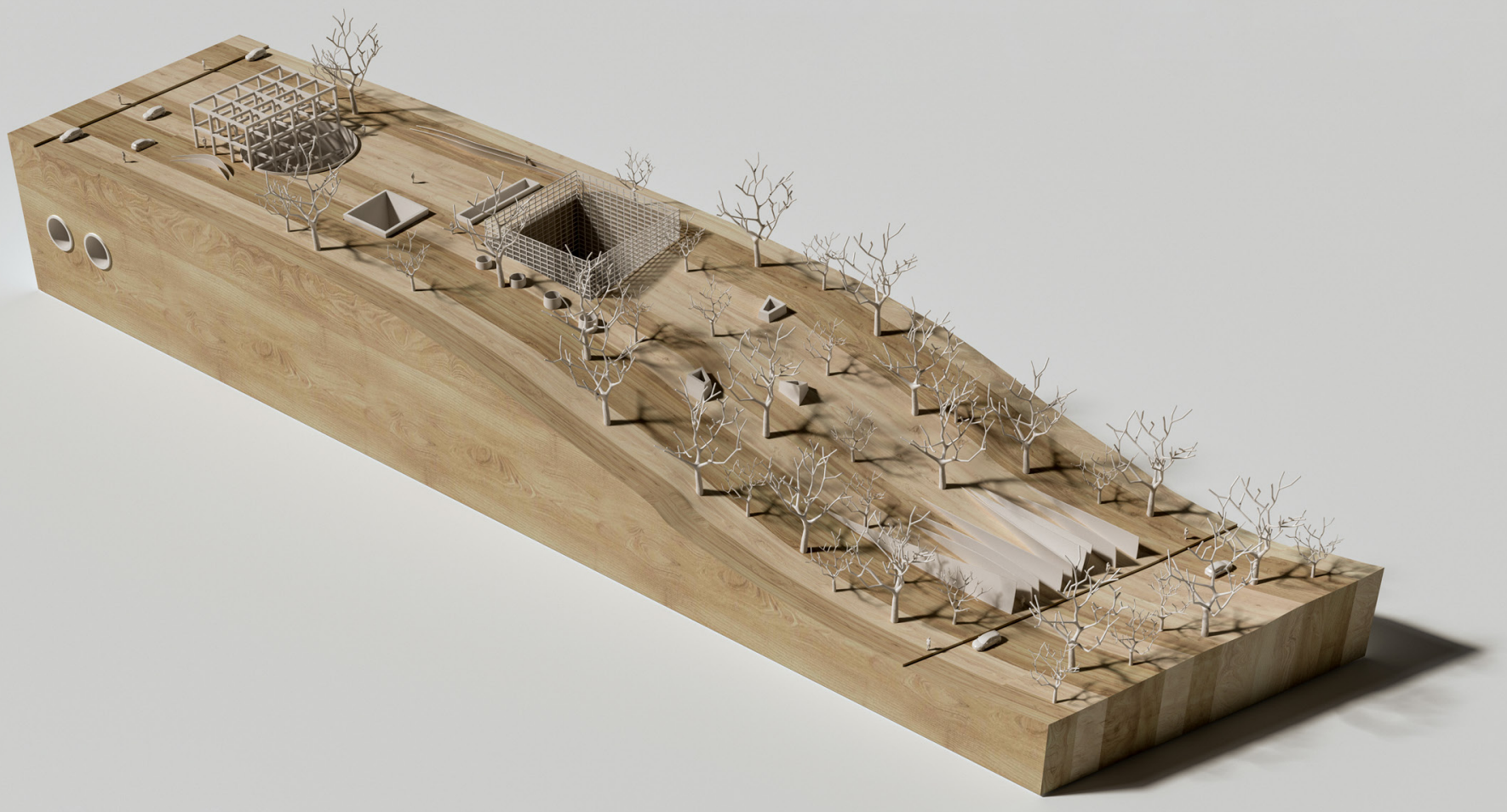

Figure No. 66

Site model [1:200] 


\subsection{CONCLUSION}

Memorable and emotional architectural experiences should not and cannot rely on the exhausted method that prioritizes visual aesthetics. Architecture needs to re-engage again with the entire body and its essential mechanisms that form the human condition - the sensorial envelope. Contemporary architecture within our digitized and globalized society has become convinced by the visualized simulations of architectural experience through the image. In doing so, we have forgotten the very sensory apparatuses that make us human, instead privileging the eye in the majority of our environmental constructions. The non-place-ness of much of our environments can be attributed to the focus on the human gaze, designing for it exclusively instead of designing an experience. As society continues their strive for more digitization and the world becomes more reliant on the pixel and image, we risk losing our very orientation in our environments through their lack of tangibility. While the significant benefits of digital technologies in a number of fields - architecture included are obvious, I am questioning whether the meaning of architectural expression should so exclusively lie within them, as through the digital we lose part of the true, unrepeatable human condition. The architect must act as an explorer, someone who sets out to discover new or lost territories for the advancement of civilization. An invisible architecture succeeds when these sensory stimulations provoked by our constructed environments become full sensory perceptions in the mind of the individual. It is at this moment within the human consciousness that memory is formed, creating both a physical attachment to place, as well as forever altering our past, present, and future. 




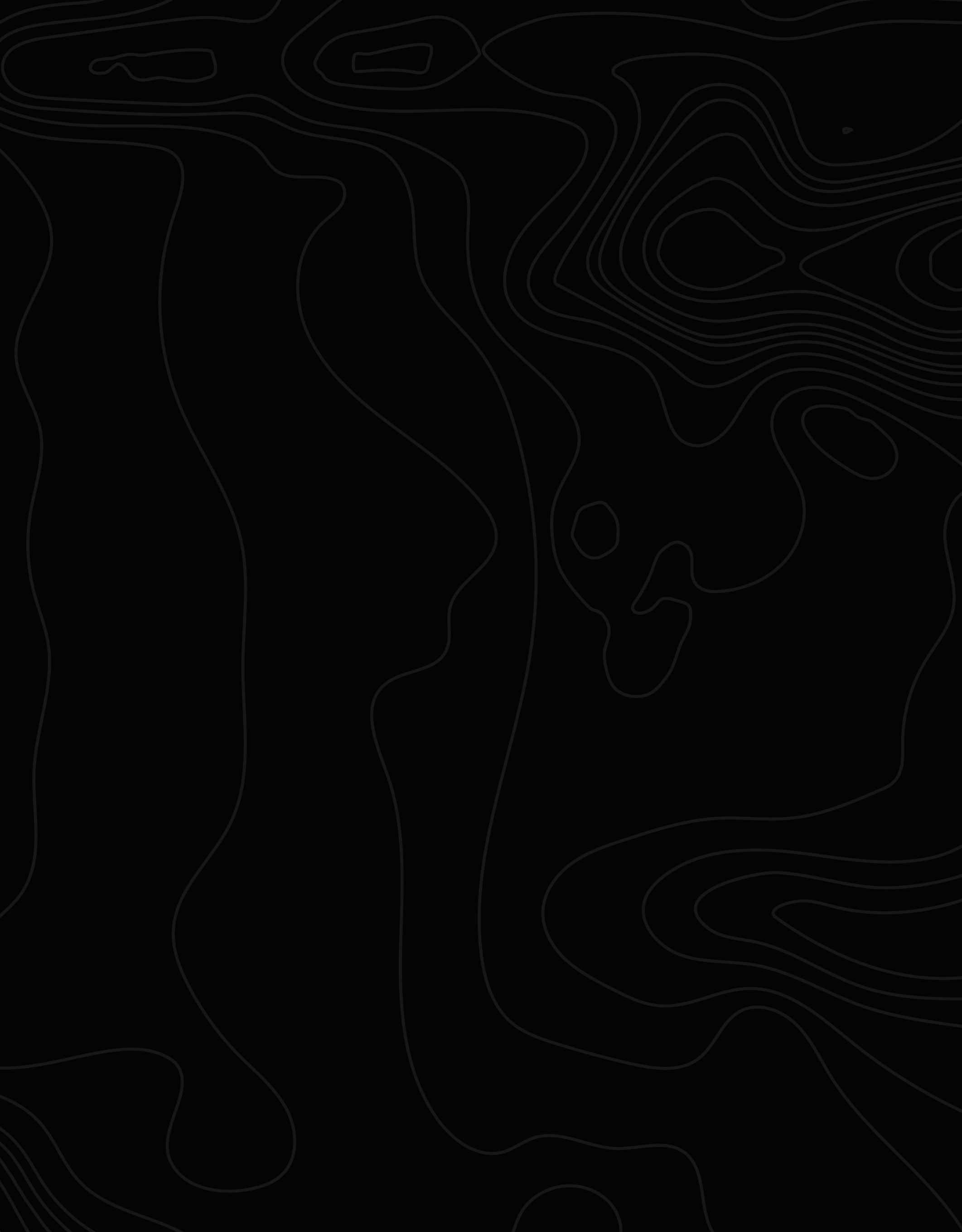




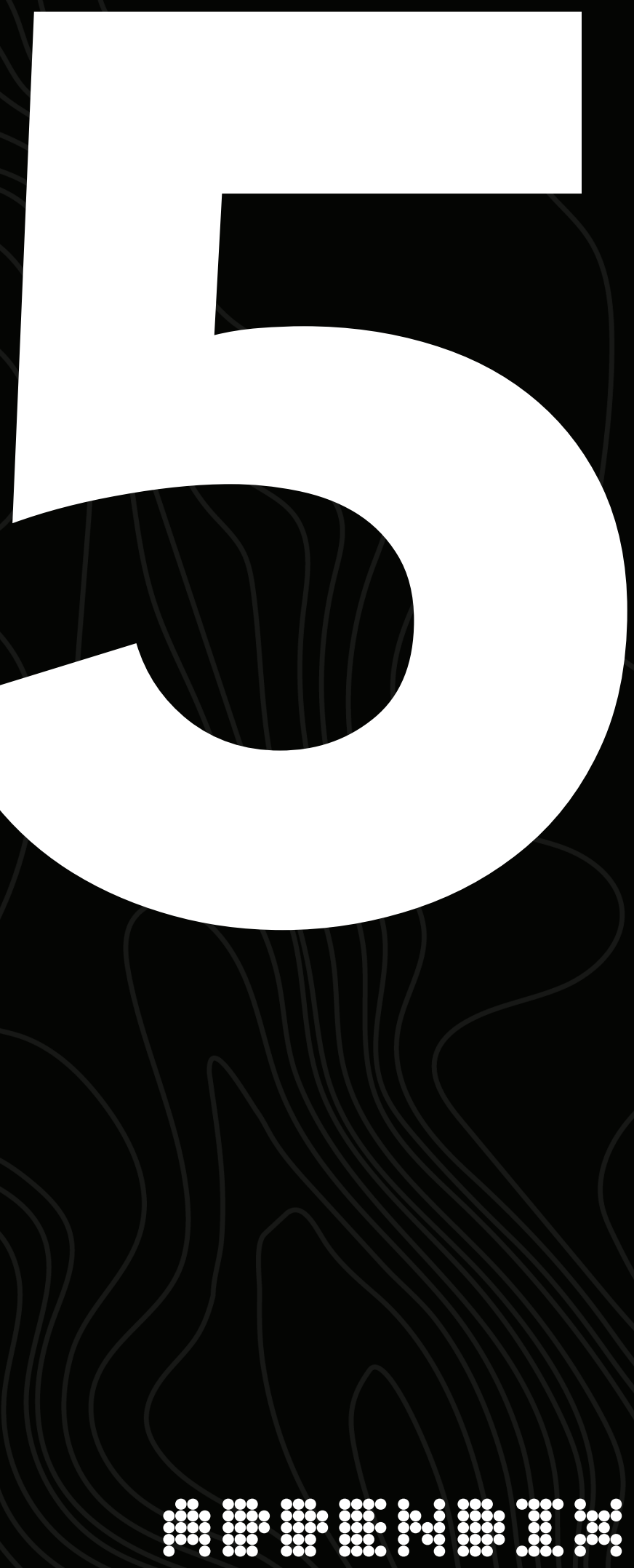





\section{BIBLIOGRAPHY}

Allen, S., \& McQuade, M. (Eds.). (2011). Landform building:

architecture's new terrain. Baden: Lars Müller Publishers.

Augé, M. (1995). Non-places: An introduction to supermodernity. London: Verso.

Aureli, P.V. (2011). The possibility of an absolute architecture.

Cambridge: The MIT Press.

Bell, P. A., Greene, T. C., Fisher, J. D., \& Baum, A. (2001). Environmental psychology (Fifth Edition). Belmont: Wadsworth.

Belova, O. (2006). The event of seeing: A phenomenological perspective on visual sense-making. Culture and Organization, 12(2), 93-107.

Breitschmid, M. (2019). Non-referential architecture. (V. Olgiati, Ed.). Zürich: Park Books.

Calvino, I. (1972). Invisible cities (W. Weaver, Trans.). New York City: Harcourt.

Campbell, C., Giovine, A., \& Keating, J. (2019). Introduction: Confronting emptiness in history. In Campbell C., Giovine A., \& Keating J.

(Eds.), Empty Spaces: Perspectives on emptiness in modern history (pp. 1-13). London: University of London Press. 
Chung, C. J., Inaba, J., Koolhaas, R., \& Leong, S. T. (Eds.). (2001). Harvard Design School guide to shopping. Köln: Taschen.

Davidson, J. (2003). Phobic geographies: The phenomenology and spatiality of identity. London: Routledge.

Dovey, K. (1999). Framing places: Mediating power in built form. London: Routledge.

Downey, C. (2016, June 6). 10 questions for Chris Downey. (A. Kilcrease, Interviewer). Interior Design. Retrieved from https://www.interiordesign. net/articles/11974-10-questions-with-chris-downey/

Frascari, M. (1996). The tell-the-tale detail. In K. Nesbitt (Ed.), Theorizing a new agenda for architecture: An anthropology of architectural theory 1965-1995 (pp. 498-514). New York City: Princeton Architectural Press.

Goldberger, P. (2009). Why architecture matters. New Haven: Yale University Press.

Goldblatt, D. (1991). The Dislocation of the Architectural Self. The Journal of Aesthetics and Art Criticism, 49(4), 337-348.

Jay, M. (1994). Downcast eyes: The denigration of vision in twentiethcentury French thought. Berkley: The University of California Press. 
Koolhaas, R. (2002). Junkspace (Vol. 100, pp. 175-190). Cambridge: The MIT Press.

Lally, S. (2014). The air from other planets: A brief history of architecture to come. Zürich: Lars Müller Publishers.

Lambert, Léopold. (2012). Weaponized architecture: The impossibility of innocence. Barcelona: DPR-Barcelona.

LeGear, C. (1950). Mercator's Atlas of 1595. Quarterly Journal of Current Acquisitions, 7(3), 9-13.

Marquardt, N., \& Greenberg, S. (2015). Proxemic interactions:

From theory to practice. Retrieved from https://www-

morganclaypool-com.ezproxy.lib.ryerson.ca/doi/pdf/10.2200/ S00619ED1V01Y201502HCl025

May, R. (1950). Meaning of anxiety. New York City: Ronald Press Co.

Merleau-Ponty, M. (1964). Sense and non-sense. (H. L. Dreyfus \& P. A. Dreyfus, Trans.). Evanston: Northwestern University Press.

Monshizade, A. (2016). Multisensory approach in architecture education: The basic courses of architecture in Iranian universities. Ambiances, Tomorrow. Proceedings of 3rd International Congress on Ambiances, 355-360. 
Pallasmaa, J. (2009). The thinking hand: Existential and embodied wisdom in architecture. Chichester: Wiley.

Pallasmaa, J. (2012). The eyes of the skin: Architecture and the senses. Chichester: Wiley.

Reiser, J., \& Umemoto, N. (2006). Atlas of novel tectonics. New York City: Princeton Architectural Press.

Robinson, J. (2012). On Being Moved by Architecture. The Journal of Aesthetics and Art Criticism, 70(4), 337-353.

Rossi, A. (1982). The architecture of the city. (P. Eisenman, Ed.). Cambridge: The MIT Press.

Schuldenfrei, R. (Ed.). (2012). Atomic dwelling: Anxiety, domesticity, and postwar architecture. London: Routledge.

Schultz, A.-C. (2007). Carlo Scarpa: Layers. Stuttgart: Edition Axel Menges.

Tanizaki, J. (1977). In praise of shadows. New Haven: Leete's Island Books.

Tuan, Y. (1979). Landscapes of fear. New York City: Pantheon Books. 
Tuan, Y. (2014). Space and place: The perspective of experience. Minneapolis: University of Minnesota Press.

Ursprung, P., \& Goodwin, K. (2014). Sensing spaces: Architecture reimagined. London: Royal Academy of Arts.

Vaucelle, C., Bonanni, L., \& Ishii, H. (2009). Design of Haptic Interfaces for Therapy. Proceedings of the 27th International Conference on Human Factors in Computing Systems, 467-470. Retrieved from https:// dspace.mit.edu/handle/1721.1/60568

Venturi, R., Brown, D. S., \& Izenour, S. (1972). Learning from Las Vegas. Cambridge: The MIT Press.

Vidler, A. (2002). Warped space: Art, architecture, and anxiety in modern culture. Cambridge: The MIT Press.

Wolfe, C., \& Kambaskovic, D. (2013). The senses in philosophy and science: From the nobility of sight to the materialism of touch. A Cultural History of the Senses in the Renaissance, 1-30.

Zumthor, P. (1998). Peter Zumthor works: Buildings and projects 19791997. Baden: Lars Müller Publishers.

Zumthor, P. (2006). Atmospheres: architectural environments, surrounding objects. Basel: Birkhäuser. 




\section{GLOSSARY}

Absorption to take up and reduce the effect or intensity of an energy or impact

Anxiety a feeling of worry, nervousness, or unease about something with an uncertain or unknown outcome

Dislocation to disturb the organization of something and displace it from the normal

Estranged no longer close or affectionate to someone; alienated

Geography the nature and relative arrangement of places and physical features viewed in relation to the body

Haptic relating to the sense of touch and the manipulation of objects though physical means

Interiority the quality of being interior or inward, suppressed, or censored

Invisible not able to be seen, ignored, or not taken into consideration

Isolation the process or fact of being separated or disconnected

Memory the faculty by which the mind stores and remembers information; whether spatial, architectural, material, or otherwise 
Ocularcentric the privileging of vision over the other senses

Perception the ability to see, hear, or become aware of something through the senses

Place a particular position or point in space engaged through perception, memory, and emotional experience

Proxemics the branch of knowledge that deals with the amount of space that people feel it necessary to set between themselves and other people or objects

Restitution to return or restore something that is lost or stolen

Sensory relating to sensation or the physical senses; transmitted or perceived by the senses

Space a continuous area or expanse that is free, available, or unoccupied

Stratification the arrangement or classification of something into different groups 


